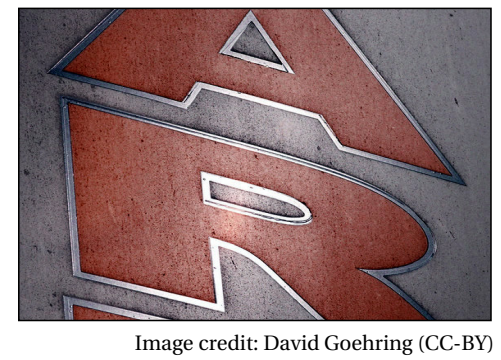

\title{
Action Research
}

Welcome to the April issue of the Technology

Innovation Management Review. We welcome your comments on the articles in this issue as well as suggestions for future article topics and issue themes.

Editorial: Action Research

Chris McPhee, Magnus Hoppe, and Erik Lindhult

Navigating Boundaries in Additive Manufacturing through Action

Research

Katharina Ruckstuhl, Rafaela C. C. Rabello, and Sally Davenport

Using Action Research to Organize Technology Transfer in Complex

Innovation Contexts Armando Machevo Ussivane and Paul Ellwood

Bridging Participatory Policy Trends and Research Traditions through Social Innovation Malin Lindberg, Daniel Hallencreutz, and Anna Tengqvist

Increasing the Impact of Industry-Academia Collaboration through

Co-Production

Anna Sannö, Anna Ericson Öberg, Erik Flores-Garcia, and Mats Jackson

A Discipline-Spanning Overview of Action Research and Its

Implications for Technology and Innovation Management Matthias Guertler, Nathalie Sick, and Anton Kriz

Choosing an Outlet for Action Research: Publication Patterns in

Innovation Journals Magnus Hoppe

Author Guidelines 


\section{Publisher}

The Technology Innovation Management Review is a monthly publication of the Talent First Network.

\section{ISSN}

1927-0321

\section{Editor-in-Chief}

Chris McPhee

\section{Advisory Board}

Tony Bailetti, Carleton University, Canada

Peter Carbone, Ottawa, Canada

Parm Gill, Gill Group, Canada

Leslie Hawthorn, Red Hat, United States

Michael Weiss, Carleton University, Canada

\section{Review Board}

Tony Bailetti, Carleton University, Canada

Peter Carbone, Ottawa, Canada

Parm Gill, Gill Group, Canada

G R Gangadharan, IBM, India

Mohammad Saud Khan, Victoria University of

Wellington, New Zealand

Seppo Leminen, Pellervo Economic Research and Aalto University, Finland

Colin Mason, University of Glasgow, United Kingdom

Steven Muegge, Carleton University, Canada

Jennifer Percival, University of Massachusetts, United States

Risto Rajala, Aalto University, Finland

Punit Saurabh, Nirma University, India

Sandra Schillo, University of Ottawa, Canada

Marina Solesvik, Nord University, Norway

Stoyan Tanev, Carleton University, Canada

Michael Weiss, Carleton University, Canada

Mika Westerlund, Carleton University, Canada

Blair Winsor, Memorial University, Canada

(C) $2007-2019$

Talent First Network

www.timreview.ca

\section{Overview}

The Technology Innovation Management Review (TIM Review) provides insights about the issues and emerging trends relevant to launching and growing technology businesses. The TIM Review focuses on the theories, strategies, and tools that help small and large technology companies succeed.

Our readers are looking for practical ideas they can apply within their own organizations. The TIM Review brings together diverse viewpoints - from academics, entrepreneurs, companies of all sizes, the public sector, the community sector, and others - to bridge the gap between theory and practice. In particular, we focus on the topics of technology and global entrepreneurship in small and large companies.

We welcome input from readers into upcoming themes. Please visit timreview.ca to suggest themes and nominate authors and guest editors.

\section{Contribute}

Contribute to the TIM Review in the following ways:

- Read and comment on articles.

- Review the upcoming themes and tell us what topics you would like to see covered.

- Write an article for a future issue; see the author guidelines and editorial process for details.

- Recommend colleagues as authors or guest editors.

- Give feedback on the website or any other aspect of this publication.

- Sponsor or advertise in the TIM Review.

- Tell a friend or colleague about the TIM Review.

Please contact the Editor if you have any questions or comments: timreview.ca/contact

\section{About TIM}

The TIM Review has international contributors and readers, and it is published in association with the Technology Innovation Management program (TIM; timprogram.ca), an international graduate program at Carleton University in Ottawa, Canada. 


\title{
Editorial: Action Research
}

\author{
Chris McPhee, Editor-in-Chief \\ Magnus Hoppe and Erik Lindhult, Guest Editors
}

\section{From the Editor-in-Chief}

Welcome to the April 2019 issue of the Technology Innovation Management Review. This is the first of two issues on the theme of Action Research, and it is my pleasure to introduce our guest editors: Magnus Hoppe and Erik Lindhult from Mälardalen University in Sweden. Magnus and Erik are also both Board Member of the Swedish Interactive Research Association (SIRA), and Erik is a Board Member of the Swedish Participative Action Research Community (SPARC).

For future issues, we are accepting general submissions of articles on technology entrepreneurship, innovation management, and other topics relevant to launching and growing technology companies and solving practical problems in emerging domains. Please contact us (timreview.ca/contact) with potential article topics and submissions, and proposals for future special issues.

\section{Chris McPhee \\ Editor-in-Chief}

\section{From the Guest Editors}

Researching together across different borders, especially in innovation, is becoming more common. Through this approach, a multitude of perspectives and knowledge enhance the chances of success. Indeed, there is much to gain from bringing together existing disciplinary fields and fertilizing thinking by purposefully encouraging people with diverging ideas and mindsets to work together, both for practical purposes and research purposes. But, for this work to proceed and succeed, borders must be broken down or overcome - including the artificial border between the researcher and the researched. Such efforts to break down borders belong not just to one tradition but many, and they are undertaken with different names, designs, and preferred outcomes (Reason \& Bradbury, 2008), where one label is "action research". This diversity of emerging traditions that seek to combine practical and research knowledge development intrigues us, but it also means that relevant insights are scattered and new borders are created.

Through this special issue and the one that follows it, we sought to publish articles that will help us better understand these mutual processes through an exploration of new and contemporary accounts of "action research" and its close relative "participatory action research", which stresses the mutuality of the approach. Action research can in turn be divided into a critical and a pragmatic tradition, according to Johansson and Lindhult (2008) where they "... associate the pragmatic orientation with a focus on praxis and practical knowledge development, cooperation between all concerned parties, and the need for finding and constructing a common ground between them as a platform for action".

Tracing the origin of action research, a pragmatic thread leads back to the United States, where Kurt Lewin (1946), the main instigator of the concept (Adelman, 1993), showed through field experiments that the participation of people in organizational and social development could overcome resistance to change. A critical thread leads us to Latin America and the quest to bring about social change through reflection/learning/knowledge creation and the engagement by scholars in the everyday life of disempowered groups (Fals-Borda \& Rahman, 1991; Freire, 1985). It is also inspired by neomarxist and 


\title{
Editorial: Action Research
}

\author{
Chris McPhee, Magnus Hoppe, and Erik Lindhult
}

critical theory (Kemmis et al., 2015) in enabling people to be critical and act in relation to social injustice.

A pragmatic and Lewinian tradition, aimed at creating dialogue for mutual benefit and to support participatory development, has been active in industrial, social, and organizational reform and development, predominantly aimed at solving more technical problems in society. Among these problems are those of innovation, where it also has become fashionable for companies to open up development processes to customers, external experts, and others. Creating knowledge together, in and through action across borders, is becoming a new norm for many companies and other organizations. Open innovation, a term coined by Henry Chesbrough (2003), can thus be said to rest on ideas connected to action research, where both open innovation and action research appear as modern in the sense of being more concerned with relevance and results than discriminating between certain established domains of practice.

More specifically, the introduction of action research in innovation processes is vague. The most cited work is by Robert Kaplan (1998), who stated that he used "innovation action research" when constructing the Business Score Card framework together with David Norton. By this, he means an iterative development process between theory and practice, a method he also advocates strongly in order to increase research relevance.

As the references to both Chesbrough and Kaplan indicate, ideas related to participative and action research are present in today's more popular practices. As they concern problems that are directly relevant to society today, it comes as no surprise. They do not discourage anyone from building theory, creating knowledge, or interpreting patterns. In this sense, action research approaches are also a threat to existing power structures in academia. Current borders that uphold disciplines, careers, and publication practices are threatened, as explored by Hoppe later in this issue by asking whether this challenging position makes make it harder to get action research articles accepted in more traditional journals.

In putting together two special issues on action research, our aim was to express this discussion in an accessible manner such that academics, industry, and the public sector can adopt the frameworks, models, and ideas presented by the authors. In this first issue, we present six articles in which the authors share their in- sights of breaking down or working across the borders that characterize the field of action research.

In the first article, Katharina Ruckstuhl, Rafaela C. C. Rabello, and Sally Davenport follow an additive manufacturing project team "in real time" as it navigates "fuzzy areas" to integrate knowledge to produce commercializable science innovation in one of New Zealand's National Science Challenges (NSC): Science for Technological Innovation - Kia Kotahi Mai: Te Ao Pūtaiao me Te Ao Hangarau (SfTI). Through action research as praxis and as critical orientation, key mechanisms are identified in interdisciplinary and transdisciplinary research for commercialization, particularly in the context of New Zealand's indigenous Māori people.

In the second article, Armando Machevo Ussivane, Chairman of a Mozambique Government agency, together with Paul Ellwood from the University of Liverpool, adopt a participatory action research methodology to investigate how the co-inquiry of action research can be used for mutual problem solving. The empirical data comes from a technology transfer project for rice production technology from China to Mozambique, which displayed a need to improve the coordination of autonomous innovation activities. Involved stakeholders identified four categories of organizational boundary problems that helped the different actors to reach an understanding of each other's positions.

Then, Malin Lindberg, from Luleå University of Technology and Daniel Hallencreutz and Anna Tengqvist, senior consultants for WSP in Sweden, use a participatory case study to distinguish the relationship and potential synergies between European Union research and innovation policies and participatory action research approaches. Through the research process, a model for social innovation support was jointly created, emphasizing the transformative goals of social innovation, where the authors conclude that European Union policies for stakeholder involvement work well with an action research approach.

Next, Anna Sannö and Anna Ericson Öberg from Volvo Construction Equipment, together with Erik FloresGarcia from Mälardalen university and Mats Jackson from Jönköping University, use six different research projects to explore how both practical and theoretical impact can be enhanced by considering certain key factors in a collaborative research process. The authors especially mention that effective management of the phases of problem formulation, methodology, and results is important for successful collaboration and, thereby, impact. 


\section{Editorial: Action Research}

\section{Chris McPhee, Magnus Hoppe, and Erik Lindhult}

Matthias Guertler and Nathalie Sick from the University of Technology Sydney (UTS), Australia, and Anton Kriz from the Australian National University (ANU) conduct a discipline-spanning, bibliographic overview of the landscape of action research and its implications for technology and innovation management (TIM). They argue that the iterative and learning character of action research is suitable for exploring complex socio-technical problems prevalent in TIM, but they find that the use of action research in TIM research is surprisingly limited but mounting. Their study shows, strikingly, "that the most productive journals (total number of articles) publishing action research are discipline-spanning and action research specific, while the most influential journals as well as articles (impact factor, citations per article) are published in discipline-specific journals". The review indicates that there is potential for enhanced use of action research in TIM and in TIM journals, and the authors use qualitative analysis to synthesize the benefits and challenges in using this type of approach.

In the final article, Magnus Hoppe from Mälardalen University in Sweden explores publication patterns for participatory and action research in innovation journals with the aim to provide advice in choosing outlets. It is done through a bibliographical review of all 33 innovation journals listed in the 2018 Academic Journal Guide, complemented with a case study of this journal, the TIM Review. The study finds positive signs that action research is moving from the margin to the mainstream, where the movement towards openness in innovation and in publication practices are supportive trends. The results are challenging the not uncommon view, also expressed in the call to this special issue, that it is more difficult to publish action research in high-ranked journals. Hoppe finds that publications are spread out over different journals but that "we lack a clear answer to the question of what is the best outlet". He invites us to reflect upon what kind of impact we want to have and to choose outlets accordingly.
The articles may diverge in many ways, but they all emphasize that action research "should not be based on the interest of only one of the stakeholders", as Sannö and colleagues phrase it in their article. By using action research, different stakeholders will be forced to at least listen to what other parties have to say. However, as described in the articles in this special issue, they will also realize that the best results come from mutual definitions of key problems as well as working together across borders in order to solve identified problems.

In closing, we emphasize that doing research together across borders require researchers and collaborators to engage in often complex issues in bridging borders and dealing with boundaries in order to integrate forms of knowing, various disciplines, and knowledge interests in producing both scientific and actionable knowledge, and both theory and transformation. This shows both the scientific and practical potential of action research in bridging and integrating action, problem solving, and transformation with research and scientific activity. The articles in this first special issue deal with and contribute to this endeavour in different ways, and we look forward to the second special issue, which will further show how action research approaches in various ways can support and enable the bridging across borders.

\section{Magnus Hoppe and Erik Lindhult Guest Editors}




\section{Editorial: Action Research}

\section{Chris McPhee, Magnus Hoppe, and Erik Lindhult}

\section{About the Editors}

Chris McPhee is Editor-in-Chief of the Technology Innovation Management Review. Chris holds an MASc degree in Technology Innovation Management from Carleton University in Ottawa, Canada, and BScH and MSc degrees in Biology from Queen's University in Kingston, Canada. He has 20 years of management, design, and content-development experience in Canada and Scotland, primarily in the science, health, and education sectors. As an advisor and editor, he helps entrepreneurs, executives, and researchers develop and express their ideas.

Magnus Hoppe is an Associate Professor at the School of Economics, Society and Engineering at Mälardalen University, Sweden. At the university, he is member of the Faculty Board and leads processes for collaborative research in sustainable development. Magnus holds a $\mathrm{PhD}$ in Business Administration from Åbo Akademi University in Finland, where he presented his thesis on organized intelligence work in modern organizations. His current research concerns both private and public organizations and spans intelligence, entrepreneurship, and innovation. A special research interest lies in questioning dominating perspectives that bind our understanding of specific topics, and he now works to establish new ways of talking and thinking about innovation. His aim is to help organizations build new insights that will enhance their ideation processes and strategy building and, thereby, improve their innovative capabilities.

Erik Lindhult (Ph.D.) is a Senior Lecturer in Innovation Management and Entrepreneurship at Mälardalen University in Sweden. He received his doctoral degree in Industrial Management from the Royal Institute of Technology in Stockholm, in the area of Scandinavian dialogue democratic approach to innovation and action research. His main area of research is participatory, collaborative, and democratic innovation and change management, as well as entrepreneurship for a sustainable development of society. His research interests also involve collaborative research methodologies, including action research and interactive research. He has been involved in a wide range of collaborative $R \& D$ projects in the private, public, and cooperative sectors, in areas such as organizational development, incubator and science park development, service innovation, societal entrepreneurship, sustainable innovation, and school development. He is board member of the Swedish Participatory Action Research Society (SPARC) and the Swedish Interactive Research Association (SIRA), as well as expert advisor to the EU SWAFS Horizon 2020 research committee.

\section{References}

Adelman, C. 1993. Kurt Lewin and the Origins of Action Research. Educational Action Research, 1(1): 7-24. https://doi.org/10.1080/0965079930010102

Chesbrough, H. W. 2003. Open Innovation: The New Imperative for Creating and Profiting from Technology. Boston, MA: Harvard Business Press.

Fals-Borda, O., \& Rahman, M. A. 1991. Action and Knowledge: Breaking the Monopoly with Participatory Action-Research. New York: Apex Press.

Freire, P. 1985. The Politics of Education: Culture, Power, and Liberation. Westport, CT: Greenwood Publishing Group.

Johansson, A. W., \& Lindhult, E. 2008. Emancipation or Workability? Critical versus Pragmatic Scientific Orientation in Action Research. Action Research, 6(1): 95-115. https://doi.org/10.1177/1476750307083713

Kaplan, R. S. 1998. Innovation Action Research: Creating New Management Theory and Practice. Journal of Management Accounting Research, 10: 89-118.

Kemmis, S., McTaggart, R., \& Nixon, R. 2015. Critical Theory and Critical Participatory Action Research. In H. Bradbury (Ed.), The SAGE Handbook of Action Research (3rd ed.): 453-464. Los Angeles: SAGE.

Lewin, K. 1946. Action Research and Minority Problems. Journal of Social Issues, 2(4): 34-46. https://doi.org/10.1111/j.1540-4560.1946.tb02295.x

Reason, P., \& Bradbury, H. 2008. Handbook of Action Research: Participative Inquiry and Practice. Thousand Oaks, CA: SAGE.

Citation: McPhee, C., Hoppe, M., \& Lindhult, E. 2019. Editorial: Action Research. Technology Innovation Management Review, 9(4): 3-6.

http://doi.org/10.22215/timreview/1228

Keywords: action research, participatory research, participative, innovation 


\title{
Navigating Boundaries in Additive Manufacturing through Action Research
}

\author{
Katharina Ruckstuhl, Rafaela C. C. Rabello, and Sally Davenport
}

\author{
" Boundaries generate turbulence. Boundaries are encountered") \\ through exploration, and the process of exploration is messy \\ ... Yet, it is within this messiness and the associated tensions \\ of shared and differing perspectives, and often at the points \\ of intersections of diverse ideas, new possibilities emerge and \\ new solutions and/or approaches are generated, which, in \\ turn, inspire and lead to transformation.
}

Lonnie Rowell, Margaret Riel, and Elena Polush (2017b)

\begin{abstract}
Action research - both as praxis but also from a critical orientation - can elaborate modes of action, identifying the borders and margins that act as both the productive spaces for collaboration as well as the fuzzy areas that require reflection and clarification. In this exploratory case study, action research is used to follow an additive manufacturing project team in real time as it navigates fuzzy areas to integrate knowledge to produce commercializable science innovation in one of New Zealand's National Science Challenges (NSC): Science for Technological Innovation - Kia Kotahi Mai: Te Ao Pütaiao me Te Ao Hangarau (SfTI). Through action research as praxis and as critical orientation, we have identified key mechanisms in interdisciplinary and transdisciplinary research for commercialization, particularly in the context of New Zealand's indigenous Māori people. Our preliminary analysis indicates that an explicit understanding of the fuzzy spaces can help teams find creative and collaborative means to navigate the productive but challenging "interstices of disciplines" (Mengis et al., 2018) to produce science innovation and discoveries and to galvanize relationships with industry and Māori participants. The findings also indicate that action research can promote structural, relational, and knowledge changes within teams, helping them solve complex problems in real time.
\end{abstract}

\section{Introduction}

Recent research into "real world problems" (Carr et al., 2018) has noted the need for interdisciplinarity. Such aspirations have been a feature of "grand challenges", which galvanize collaborations between governments, academia, and industry, directing the science sector to pursue "societal goals" (Kaldewey, 2018) in areas as diverse as health and development, global food security, climate change, energy, and aging populations.

Action research - both as praxis but also from a critical orientation (Bleach et al., 2016; Rowell et al., 2017a) can elaborate modes of actions, identifying the borders and margins that act as both the productive spaces for collaboration as well as the "fuzzy" spaces that require clarification. In this study, we show how action re- search can be used to navigate such fuzzy spaces to help researchers understand how to integrate knowledge to produce commercializable science innovation in New Zealand's National Science Challenges (NSC). New Zealand has heavily invested in physical sciences and engineering research to grow the country's economy through a ten-year national science challenge: Science for Technological Innovation - Kia Kotahi Mai: Te Ao Pūtaiao me Te Ao Hangarau (SfTI).

The SfTI challenge has brought together interdisciplinary research teams to collaborate with enterprises - including Māori, New Zealand's indigenous people - to help unlock innovation and contribute to the country's economy. The combination of different specialized knowledge domains across numerous public and private organizations has the potential to both propel and obstruct innovation. If the SfTI approach to innova- 


\title{
Navigating Boundaries in Additive Manufacturing through Action Research
}

\author{
Katharina Ruckstuhl, Rafaela C. C. Rabello, and Sally Davenport
}

tion is to succeed, then it is important to look for ways to minimize or eliminate the barriers and increase or accelerate the innovation enablers, with such findings expected to be shared and incorporated more widely across the traditional science boundaries.

In order to build this evidence base, a team of social science researchers - the Building New Zealand's Innovation Capacity team (BNZIC) - has been following "in real time" the diverse projects that have been funded through SfTI. The BNZIC team has adopted an action research approach to identify the tensions and the structural and relational mechanisms that inhibit and promote innovation knowledge transfer. The team adopted two action research modes: action research as praxis and action research as critical orientation. Through these two modes, the BNZIC team has identified that research interstices, in both their physical and abstract forms (Corsaro, 2018; Huang \& Huang, 2013), should be consciously foregrounded in interdisciplinary and transdisciplinary research to accelerate such teams' progress towards their innovation objectives and to more consciously include Māori participants who might contribute towards such innovation. Such foregrounding has allowed the BNZIC team to provide reflections back to the science teams to help them understand the processes, people, and resources required to achieve the SfTI mission.

This article presents a deep inquiry (Riel, 2010) into individual and team practices from one of the SfTI projects: additive manufacturing. In this context, deep inquiry refers to cyclical and interactive processes of observing, planning, acting, and reflecting (Piggot-Irvine, 2009) upon the additive manufacturing team's innovation processes. The question that has guided this inquiry is: How can action research, as praxis and critical orientation, help interdisciplinary teams transform science innovation processes, particularly in the context of engagement with Māori? The article aims to show how being attentive to the fuzzy spaces between individuals and groups helps navigate the productive but challenging "interstices of disciplines" (Mengis et al., 2018: 2; Nicolini et al., 2012) to produce science innovation and to galvanize engagement with business and Māori.

The article is divided into four sections. The first introduces the broader SfTI mission and the additive manufacturing programme. The second describes the research design methods and provides a brief outline of the data collection and analysis processes. The third addresses the question of action research as transformat- ive praxis, outlining action research theory in reference to critical design and boundary object theory, to explicate how the research scientists are transforming practice to solve complex technical problems. The fourth section concerns action research as critical orientation and explores how this approach is promoting relational and knowledge changes within the additive manufacturing team, to help them critically reflect upon their engagement with Māori participants. We begin by introducing the SfTI challenge.

\section{The SfTI National Challenge}

The Science for Technological Innovation, Kia Kotahi Mai: Te Ao Pütaiao me Te Ao Hangarau, (SfTI) challenge aims to enhance New Zealand's capacity to use physical sciences and engineering for economic growth through its scientific innovation and discoveries. The challenge aims to incorporate New Zealand's human, relational, and technological capacities to grow the country's economy. The contention is that a more technology-driven and prosperous economy will emerge from more focused and connected research efforts (Daellenbach et al., 2017; Davenport et al., 2015; SfTI, 2018). SfTI funds projects in the areas of sensors, robotics and automations, IT, data analytics and modelling, and materials, manufacturing, and design.

Along with investment into the technical science, SfTI supports a capacity development programme, so that scientists might become more confident in leading conversations with and being more proactive in their engagement with industry partners, including Māori. This latter requirement is because of the Vision Matauranga (Māori knowledge) science policy, which has become a required consideration for all science funding in New Zealand (Daellenbach et al., 2017; Davenport et al., 2015; MoRST, 2007). In response to this policy, SfTI has developed three pillars: to advance Māori knowledge; to have more Māori leading and participating in technological research; and to bring greater benefit to Māori by prioritizing and tailoring research for Māori (SfTI, 2018).

Over 250 researchers and 29 different organizations from across New Zealand and internationally are involved in SfTI projects (SfTI, 2018). SfTI allocates funding to two levels of research: large "Spearhead" projects and smaller "Seed" projects. There are eight Spearhead Projects, four of which commenced in 2016, of which one - the 3D/4D additive manufacturing of biopolymers - is the subject of this case study, and to which we now turn. 


\title{
Navigating Boundaries in Additive Manufacturing through Action Research
}

\author{
Katharina Ruckstuhl, Rafaela C. C. Rabello, and Sally Davenport
}

\section{SfTI's additive-manufacturing project}

Additive manufacturing, or 3D/4D-printing technology, is where physical objects are created by building up parts through the laying of materials from powder or liquid combined with a binding agent such as heat, UV light, or laser (André, 2017a; Horvath, 2014; Khare et al., 2017; Zeidler et al., 2018). 3D-printed objects are static compared to $4 \mathrm{D}$-printed objects that actuate through triggering (sensing) elements (e.g., water and light) embedded within their underlying material (Tibbits, 2014; Tibbits et al., 2014). A 4D object's actuation is independent of external devices or electromechanical systems, and it is constructed using a 3D-printing platform combined with a $3 \mathrm{D} / 4 \mathrm{D}$ printing interface in a singular system (Khare et al., 2017; Tibbits, 2014; Tibbits et al., 2014).

Additive manufacturing enables flexible production of personalized products, with reduced costs of production and wastage of feedstock resources (André, 2017a; Weller et al., 2015). It also allows for fast prototyping by reducing the number of intermediaries between the designer and the final product, speeds up product creation and production time, and reduces storage costs (André, 2017a, b). 3D/4D printing technology also poses challenges, in particular, the manufacturing feedstock that is mostly from non-renewable sources, which poses environmental dangers (Huang \& Huang, 2013; Zeidler et al., 2018).

Responding to such opportunities and challenges, a geographically dispersed, cross-disciplinary team, composed of chemists, engineers, and designers, is working towards developing bio-based $3 \mathrm{D} / 4 \mathrm{D}$ materials and equipment in New Zealand (Zeidler et al., 2018). To confirm that this new technology is attuned to market demands (Edwards, 2005; Mäenpää et al., 2016) the team has built-in regular engagement with industry.

Combining knowledge across different specialized domains can either propel or impede innovation. This depends on how knowledge is shared, incorporated, and transformed across boundaries (Carlile, 2004; Corsaro, 2018). According to Hsiao, Tsai, and Lee (2012), a boundary refers to the limits or the interstices of a domain, which may be "physical, geographical, social, cognitive, relational, cultural, temporal/spatial, divisional, occupational, and disciplinary".

Recognizing boundaries is an essential part "of systems work/inquiry/thinking” (Williams \& Imam, 2007 in Rowell, Riel, \& Polush, 2016). Such recognition raises actors' awareness of the tensions in boundaries, open- ing up dialogical spaces to transform and catalyze knowledge (Rowell et al., 2017a). Recognition of these boundaries through the BNZIC team's action research with the science team in the context of their interactions with industry and Māori aims to transform science innovation praxis - both practically and critically. We now explore the research design and methods.

\section{Research Design and Methods}

This is an exploratory case study that was conceived as a "real-time" examination with the BNZIC team of social scientists following the additive manufacturing team as they developed their ideas and technologies. An ethnographic approach (Agar, 1996; Gibson-Graham, 2014; Hymes, 2013) was chosen given the exploratory nature of the science in a newly-formed science team with a very broad mandate to develop novel and commercializable research. The BNZIC researchers used a range of data collection methods including observations and active participation at team meetings and social occasions; examination of science reports and emails; informal and formal interviews; and surveys.

This case study draws on the draft report and presentation supplemented by the additive manufacturing team's science reports, as well as broader SfTI reports about the additive manufacturing team's research. These reports are complemented by 28 semi-structured and open-ended interviews with the additive manufacturing team members as well as participants who took part in the team's workshops with industry. These interviews took place over a 30-month period and were audio recorded then transcribed (Lapadat, 2000; Lapadat \& Lindsay, 1999; Scheurich, 1995). A qualitative data analysis software package, NVivo, was used to organize and code data with an inductive approach adopted to analyzing the data (Braun \& Clarke, 2006).

In the following section, we give a brief overview of the aims and processes of action research. We then assess how this approach has informed the additive manufacturing team to transform science and engagement practice.

\section{Transforming Praxis in the SfTI Additive- Manufacturing Project}

Action research refers to a participatory process that seeks to bring together practice, theory, and reflexivity in order to develop practical solutions (Reason \& Bradbury, 2001). In the additive-manufacturing project, two 


\section{Navigating Boundaries in Additive Manufacturing through Action Research}

\section{Katharina Ruckstuhl, Rafaela C. C. Rabello, and Sally Davenport}

orientations of action research were combined: pragmatic and critical (Hadfield, 2012; Johansson \& Lindhult, 2008). Within a pragmatic orientation, researchers and practitioners reflect upon their ongoing process of engagement and knowledge creation to act concurrently to overcome existing obstacles. Within a critical orientation, researchers and practitioners interrogate power relations (Johansson \& Lindhult, 2008). In the additive manufacturing project, coordinated action was needed to create new innovation knowledge for commercialization (pragmatic orientation) while critical reflection (critical orientation) was required to transform knowledge and relationships between researchers and Māori.

Pragmatically oriented action research is often composed of a hybrid methodology that aims to connect theory to practice. Rowell and co-authors (2017a) emphasize that co-constructing common ground between researchers and practitioners creates the platform for action. To establish this common ground, the BNZIC team took a "spiral of steps" approach (Lewin, 1946; Minkler, 1981) by attending 13 formal meetings, workshops, and team-building functions (dinners and laboratory visits); observing and taking part in presentations; and offering regular formal and informal reflections at the individual and group levels. This embedded but reflexive participatory approach enabled some key insights to be shared.

The first insight is how design acts as an upstream innovation catalyst through the iterative embodiment of innovation prototypes based on the designers' understanding of the scientists' technically uncertain research. By identifying how design literally objectifies boundaries between the downstream understandings and expectations of end users and the upstream scientific invention of the researchers, the BNZIC team showed the value of design in very early science. Designers are more commonly used as a mid-stream mechanism (Luo, 2015), when the technical uncertainties of the science have been worked out and the researchers have set the direction for the science (Friesike et al., 2015; Schuurbiers \& Fisher, 2009). In the additivemanufacturing project, the designers have worked in tandem with the scientists to act as boundary intermediaries between the uncertainty of the scientists' new technology and the market demand of industry. This is an important consideration for not only the additivemanufacturing team but also the wider SfTI challenge.

The following quotation exemplifies how many of the scientists felt during early meetings with industry:

\begin{abstract}
"Well the problem is that the meeting was all about what they [emphasis added] wanted; so one group ... wanted us to print an airline seat and all kinds of weird things. I'm scared they get disappointed when they now hear we're actually dealing with science stuff and we're not actually focusing on one end product." (Additive-manufacturing scientist)
\end{abstract}

The comments that the meetings were all about what they (i.e., industry) wanted and that the project was really about "science stuff" can be considered an example of a "cognitive trap" where participants draw quick conclusions based on their own experiences and expectations rather than on direct observation and interaction with others (Butler \& Roberto, 2018). Such cognitive traps interfere with knowledge co-creation at a boundary interstice because they hinder collaboration. In contrast, Butler and Roberto (2018) identify that a design-led approach creates pathways to connect theory and practice by first developing empathy, and then through the ideation and prototyping-testing processes.

Developing empathy is a "human-centred" process (Kimbell, 2011) supporting understandings about and expectations of end users. A key feature of the additivemanufacturing project has been its formalized meetings with industry representatives. Involving companies upstream has been a boundary challenge requiring skilled facilitation. Initially, a business facilitator was used to identify industry's interest in 3D-printed biomaterials, however, subsequent meetings have focussed more on developing shared understanding of what makes an impact for industry. Developing empathy for industry's viewpoint, needs, and concerns has been an iterative process. A professional external contractor skilled in bridging diverse worldviews has been employed to explore not only the possibilities of the unknown science but also to allow both scientists and industry to "understand each other's language" (Additive-manufacturing scientist). The shift from the concerns expressed in an early workshop to a more collaborative understanding is expressed in the following:

"[The] team came together with members all in one room. Wouldn't have expected to get that far in one day. Eight organizations with people from different sectors and capabilities. Intense and focused and good will and wanting to make it work." (Additive-manufacturing participant)

What part did BNZIC play in this iteration? While the leadership team had planned for regular interaction 


\section{Navigating Boundaries in Additive Manufacturing through Action Research} Katharina Ruckstuhl, Rafaela C. C. Rabello, and Sally Davenport

with industry, the draft report after the first year showed the value of continuing to focus on empathy development between industry and science as opposed to a process of merely listening to industry as evident in the initial meeting. In other words, research focus on the pragmatics of empathy has reinforced and confirmed a practice in this upstream science, giving confidence to continue in this direction. Additionally, this finding posits that empathy intermediaries are not only a "nice to have" at the start of a science process, but can play an important role throughout the innovation process enabling industry to have early insight into the science. Co-innovation, rather than a theoretical concept, becomes more of a reality with such an approach.

Empathy has also been key to supporting the ideation process. Design-led ideation entails brainstorming possible solutions to meet the needs and expectations of end users (Butler \& Roberto, 2018) and to turn science problems into innovation opportunities (Kimbell, 2011). As identified in the additive manufacturing team's research mission, the printing of bio-based materials was the focus of the science because:

“... at the time, there were none [sic] other than the medical tissue stuff ... and so, basically, 3D printing was built on the standard petroleum, plastics, and metals. And still predominantly is. At the time we found ... there's still not a bio-base out there." (Additive-manufacturing scientist)

However, identifying an opportunity is one thing: turning it into reality with a newly formed team is another. Unsurprisingly, there was an "element of frustration" as the team struggled to understand the linkages between their science, the role of the designers within the science and the expectations of industry.

\footnotetext{
"At one end, we've got a selection of materials that people think might be useful and, at the other end, we've got, well, what applications we want to use them for. So, how to join those up? And I think, at some point, it's a ... look there is no right answer, there's no wrong answer, let's agree on a focus and just get on and do it." (Additive-manufacturing scientist)
}

In relation to the "how to join" problem, it was the designers who provided the impetus for the scientists to "agree on a focus". There had been a "split of opinions" as to whether to focus on "physical products" or "new technologies or processes" (Additive-manufacturing scientist). This was resolved when, through a repetitive series of design offerings that included speculative articulations of future 3D/4D scenarios, current products printed using novel design approaches, and experimental design methods, the scientists agreed to integrate their efforts by printing demonstrators that combined the novel chemical materials with the equipment modifications needed to print the materials. From a design perspective, a demonstrator or physical prototype can facilitate knowledge transfer, translation, and transformation across interdisciplinary teams (Jensen \& Kushniruk, 2016). Such prototypes "elicit a more nuanced understanding of product attributes ... facilitating future iterations of design" (Henderson, 1995; Seidel \& O'Mahony, 2014: 694; Stigliani \& Ravasi, 2012), thus helping to "describe a potential future worth testing" (Bletcher, 2017).

Physical prototypes are also boundary objects: common points of reference that can facilitate or act as barriers to effective knowledge sharing, co-ordination, and transformation among individuals and institutions of different specialized domains (Corsaro, 2018). In other words, boundary objects are conduits to cross knowledge boundaries (Marheineke, 2016).

The following illustrates how the role of the BNZIC researcher enabled reflection on prototypes as boundary objects through the collaborative process:

BNZIC researcher: "Now that you've got some prototypes or some targets that you're all agreed on, that's actually liberated everybody to..."

Additive-manufacturing scientist: "At least this, now also when we have the meetings, you can ... say, all right, you've made an ultra-light material what will you use it for? Up 'till that point it was, you make material and then look for a solution for a problem that it could resolve. Whereas now it is, okay - swimming fin, for example."

In the above excerpt, while the term "boundary object" (the swimming fin) is not mentioned by the BNZIC researcher, the question allowed the scientist to reflect on the positive shift from the frustration of the "openended exploration" (Stappers, 2013) or the "suck it and see" approach described by one scientist. Subsequent to the above interview, the BNZIC researcher has introduced the idea of the boundary object as a way for the team to understand collectively some of the fuzzy boundary interstices that may have led to their earlier frustration. This concept has also allowed them to have 


\title{
Navigating Boundaries in Additive Manufacturing through Action Research
}

\author{
Katharina Ruckstuhl, Rafaela C. C. Rabello, and Sally Davenport
}

a greater appreciation of why the design-led approach, which initially was not well understood by either the scientists or the designers has accelerated the science. Design has helped integrate not only their collaborative science but also created better empathy with industry to the extent that:

"there is a real sense of excitement from industry in terms of seeing quite tangible outcomes ... I think they got an understanding of what it was all about, and what was planned." (Workshop facilitator)

In the next section, we move from action research as praxis to action research as critical orientation, and the "spiral of steps" approach (Lewin, 1946) that has been necessary to facilitate new thinking and new action.

\section{Transforming Additive-Manufacturing En- gagements through Critical Orientation}

Action research as critical orientation involves taking a critical stance regarding issues of social injustice and draws on the works of diverse critical traditions (Hadfield, 2012; Johansson \& Lindhult, 2008; Rowell et al., 2017a). As such, it is emancipatory and calls for the recognition of tensions and conflicting interests between unbalanced power relations (Rowell et al., 2017a; Rowell et al., 2017b). Within the New Zealand context, unbalanced power relations apply to the situation between Māori and Pākehā (non-Māori, largely European New Zealanders) because of New Zealand's colonial legacy. This history marginalized Māori lifeways and, through the alienation of land as an economic resource, led to disproportionate levels of socio-economic deprivation (Rewi \& Rātima, 2018). These processes continue to reproduce unequal power relations between Pākehā and Māori (Smith, 2009), particularly as it relates to Māori science knowledge, or mātauranga. New Zealand's Vision Mātauranga (VM) science policy, aims to "unlock the innovation potential of Māori knowledge, resources and people to assist New Zealanders to create a better future" (MoRST, 2007). However, with few Māori scientists in R\&D technical areas such as additive manufacturing, Māori knowledge and the accompanying human and relational capacity to work with Māori communities and businesses is inhibited. Hence, the BNZIC researchers, one of whom is Māori, adopted a critical orientation to analyze the human and relational capacities of the additive manufacturing team and to explore opportunities to implement the VM policy in a way that addressed power imbalances within the science.
A critical perspective emphasizes that reality is subjective and construed through power hierarchies (Lather, 2006) thus shaping human relations (Kincheloe \& McLaren, 2002). In this article, we adopt MacDonald and co-authors' (2002) critical positioning that some groups in society are powerful, while others are powerless or less powerful. Powerful groups have interest in maintaining the power status quo. This can be seen in the initial formation of the additive-manufacturing scientists and in the early engagements with industry where Māori were not represented, despite biomaterials derived from indigenous flora or fauna being of key interest to Māori, who regard these as "taonga" or inherently precious. Many tribal groups list such taonga within their traditions and within legislation where tribes have legal agreements or settlements with the government.

While the leadership team was aware of the need to address VM, the ability to enact this within the science itself or with industry-focused Māori relationships proved challenging. Some team members viewed the VM policy as the Government:

“... pushing their tokenism down the line and expecting us to do tokenistic things to solve problems that they've identified. I think it's a little bit contrived. They're trying to make it genuine, but it's still - the framework, in my opinion, is quite tokenistic."

Other team members rhetorically refrained from recognizing or legitimizing VM as one of SfTI's aspirations as in the following:

"Sorry, when you say VM policy; whose [italics added] policy?"

Action research as critical orientation requires bringing into consciousness the reality of occupying powerful or less-powerful positions, and finding fresh meanings for a newly revealed reality (Freire, 1987). Disrupting notions that VM is "tokenistic" or is someone else's concern - "whose policy?" - involves struggle and resistance that is often unconscious to the individual (Johansson \& Lindhult, 2008; Macdonald et al., 2002). For the BNZIC team, the VM policy and how it is implemented at the site of science production, is a border that requires considerable interrogation if Māori knowledge and engagement for innovation are to be "genuine". This will require the powerful - in this, case scientists - to "liberate" themselves from long-standing power imbalances by assuming an active role with 


\title{
Navigating Boundaries in Additive Manufacturing through Action Research
}

\author{
Katharina Ruckstuhl, Rafaela C. C. Rabello, and Sally Davenport
}

Māori via "dialogue" (Freire, 1987). This is more than having a "token" relationship, as expressed above. Rather, it is the practice of challenging and disputing words and ideals expressed in spoken and written words (Freire, 1987; McLaughlin \& DeVoogd, 2004), including understanding that language, as social practice, is connected intrinsically with broader social and political concerns (Freire \& Macedo, 1995) as is expressed in a policy like VM.

Such a "dialogical space" is a work in process for the scientists. In the first instance, the team sought to introduce Māori high school students to 3D technology, a practice that might be seen as an educative activity that maintains the power status quo (i.e., the more powerful "bringing" technology to the less powerful). When asked about the utility of this approach, the BNZIC team assessed that it would not meet the team's science objective, thus this activity was not pursued. However, within the team itself, some individuals could see the transformative potential of Māori knowledge. For example, one scientist described how waste from Māori fisheries had the potential to become additive manufacturing feedstock, and another posited that Māori design concepts might offer potential novel design pathways. These insights were relayed back to the science leadership team to identify that there were opportunities for further Māori innovation engagement.

Being open to the VM dialogic space as a site of innovation opportunity - Freire's (1987) newly revealed reality - has been activated through the broader SfTI capacity development programme, with one scientist noting that:

“... the workshops they conducted at University of Auckland, particularly around Vision Mātauranga and all that; it was really helpful ... I had a better idea of what it actually means. So, it is allowing me to address these issues [engagement with VM] in a better way than what I could have done before the whole thing started. So, it opened up a better insight into the process."

Another scientist confessed that:

“... maybe I rolled my eyes at [VM] about two years ago ... I now really love sitting down with, not just a Māori researcher, but sitting down with somebody with a Māori perspective - around why is this material so special to you - what is the significance of this region - why are we concerned about this fish waste product, and not concerned about the economy, but what does it mean to you as a people?"

While these human capacity activities have been helpful to destabilize notions that Māori are powerless bystanders in science endeavours, they have not transformed the performance of the actual science itself, in either its design or its participants. To achieve this outcome requires stronger measures. As suggested by the BNZIC team, Māori artists and technicians from a national Māori arts and crafts training school were invited to the third industry workshop. Positioning the Māori artists as equivalent to industry moves the artists from the "token" to the "innovation" dialogic space. While a useful step in that the discussions at the workshop involved understanding the innovation potential of $3 \mathrm{D}$ and 4D materials and objects for Māori, such a positioning still does not truly deal with the "power structures" (Geib, 2017) of science itself. For this to occur, the BNZIC Māori researcher has suggested that the additivemanufacturing team step out of their laboratories and engage in the Māori world. In other words, the dialogic space is a literal space, where power relations are reversed. The traditional Māori meeting space, the marae, is one where Māori language is spoken; where tikanga (Māori norms) govern relationships; and where mātauranga, traditional and transformative Māori knowledge, provides the underpinning framework for science innovation. The impact of such dialogue will be observed as the science unfolds in the forthcoming years.

\section{Conclusion}

This article presents initial findings from an additivemanufacturing case study, to show how action research can elucidate the fuzzy but productive boundaries that underpin science innovation processes. The article aimed to address how action research - both as praxis and as critical orientation - can help interdisciplinary teams transform science innovation processes to connect with end users, whether industry or Māori.

As the case study indicates, action research as praxis has shown that upstream design-led approaches that focus on the creation of empathy, ideation, and prototyping can accelerate knowledge transfer across science disciplinary and science-industry boundaries. This understanding shows that incorporating design thinking in upstream exploratory science has value - both in the way that it creates relational empathy for end users but also as a way to resolve technical issues by co-ordinating action around actual objects. As critical orientation, 


\section{Navigating Boundaries in Additive Manufacturing through Action Research}

\section{Katharina Ruckstuhl, Rafaela C. C. Rabello, and Sally Davenport}

the action research approach has identified the need for dialogic space to be opened up, requiring the literal border crossing from the laboratory to the marae if issues of power within the science system are to be reconfigured to take advantage of Māori innovation knowledge.

Findings from this research have both theoretical and practical implications that are intended to be shared and implemented not only with the additive manufacturing team but also across the broader SfTI challenge. Additionally, we have shown the value of action research in the innovation space within the context of the broad aspirations of science challenges to address realworld problems. Despite the messiness and tensions, it is only through exploring and reflecting on such differing perspectives at the margins of disciplines and organizations that transformative change can be enacted.

Citation: Ruckstuhl, K., Rabello, R. C. C., \& Davenport, S. 2019. Navigating Boundaries in Additive Manufacturing

(cc) BY

through Action Research. Technology Innovation

Management Review, 9(4): 7-16.

http://doi.org/10.22215/timreview/1229

Keywords: action research, transformative praxis, critical orientation, science, innovation, SfTI

\section{About the Authors}

Katharina Ruckstuhl is an Associate Dean at the Otago Business School, University of Otago, New Zealand. She also holds a PhD from Otago. Dr Ruckstuhl co-leads the "Building New Zealand's Innovation Capacity" social science research of the National Science Challenge, Science for Technological Innovation. She is also the Vision Mătauranga (Māori knowledge) leader, a "Theme" that crosses all of the Challenge's research activities. She has published in the areas of: Māori language; resource extraction in Māori territories; Māori entrepreneurship in SMEs; Indigenous science and technology; and Indigenous knowledge.

Rafaela C. C. Rabello holds a PhD in Social Investment in the oil and gas sector and a Master's degree in Education, awarded with distinction by the University of Otago, New Zealand. Rafaela also holds a BA in Psychology from the University Center of Brasilia, Brazil. Rafaela has worked within the fields of corporate social responsibility - in the oil and gas sector - and education for more than 10 years. She has published in the areas of: corporate social responsibility; social investment in the oil and gas sector; higher education and good teaching and effective learning methodologies in higher education.

Sally Davenport is a Professor of Management at Victoria University of Wellington, New Zealand. Sally is the Director of the New Zealand National Science Challenge "Science for Technological Innovation" (SfTI). Sally's academic life began as a research chemist, but she now has research interests covering the commercialization of scientific research, entrepreneurship and the growth of hightech firms, innovation strategy, and policy. Sally has previously led major research projects on competitive advantage in New Zealand firms, into organizations, and networks in biotechnology. Sally is a Commissioner with the New Zealand Productivity Commission and is also an Adjunct Professor in the College of Business and Economics at the Australian National University, a Fellow of the International Society for Professional Innovation Management, and a member of Global Women. In 2018, she was made a Member of the New Zealand Order of Merit for her services to science. 


\section{Navigating Boundaries in Additive Manufacturing through Action Research Katharina Ruckstuhl, Rafaela C. C. Rabello, and Sally Davenport}

\section{References}

Agar, M. H. 1996. The Professional Stranger: An Informal Introduction to Ethnography. New York: Academic Press.

André, J.-C. 2017a. From Additive Manufacturing to 3D/4D Printing 1: From Concepts to Achievements. Hoboken, NJ: John Wiley \& Sons.

André, J.-C. 2017b. From Additive Manufacturing to 3D/4D Printing 2: Current Techniques, Improvements and Their Limitations. Hoboken, NJ: John Wiley \& Sons.

Bleach, J., Feldman, A., Kim, M., McAteer, M., McNiff, J., Polush, E., Riel, M., Rowell, L., Santos, D., Shosh, J., Thomas, S,. Wamba, N., \& Wood, L. 2016. ARNA Symposium: The Palgrave International Handbook of Action Research. Paper presented at the Conference of the Action Research Network of the Americas, Knoxville, TN.

Bletcher, J. 2017. The Constellation: A Framework for Conceptualising Design as a Process of Innovation. The Design Journal, 20 (Sup 1): S4552-S4564.

https://doi.org/10.1080/14606925.2017.1352952

Braun, V., \& Clarke, V. 2006. Using Thematic Analysis in Psychology. Qualitative Research in Psychology, 3(2): 77-101. https://doi.org/10.1191/1478088706qp063oa

Butler, A. G., \& Roberto, M. A. 2018. When Cognition Interferes with Innovation: Overcoming Cognitive Obstacles to Design Thinking: Design Thinking Can Fail when Cognitive Obstacles Interfere; Appropriate Cognitive Countermeasures Can Help Disarm the Traps. Research-Technology Management, 61(4): 45-51. https://doi.org/10.1080/08956308.2018.1471276

Carlile, P. R. 2004. Transferring, Translating, and Transforming: An Integrative Framework for Managing Knowledge Across Boundaries. Organization Science, 15(5): 555-568. http://doi.org/10.1287/orsc.1040.0094

Carr, G., Loucks, D. P., \& Blöschl, G. 2018. Gaining Insight into Interdisciplinary Research and Education Programmes: A Framework for Evaluation. Research Policy, 47(1): 35-48. https://doi.org/10.1016/j.respol.2017.09.010

Corsaro, D. 2018. Crossing the Boundary between Physical and Digital: The Role of Boundary Objects. IMP Journal, 12(2): 216-236. https://doi.org/10.1108/IMP-06-2017-0036

Daellenbach, U., Davenport, S., \& Ruckstuhl, K. 2017. Developing Absorptive Capacity for Midstream Science in Open Innovation Contexts. International Journal of Technology Transfer Commercialisation, 15(4): 447-462.

https://doi.org/10.1504/IJTTC.2017.089674

Davenport, S., Daellenbach, U., Ruckstuhl, K., Hyland, M., \& Leitch, S. 2015. Rethinking Absorptive Capacity for Open Innovation Contexts. Presented at the ISPIM Innovation Symposiumm, December 6-8, 2015, Brisbane, Australia.

Edwards, A. 2005. Relational Agency: Learning to Be a Resourceful Practitioner. International Journal of Educational Research, 43(3): 168-182.

https://doi.org/10.1016/j.ijer.2006.06.010

Freire, P. 1987. Pedagogia do oprimido. Rio de Janeiro: Paz e terra.

Friesike, S., Widenmayer, B., Gassmann, O., \& Schildhauer, T. 2015. Opening Science: Towards an Agenda of Open Science in Academia and Industry. The Journal of Technology Transfer, 40(4): 581-601.

https://doi.org/10.1007/s10961-014-9375-6
Geib, C. 2017. How Much Should Expectation Drive Science? Answers to the Biggest Mysteries May Lie Well Outside Traditional Paradigms. Dark Matter, March 2017.

Gibson-Graham, J. K. 2014. Rethinking the Economy with Thick Description and Weak Theory. Current Anthropology, 55(S9): S147-S153.

https://doi.org/10.1086/676646

Hadfield, M. 2012. Becoming Critical Again: Reconnecting Critical Social Theory with the Practice of Action Research. Educational Action Research, 20(4): 571-585.

https://doi.org/10.1080/09650792.2012.727647

Henderson, K. 1995. The Political Career of a Prototype: Visual Representation in Design Engineering. Social Problems, 42(2): 274-299. https://doi.org/10.2307/3096905

Horvath, J. C. 2014. Mastering 3D Printing. New York: Apress. https://doi.org/10.1007/978-1-4842-0025-4

Hsiao, R. L., Tsai, D. H., \& Lee, C. F. 2012. Collaborative Knowing: The Adaptive Nature of Cross-Boundary Spanning. Journal of Management Studies, 49(3): 463-491. https://doi.org/10.1111/j.1467-6486.2011.01024.x

Huang, E. Y., \& Huang, T. K. 2013. Exploring the Effect of Boundary Objects on Knowledge Interaction. Decision Support Systems, 56: 140-147. https://doi.org/10.1016/j.dss.2013.05.012

Hymes, D. 2013. Foundations in Sociolinguistics: An Ethnographic Approach. Abingdon, UK: Routledge.

Jensen, S., \& Kushniruk, A. 2016. Boundary Objects in Clinical Simulation and Design of eHealth. Health Informatics Journal, 22(2): 248-264.

https://doi.org/10.1177/1460458214551846

Johansson, A. W., \& Lindhult, E. 2008. Emancipation or Workability? Critical versus Pragmatic Scientific Orientation in Action Research. Journal of Action Research, 6(1): 95-115. https://doi.org/10.1177/1476750307083713

Kaldewey, D. 2018. The Grand Challenges Discourse: Transforming Identity Work in Science and Science Policy. Minerva, 56(2): 161-182.

https://doi.org/10.1007/s11024-017-9332-2

Khare, V., Sonkaria, S., Lee, G.-Y., Ahn, S.-H., \& Chu, W.-S. 2017. From $3 \mathrm{D}$ to $4 \mathrm{D}$ Printing-Design, Material and Fabrication for MultiFunctional Multi-Materials. International Journal of Precision Engineering Manufacturing-Green Technology, 4(3): 291-299. https://doi.org/10.1007/s40684-017-0035-9

Kimbell, L. 2011. Rethinking Design Thinking: Part I. Design Culture, 3(3): 285-306.

https://doi.org/10.2752/175470811X13071166525216

Kincheloe, J. L., \& McLaren, P. 2002. Rethinking Critical Theory and Qualitative Research. In Ethnography Schools: Qualitative Approaches to the Study of Education: 87-138. https://doi.org/10.1007/978-94-6091-397-6_23

Lapadat, J. C. 2000. Problematizing Transcription: Purpose, Paradigm and Quality. International Journal of Social Research Methodology, 3(3): 203-219. https://doi.org/10.1080/13645570050083698 


\section{Navigating Boundaries in Additive Manufacturing through Action Research Katharina Ruckstuhl, Rafaela C. C. Rabello, and Sally Davenport}

Lapadat, J. C., \& Lindsay, A. C. 1999. Transcription in Research and Practice: From Standardization of Technique to Interpretive Positionings. Qualitative Inquiry, 5(1): 64-86.

https://doi.org/10.1177/107780049900500104

Lather, P. 2006. Paradigm Proliferation as a Good Thing to Think With: Teaching Research in Education as a Wild Profusion. International Journal of Qualitative Studies in Education, 19(1): 35-57.

https://doi.org/10.1080/09518390500450144

Lewin, K. 1946. Action Research and Minority Problems. Journal of Social Issues, 2(4): 34-46.

https://psycnet.apa.org/doi/10.1111/j.1540-4560.1946.tb02295.x

Luo, J. 2015. The United Innovation Process: Integrating Science, Design, and Entrepreneurship as Sub-Processes. Design Science, 1: E2.

https://doi.org/10.1017/dsj.2015.2

Macdonald, D., Kirk, D., Metzler, M., Nilges, L. M., Schempp, P., \& Wright, J. 2002. It's All Very Well, in Theory: Theoretical Perspectives and Their Applications in Contemporary Pedagogical Research. Quest, 54(2): 133-156.

https://doi.org/10.1080/00336297.2002.10491771

Mäenpää, S., Suominen, A. H., \& Breite, R. 2016. Boundary Objects as Part of Knowledge Integration for Networked Innovation. Technology Innovation Management Review, 6(10): 25-36. https://doi.org/10.22215/timreview/1025

Marheineke, M. 2016. Designing Boundary Objects for Virtual Collaboration. Berlin: Springer.

McLaughlin, M., \& DeVoogd, G. 2004. Critical Literacy as Comprehension: Expanding Reader Response. Journal of Adolescent Adult Literacy, 48(1): 52-62. https://doi.org/10.1598/JAAL.48.1.5

Mengis, J., Nicolini, D., \& Swan, J. 2018. Integrating Knowledge in the Face of Epistemic Uncertainty: Dialogically Drawing Distinctions. Management Learning, 49(5): 595-612. https://doi.org/10.1177/1350507618797216

Minkler, M. 1981. "Unfreezing” Lewin: The Case for Alternative Change Strategies in Health Education. International Quarterly of Community Health Education, 1(2): 169-182. https://doi.org/10.2190/FM63-4VN9-MKD7-X7DN

MoRST. 2007. Vision Màtauranga: Unlocking the Innovation Potential of Màori Knowledge, Resources and People. Wellington, New Zealand: New Zealand Government, Ministry of Research, Science+ Technology (MoRST).

Nicolini, D., Mengis, J., \& Swan, J. 2012. Understanding the Role of Objects in Cross-Disciplinary Collaboration. Organization Science, 23(3): 612-629.

https://doi.org/10.1287/orsc.1110.0664

Piggot-Irvine, E. 2009. Action Research in Practice. Wellington, New Zealand: New Zealand Council for Educational Research (NZCER) Press.

Rau, H., Goggins, G., \& Fahy, F. 2018. From Invisibility to Impact: Recognising the Scientific and Societal Relevance of Interdisciplinary Sustainability Research. Research Policy, 47(1): 266-276.

https://doi.org/10.1016/j.respol.2017.11.005

Reason, P., \& Bradbury, H. 2001. Handbook of Action Research: Participative Inquiry and Practice. London: SAGE.
Rewi, T., \& Rātima, M. 2018. Ngā Hurihanga o te Reo Māori i te Mātauranga: Changes in Māori Language Education. In M. Reilly, S. Duncan, G. Leoni, \& L. Paterson (Eds.), Te Koparapara: An Introduction to the Maori World: 304-323. Auckland, New Zealand: Auckland University Press.

Riel, M. 2010. Understanding Action Research. Research Methods in the Social Sciences, 17(1): 89-96.

Rowell, L. L., Bruce, C. D., Shosh, J. M., \& Riel, M. 2017a. The Palgrave International Handbook of Action Research. Basingstoke, UK: Palgrave Macmillan.

Rowell, L. L., Riel, M. M., \& Polush, E. Y. 2017b. Defining Action Research: On Dialogic Spaces for Constructing Shared Meanings. In The Palgrave International Handbook of Action Research: 85-101. Berlin: Springer.

Scheurich, J. J. 1995. A Postmodernist Critique of Research Interviewing. International Journal of Qualitative Studies in Education, 8(3): 239-252.

https://doi.org/10.1080/0951839950080303

Schuurbiers, D., \& Fisher, E. 2009. Lab-Scale Intervention. EMBO Reports, 10(5): 424-427. https://doi.org/10.1038/embor.2009.80

Seidel, V. P., \& O’Mahony, S. 2014. Managing the Repertoire: Stories, Metaphors, Prototypes, and Concept Coherence in Product Innovation. Organization Science, 25(3): 691-712. https://doi.org/10.1287/orsc.2013.0879

SfTI. 2018. Second Tranche Forward Strategy (2019-2024). New Zealand: Science for Technological Innovation (SfTI). https://www.sftichallenge.govt.nz/sites/default/files/2018-12/Future \%20Strategy\%20SfTI\%2020\%20June\%202018.FINAL_November.pdf

Smith, G. H. 2009. Mai i te maramatanga, ki te putanga mai o te tahuritanga: From Conscientization to Transformation. In Social Justice, Peace, and Environmental Education: 31-40. Abingdon, UK: Routledge.

Stappers, P. J. 2013. Prototypes as Central Vein for Knowledge Development. In L. Valentine (Ed.), Prototype: Design Craft in the 21st Century: 85-98. London: Bloomsbury Academic. https://doi.org/10.5040/9781350036031.ch-006

Stigliani, I., \& Ravasi, D. 2012. Organizing Thoughts and Connecting Brains: Material Practices and the Transition from Individual to Group-Level Prospective Sensemaking. Academy of Management Journal, 55(5): 1232-1259. https://doi.org/10.5465/amj.2010.0890

Tibbits, S. 2014. 4D Printing: Multi-Material Shape Change. Architectural Design, 84(1): 116-121.

https://doi.org/10.1002/ad.1710

Tibbits, S., McKnelly, C., Olguin, C., Dikovsky, D., \& Hirsch, S. 2014. 4D Printing and Universal Transformation. In Proceedings of the 34th Annual Conference of the Association for Computer Aided Design in Architecture: 539-548. Los Angeles, October 23-25, 2014.

Weller, C., Kleer, R., \& Piller, F. T. 2015. Economic Implications of 3D Printing: Market Structure Models in Light of Additive Manufacturing Revisited. International Journal of Production Economics, 164: 43-56. https://doi.org/10.1016/j.ijpe.2015.02.020

Zeidler, H., Klemm, D., Böttger-Hiller, F., Fritsch, S., Le Guen, M. J., \& Singamneni, S. 2018. 3D Printing of Biodegradable Parts Using Renewable Biobased Materials. Procedia Manufacturing, 21: 117-124. https://doi.org/10.1016/j.promfg.2018.02.101 


\title{
Using Action Research to Organize Technology Transfer in Complex Innovation Contexts
}

\section{Armando Machevo Ussivane and Paul Ellwood}

\author{
(6 Diversity: the art of thinking independently together. \\ Malcolm Forbes (1919-1990) \\ Entrepreneur and publisher
}

\begin{abstract}
Technology transfer projects increasingly consist of multiple, diverse organizations, with each pursuing their own agenda as well as that of the overarching programme. In this article, we adopt a participatory action research methodology in order to explain and improve the coordination of the autonomous innovation activities within an organizationally complex project. The context of the research involved the transfer of rice production technology from China to Mozambique. The action research identified four categories of boundary within the project that were hindering performance: Intellectual/Land property rights; Public/Private sector logics; Inside/Outside programme; and Collaboration/Competition between programme actors. The process of co-inquiry with stakeholders enabled by the action research allowed programme actors to reach an understanding of others, and it created a new thinking space for mutual problem solving. By these means, the action research process makes a resource of the differences between stakeholders rather than it being seen as a barrier to be compromised through negotiation.
\end{abstract}

\section{Introduction}

Technology innovation management increasingly involves working across multiple organizational borders (West \& Bogers, 2017). In addition, the types of organization participating in technology transfer projects are not limited to large, for-profit firms but also involves SMEs (Brunswicker \& Van de Vrande, 2014), universities (Perkmann \& Walsh, 2007), and government agencies (Chesbrough \& DiMinin, 2014). However, a consequence of such organizational complexity is the need for projects to deliver against multiple performance criteria. The resulting models of technology transfer (e.g., Bozeman et al., 2015) can themselves be so complex and contingent that it becomes difficult to discern general implications for the management and organization of such projects. In this article, we adopt an alternative approach to organizing technology transfer in very complex contexts, and we advocate for the use of participatory action research as a means of realizing the diverse objectives of stakeholders while also yielding academic insights.

Action research is designated participatory if it is associated with the emancipation or empowerment of parti- cipants (McTaggart, 1997; Whyte, 1991). The research context of this article is that of agriculture innovation, and this is a context in which participatory forms of action research have become well established (Oreszczyn et al., 2010). They started to be promoted in the 1980s as an alternative over perceived limitations to technology transfer drawn from Rogers' (1962) model of innovation diffusion. At that time, agricultural professionals had begun to realize the inappropriateness of diffusing high-input technologies in diverse, risk-prone and variable farming conditions (Rivera \& Sulaiman, 2009). Participatory research methods became viewed as the types of research needed to empower farmers toward active engagement in knowledge co-creation to solve problems. The underlying assumption was that farmers had considerable relevant and contextual knowledge although their capacity to use and improve such knowledge could be strengthened (Rivera \& Sulaiman, 2009).

Our article reports on a complex context of technology innovation management of significant contemporary importance. The development aid between an economically advanced nation and an emerging nation often includes technology transfer, and it is under-researched in the management literature. Specifically, we 


\section{Using Action Research to Organize Technology Transfer in Complex Innovation Contexts Armando Machevo Ussivane and Paul Ellwood}

examine the case of the transfer of rice production technology between China and Mozambique: the Baixo Limpopo Irrigation Scheme, one of largest technology transfer projects in Africa (Chuanhong et al., 2015). The majority of the research on China-Africa technology transfer has treated China as the dominant driving force in China-Africa relations such that Africans are simply reduced to passive actors (Dollar, 2016). A further limitation of current research is the excessive focus on the nation state with relatively little consideration for micro-level mechanisms of collaboration at the project-implementation level (Chuanhong et al., 2015). The research described in this article operates at the organizational level and documents the application of a participatory action research methodology to enable the coordination of the autonomous activities of the project's different stakeholders. The combination of an action research methodology and a rich data set allows us to explore a range of border issues within a technology transfer project. Rather than framing such borders as something to be broken down, we argue that the very diversity that creates the borders in the first place can be mobilized (through a participatory action research process) to enable project actors to generate insights that lead to the creation of organizational solutions.

\section{Research Issue}

The decision to initiate a technology transfer programme was taken at the level of national economic policy, and it follows decades of economic development collaboration between China and Mozambique. This article is concerned with the organizational level issues of implementing this multi-stakeholder programme. In the early months of the programme, it was evident that multiple identities, interests, and expectations were hindering efforts to co-ordinate the activities of different stakeholders. In this section, we present an account of the programme complexity underpinning this issue by describing the programme context and drawing upon research literature relevant to this context. The objective of the participatory action research project is then understood as providing a more thorough understanding of the programme complexity and developing solutions to coordinate the technology transfer activities of autonomous stakeholders.

\section{Research context}

The context of this research is one of the most significant contemporary Chinese agricultural investments in Africa and involves the transfer of rice farming technologies from China to Mozambique (Chuanhong et al., 2015). These technologies range from high-tech (e.g., new seed varieties) to low-tech (e.g., irrigation and pregermination) and involve the adoption of new (innovative in context) work practices (e.g., soil paddling). The efficacy of new agricultural practices and the viability of new seed varieties in the Mozambique bio-physical environment had previously been tested in demonstrator projects at the level of "friendship farms". The technology transfer programme that we report on in this article was concerned with a step-change scale-up in operations that involved an investment of $\$ 250$ million USD and that employed 2,000 local workers in addition to 700 Chinese workers. The programme was coordinated by a Mozambique Government agency (hereafter RBL) under a platform of cooperation with Wanbao, a private agricultural enterprise from Hubei province (China). The Chairman of RBL is a co-author (AU) of this article and facilitated the participatory action research group.

The complexity of this technology innovation context is evident not only in the variety of technology types but also in the diverse array of autonomous participants (government and local public agencies, local and international farmers, NGOs, banks, and private firms), their different national cultures and different agenda. We suggest that this context is representative of contemporary knowledge transfer where diverse and large numbers of different stakeholders are involved. Seeking to address what we know already about organizing technology transfer in such contexts, we examined the literature related to agricultural technology adoption, cross-cultural relations, and inter-organizational collaborations.

\section{Literature review}

Agricultural innovation scholars (Li et al., 2014; Rogers, 1962; Rogers \& Shoemaker, 1971) have approached technology transfer in terms of the processual relationship between technology source and technology recipient. Consistent with this view, Rogers (1962) advanced a model of the technology transfer as a diffusion of innovation whereby practices or ideas considered new originate in research or science and are then applied to the production process, after which they are diffused (by imitation or through active technology transfer) to the consumers (recipients) if economically successful. Difficulties for effective transfer may happen because much of the expertise is tacit in nature. This tacit dimension reflects the fact that part of knowledge associated with technologies is embedded in processes and behaviours of people (Polanyi, 1966): it is accumulated through practical skills or experiences, and it is therefore difficult to formalize and share with others. The 


\section{Using Action Research to Organize Technology Transfer in Complex Innovation Contexts Armando Machevo Ussivane and Paul Ellwood}

challenge of technology transfer may be heightened because stakeholders have different national cultures.

Culture has been conceptualized as "the collective programming of the mind which distinguishes one group or category of people from another" (Hofstede, 1993), in a way that cultural distance has a strong implication on the nature of transacting patterns between the people involved. Hofstede (1980) has mapped national cultures onto a multi-dimensional framework showing how difference in cultural orientations among people lead to misinterpretations during interaction. People improve their communication with one another by developing their intercultural competence (Lloyd \& Hartel, 2010). This allows them to evaluate more accurately how their own behaviour is affecting cross-cultural collaboration. The negotiation of interpretive differences may be mediated through the activity of translation (Kellogg et al., 2006) and through learning about the differences (Carlile, 2002).

The inter-organizational collaboration literature delineates the forces driving collaboration among autonomous organizational stakeholders. This raises challenges from the fact that each stakeholder must comply with its own agenda, while at the same time committing towards a shared programme purpose. Since neither hierarchy structure of authority nor market exchange enforcements are applicable in such a context (Powell, 1990), the stakeholders are driven into engagement by their high stake and interdependence and the desire to realize mutual gains (Thomson \& Perry, 2006). In order for these to be realized, trust among project stakeholders is needed.

The three threads of literature examined in this section explain the ways in which the management task faced by stakeholders in this context is complex. However, this very complexity prevents a simple application of literature models and frameworks. We argue that a participatory action research methodology is necessary in such circumstances, not only (as discussed above) to empower all stakeholders and unlock their tacit knowledge, but also to mobilize ideas from the literature. In this manner, these literatures did not provide a strong framing of the research, but rather constituted one guide during the discussions in the participatory action research sessions. The literature became, in effect, but one "voice" within the participatory action research process. In summary, an exploratory research question was posed to guide our empirical work: how can the coordination of interdependent activities be achieved in technology transfer programmes consisting of multiple stakeholders? Participatory action research, with its commitment to collaboration between stakeholders in pursuit of both scientific insight and practical impact, is particularly suited to addressing this question.

\section{Methodology}

Participatory action research was adopted in order to give voice to otherwise marginalized perspectives and because it operates by purposefully encouraging people with diverging ideas and mindsets to work together. Adopting participatory action research as a research methodology is to recognize that a collective agency resides within such projects. Notwithstanding the pedigree of the participatory action research methodology within agricultural innovation settings, the decision to adopt the method was taken by AU (co-author and Chairman of RBL) following his own observations of breakdown in the coordination of autonomous programme activities. This very decision by a senior manager risks being problematical in relation to the emancipatory philosophy of participatory action research. Therefore, the research design incorporated a "pre-participatory action research" stage that sought to elicit a wide range of viewpoints on the organizational challenges within the programme, and to test interest in a participatory action research project. Thus, Stage 1 of the research design involved semi-structured interviews with representatives of all programme's stakeholders (17 interviews). These interviews revolved around participants' experience of working with other organizations in the programme and their contribution to the programme's aims. Each participant was approached on the basis that they had been involved in the project for at least one year. The interviews incorporated a conversation about the idea of forming a group of all stakeholders in order to collectively examine the findings from the interviews, and they engaged in a process of identifying, implementing, and evaluating actions to improve the organizational arrangements within the programme (i.e., a participatory action research project). This proposal met with unanimous interest and the second stage of the research design was pursued.

Stage 2 involved convening a participatory action research group constituted of representatives of major stakeholders (Table 1). The participatory action research group discussions were facilitated by AU using the Torbert and Associates action inquiry process (2004). This process seeks to combine inquiry with advocacy by placing in a public forum specific suggestions, inferences, and assumptions in order to subject 


\section{Using Action Research to Organize Technology Transfer in Complex Innovation Contexts Armando Machevo Ussivane and Paul Ellwood}

them to critique and testing. At the first meeting, AU presented his thematic analysis of the Stage 1 interview data. In this manner, the findings of Stage 1 became a resource for the group in their first cycle of action and reflection. Subsequent cycles worked through the production of an action plan to improve the management of the programme, its implementation, and its evaluation. Data were collected during these action-related phases of the research in the form of workshop notes, programme documents, audio-taped observations, AU's research journal, and field notes.

\section{Research Findings}

Stage 1: Constructing the issue

In keeping with the methodological commitment not to impose possible solutions that originated external to the programme, the first stage of the research design sought to engage all stakeholders in the definition of the organizational issue to be addressed. The literature review was useful in guiding the search for data. However, care was taken to ensure the questioning remained openended and did not constrain discussion to categories from the innovation literature. A thematic analysis (Gioia et al., 2013) was conducted with the aim of articulating a grounded theory of the technology innovation management process operating in the programme. This was summarized into three broad phases of initial conditions, stakeholder engagement mechanisms, and desired conditions.

Regarding initial conditions, interviewees agreed that the key programme inputs were Chinese rice-farming technology and practices, along with the bio-physical factors of the programme's location. As the new technology was mobilized in this setting the initial challenges included the set-up and technology demonstration. The change in bio-physical context from that of China and the earlier "friendship farms" necessitated both the modification of agricultural practices and the creation of new policy instruments (e.g., in relation to land allocation).

The operation of the programme involved partners interacting with each other in multiple ways. The interviews afforded a rich picture of innovation activities as stakeholders pursued their own agendas in collaboration with programme partners. Three sub-themes of mechanism emerged from the analysis: the varied motivations for joining the programme; partnership forums and meetings; and integrating the work of different groups in order to adapt the technology to

Table 1. List of participatory action research participants

Organization Role in the Programme

RBL (government agency responsible for coordinating programme)

Farmers
Position of the Participant

- Chief Executive (and co-author AU)

- 5 local farmers

- President of Farming Association

- Young graduate farmer

Chinese Investment Company

- Local manager

- Technical staff

Mozambique Government Agencies

- District commissioner

- District director of economic activities

Local NGO - Women Development Fund (FDM)

- Local manager

Private financial services provider

- Local manager

Local government agency responsible over media broadcasting

- Local coordinator

Local NGO for community mobilization and advocacy over land-related issues

Local private agricultural firm providing land preparation services 


\section{Using Action Research to Organize Technology Transfer in Complex Innovation Contexts Armando Machevo Ussivane and Paul Ellwood}

local conditions. In addition to detailing these engagement mechanisms, interviewees spoke of the problems that had emerged. For example, one of the research participants we interviewed said about his work relationship with the Chinese partners, "My work with the Chinese has become transaction-based and is not cooperation anymore... I have to pay money to receive full package of services from the Chinese." His words exemplify how most farmers in the programme viewed their engagement with the Chinese in the programme. However, they also show a lack of alignment with the programme obligations of the Mozambique/China partnership agreement reached at a political level. Finally, in speaking about their hopes for the project, the interviewees made evident the different organizational agendas that were running in parallel, and that needed integration. The interviews validated the objective of the research: to improve the coordination (integration of interdependent activities) between the programme's stakeholders. The experiences captured through the interviews, and their processual ordering following thematic analysis, provided a rich picture of how technology transfer was being organized within the programme. It constituted a comprehensive resource with which to initiate the participatory action research stage of the research design.

\section{Stage 2: Participatory action research sessions}

The rich processual picture generated from the interviews was used to stimulate discussion in the participatory action research group sessions. Using this forum empowered participants toward active engagement in the creation of an agenda for social change. Experiences and stories from the programme were shared and examined for common themes. The tensions and conflicts within the programme could be understood in relation to "boundaries", which highlighted differences in meanings, behaviours, attitudes, or values. These boundaries are presented in Table 2 and are explained in the following sub-sections.

\section{Property rights boundary (intellectual vs land)}

A conflict emerged concerning land use within the geographical area of the programme. This was manifest as demands from the local community that they be granted access to the programme's developed land as a form of compensation after their grazing land had suffered reduction as a consequence of the programme. Under Mozambican land law, the State retains ownership of all land (and so could allocate land for the programme) and yet the rights and participation of local communities in land tenure (customary land use rights by fact of occupation) are stronger. Granting such access meant

Table 2. Summary of tensions at different boundaries within the technology transfer programme

Boundary Nature of Organizational Tension

Intellectual - Land

(property rights)

Return on investment for the provision of intellectual property

- versus -

Return from exercise of traditional land rights

Public - Private

Long-term aim of public policy to improve performance of rice farming through the introduction of new technologies and practices,

- versus -

Short-term aim of private firms to survive by optimizing business operations

Inside - Outside

(programme)

Obligation to work only with and through those partners identified with the programme

- versus -

Freedom to work with any organization offering suitable services or products

Collaboration -

Competition

Chinese actors as collaborators supporting Mozambicans through active development aid

- versus -

Chinese actors as competitors to Mozambican farmers and businesses 


\section{Using Action Research to Organize Technology Transfer in Complex Innovation Contexts Armando Machevo Ussivane and Paul Ellwood}

the local people being trained in the new rice-growing practices. However, there was a high likelihood of production losses during the training period, which represented a risk to private investors in the new technology.

This new understanding - a shift from a comparison of loss and subsequent compensation into an understanding of the challenge as one of de-risking losses for both investors and community - translated into social change. There was a change in attitude from stakeholders as evidenced by an agreement between RBL and a Chinese private investor to co-finance costs for training of local farmers. In addition, an assurance was given that large farming plots in developed areas were gradually allocated to local farmers after they were rigorously selected and had successfully completed training in a small size of plot.

\section{Tensions between public policy and private business}

Stakeholders diverged in their views regarding the ongoing policy agenda, which encourages optimization of land use through growing of rice twice a year. It had become costly researching adaptable new varieties of rice seeds to achieve this goal, within a programme that was experiencing operational difficulties and struggled to survive. Discussions in the participatory action research sessions revolved around whether the programme, rather than pursue agricultural research goals with a long-term reward horizon, should rather limit its focus to more short concerns of the farmers (e.g., improving the management of irrigation infrastructure). As a Chinese investor explained: “...the project cannot survive and help farmers if it does not make money... there is need to divide the risks between partners and to do profitable operations now...". By realizing the need for change in the research agenda, the Chinese investor and RBL were able to establish a research unit that helped to address the immediate and practical problems in the programme.

\section{Tensions between participants inside the programme and agricultural firms outside it}

Local farmers argued for the right to use alternative service providers (to the Chinese) and to purchase cheaper fertilizer in local markets. In this way, they were wanting to make use of their own local knowledge. And yet, the overarching (China-Mozambique) partnership agreement that helped to secure land, financing, and government support also implied obligations between farmers and Chinese technology providers. A local farmer in the meeting talked about the need to improve the selling of rice production: “...the project needs to change from the current scheme in which we sell all our rice to the Chinese." A second local farmer explained in the following terms, "Part of our technology can be used within the Chinese technology, ...the fertilizers we use in the programme should be the ones we are already used to. This would reduce our dependence." The tensions between national and local interests were also evident here, with the farmers wanting to break the rules of the business model to optimize their income. The path creative (and emergent) nature of the technology innovation were evident through this research as local farmers and Chinese modified and adapted some of their existing knowledge to suit the context of the programme.

\section{Tensions between partner in aid and private investor (collaborator or competitor)}

From the earliest days of Mozambique's independence from Portuguese colonial rule, China had been viewed as a strategic partner for economic development. The programme itself was a product of three decades of China-Mozambique collaboration, and yet the very complexity of the programme created role conflict. In one of the participatory action research sessions, a technician from the Chinese investment company explained that, following the construction of the irrigation system, they had allocated developed farms to four Chinese State farms that also were provided with the responsibility to provide farming services and technical assistance to local farmers. These Chinese teams owned and had full control of most of the machinery and equipment for rice farming. The investment company retained responsibility for buying the farmers' rice production and the control of the rice processing facilities. Reacting to this information, a manager from a local farm holding company said of the Chinese business model, "These Chinese teams are also farmers doing business... they could never transfer the technology successfully to the local farmers". The social actions and empowerment following these participatory action research discussions were realized as the Chinese investor, Chinese teams, and RBL were recommended by the participatory action research group to undertake segregation of their roles: the role of knowledge transfer was separated from that of service provider and farmers' buyer.

\section{Discussion}

Through this research, we sought to answer the question: how can the coordination of interdependent activities be achieved in technology transfer programmes consisting of multiple stakeholders? The discussion considers the way in which the participatory action research process contributed to and influenced the 


\section{Using Action Research to Organize Technology Transfer in Complex Innovation Contexts Armando Machevo Ussivane and Paul Ellwood}

performance in this technology transfer programme. We argue that adopting this methodology allowed participants not only to identify different categories of border and their associated tensions, but also to use this knowledge to initiate new organizational solutions. The mechanisms behind this research process are not concerned with dissolving boundaries between groups, but rather enabling ways of working across those boundaries. This research is therefore germane to the idea explored in this special issue concerning the benefits of action research for breaking down borders, broadening participation, and increase the relevance of innovation management research. We suggest that combining participatory action research with the boundary and translation focus represents a methodological contribution in inquiring into technology transfer/translation and in dealing with it to reach practical effects in diverse, changing, and complex organizational settings. Unlike conventional social science research, whose desire is to describe, understand, and explain the world (Coghlan, 2011), participatory action research changes the world. We suggest that methodologies without action inquiry at their core would not have worked since they do not change people's views, nor empower them. In this section, we discuss how participatory action research contributed to achieving research findings and enabled subsequent impacts by reflecting upon the following four themes: diversity of participants, need to deliver practical benefits and people empowerment, path creative nature of contemporary technology innovation, and complexity in the programme.

The wide diversity of stakeholders was made manifest through the participatory action research process through the different types of contribution that participants brought to the participatory action research sessions. The Chinese investors and farmers contributed their experience in technology diffusion and cross-cultural interaction in the programme; the agricultural service firm and financing service provider shared their expertise in organizing supply chains. Helping to surface and translate (Kellogg et al., 2006) the community perspectives was one role played by a few organizations, namely the local non-governmental organization for land rights, a local government broadcasting agency, Mozambique government agencies, and a local women development fund. Every stakeholder in the programme was autonomous, pursuing its own mission, while also committing towards a shared programme purpose. The participatory action research methodology brought an inquiry orientation to the participants. Despite the appearance of large differences in knowledge, financial capacity, and political resources, the participatory action research process still allowed participants to work together.

The practical benefits of participatory action research are manifest in the way in which participant discussions were being translated into social actions and people empowerment. Adopting a forum and set of reflection routines that gives voice to all participants' experience makes possible the creation of an agenda for social change and people empowerment. Participation in such an (action research) forum motivates participants to seek new explanations in light of current dissatisfactions. And, introducing different perspectives as an aid to inquiry (rather than a negotiation position) enables problem solving and leads to the formation of collective judgements. The participatory action research process helped participants to clarify the issues and challenges facing them, created awareness of the need for action, focused attention on specific areas of concern, identified resources and strategies for change, and helped to assess the impact of those strategies. By means of increasing participants' control over their own situations, an emancipatory outcome was realized: local communities (via farmers' contributions to the participatory action research forums) were not simply the recipients of aid but were able to contribute to the way in which the programme was enacted.

That social actions and empowerment were realized is illustrated in the way in which the conflict between land and intellectual property rights was resolved through the participatory action research process. The case for expecting returns on these different categories of property rights was judged reasonable once the owners of those rights had a forum to explain their dissatisfactions. This led to the challenge at hand being re-framed as a matter of de-risking both losses, rather than comparison of loss and subsequent compensation. This, in turn, enabled the identification and testing of de-risking actions. The end result saw the RBL and Chinese private investor reach agreement in two areas: i) co-financing costs for training of local farmers and ii) assuring that large farming plots in developed areas were gradually allocated to local farmers after they were rigorously selected and had successfully completed training in a small size of plot.

Following a participatory action research methodology is consistent with the path creative nature of contemporary technology innovation. Garud, Kumaraswamy, and Karnøe (2010) argue that the path creative nature of such innovation is founded upon a notion of agency 


\section{Using Action Research to Organize Technology Transfer in Complex Innovation Contexts Armando Machevo Ussivane and Paul Ellwood}

that is distributed and emergent through relational processes between diverse stakeholders. Contemporary technology innovation is characterized as working across boundaries (e.g., West \& Bogers, 2017), and it is subject not only to the absence of a common syntax and interpretive differences that result from stakeholders' different national cultures, but also to dependences between actors (Carlile, 2004). Actors' dependences in this programme were made evident through the discussions and experimentation within the participatory action research methodology as local farmers and Chinese actors modified and adapted some of their existing knowledge to the new context.

As the study's findings illustrate, action research succeeds when working across borders, because it surfaces differences and makes a resource of them, rather than hardening the differences into a barrier to be knocked down. Consistent with Bartel and Garud's (2009) theory of innovation narratives, this sharing and exploring of experiences shows that knowledge does not simply diffuse (cf. Rogers, 2003), but rather there is an active process of continuous translation wherein current knowledge (localized, embedded, and invested in practice) is transformed through application to a given context. This process was judged effective to the extent that the participatory action research sessions were continued within the technology transfer programme after the formal research study had finished.

The complexity of the whole programme evident throughout this discussion means that the adoption of a systemic methodology like participatory action research is preferred if the research objective is more than simply introducing a new technology. There was not only technology change in the programme but also: changes in user practices and institutional structures; the introduction of complementary technology; the design of new supply chains; and the construction of modern agricultural infrastructures. Challenges in such a system emerge as a result of multiple causes and effects that interact over time (Coghlan \& Brannick, 2010). The participatory action research methodology provided a perspective on understanding how the programme was held together by patterns of action and reaction, relationships between actors, different meanings they constructed and their hidden assumptions, and how all these changed over time. In realizing research impacts, then, participatory action research also considered interventions that enabled changes in these patterns, where required.

\section{Conclusion}

The starting premise for this article was that the increasing stakeholder diversity within contemporary technology transfer projects necessitated new approaches to both researching those projects, as well as realizing diverse practical impacts. We adopted a participatory action research methodology within an organizationally complex technology transfer project in order to explain and improve the coordination of the autonomous activities of the project's varied stakeholders. The action research surfaced four categories of organizational boundary within the project that were hindering performance. These boundaries between groups could be explained in terms of differences in the institutional logics and tacit knowledge that constitute the agendas of different stakeholders. That these agendas were highly invested in the practices of stakeholders explains the observed difficulties in coordinating dependent innovation activities. The process of co-inquiry with stakeholders that action research enabled allowed programme actors to reach an understanding of others, and it created a new thinking space for mutual problem solving. By these means, the action research process mobilized the differences between stakeholders as a resource for problem solving, rather than it being seen as a barrier to be compromised through negotiation.

Finally, the positioning (cf. Herr \& Anderson, 2005) of co-author AU as contributing both outside the project (as a scholar) and inside (as a practitioner) merits further research in other technology management contexts. In this study of exploring boundaries, then having a facilitator who themselves operated at the border between the scholarly (being an expert with the theoretical background to the study and methodology) and the practitioner (being knowledgeable about the technology domain) brought another beneficial source of diversity for realizing the research objectives. 


\section{Using Action Research to Organize Technology Transfer in Complex Innovation \\ Contexts Armando Machevo Ussivane and Paul Ellwood}

\section{About the Authors}

Armando Machevo Ussivane is the Chairman of RBL, E.P - a Mozambique Government agency in charge of the management of the Baixo Limpopo Irrigation Scheme. The objectives of this scheme are food security and poverty alleviation through improved agricultural productivity. His career includes 18 years of experience in the management of agriculture development projects. His research interests lie within the areas of inter-organizational collaboration including partnerships and technology transfer in cross-cultural agriculture contexts. Armando holds a Doctorate in Business Administration from the University of Liverpool, United Kingdom.

Paul Ellwood is a Senior Lecturer in Management at the University of Liverpool. His research interests are broadly in the area of science-led innovation and include technology transfer, responsible innovation, and the organization of university scientific research groups. His early career included leadership positions in a private science-based industry. Since moving to a university management school, he has become increasingly interested in issues relating to the engagement between academic research and management practice.

\section{References}

Bartel, C. A., \& Garud, R. 2009. The Role of Narratives in Sustaining Organizational Innovation. Organization Science, 20(1): 107-117. https://doi.org/10.1287/orsc.1080.0372

Bozeman, B., Rimes, H., \& Youtie, J. 2015. The Evolving State-of-theArt in Technology Transfer Research: Revisiting the Contingent Effectiveness Model. Research Policy, 44(1): 34-49. https://doi.org/10.1016/j.respol.2014.06.008

Brunswicker, S., \& van de Vrande, V. 2014. Exploring Open Innovation in Small and Medium-Sized Enterprises. In $\mathrm{H}$. Chesbrough, W. Vanhaverbeke, \& J. West (Eds.), New Frontiers in Open Innovation: 135-156. Oxford: Oxford University Press.

Carlile, P. R. 2004. Transferring, Translating, and Transforming: An Integrative Framework for Managing Knowledge Across Boundaries. Organization Science, 15(5): 555-568. https://doi.org/10.1287/orsc.1040.0094

Carlile, P. P. 2002. A Pragmatic View of Knowledge and Boundaries: Boundary Objects in New Product Development. Organization Science, 13(4): 442-455.

https://www.jstor.org/stable/3085976
Chesbrough, H., \& DiMinin, A. 2014. Open Social Innovation. In H. Chesbrough, W. Vanhaverbeke, \& J. West (Eds.), New Frontiers in Open Innovation: 169-188. Oxford: Oxford University Press.

Chuanhong, Z., Xiaoyun, L., Gubo, Q., \& Yanlei, W. 2015. Interpreting China-Africa Agricultural Encounters: Rhetoric and Reality in a Large Scale Rice Project in Mozambique. Future Agricultures, Working Paper, 126: 1-17.

Coghlan, D. 2011. Action Research: Exploring Perspectives on a Philosophy of Practical Knowing. The Academy of Management Annals, 5(1): 53-87.

https://doi.org/10.1080/19416520.2011.571520

Coghlan, D., \& Brannick, T. 2010. Doing Action Research in Your Own Organisation (3rd ed.) London: SAGE.

Dollar, D. 2016. China's Engagement with Africa - From Natural Resources to Human Resources. John L. Tornton China Center Working Paper. Washington, DC: Brookings Institution.

Garud, R., Kumaraswamy A., \& Karnøe, P. 2010. Path Dependence or Path Creation? Journal of Management Studies, 47(4): 760-774. https://doi.org/10.1111/j.1467-6486.2009.00914.x

Gioia, D. A., Corley, K. G., \& Hamilton, A. L. 2013. Seeking Qualitative Rigor in Inductive Research: Notes on the Gioia Methodology. Organizational Research Methods, 16(1): 15-31. https://doi.org/10.1177/1094428112452151

Herr, K., \& Anderson, G. L. 2005. The Action Research Dissertation: A Guide for Students and Faculty. Thousand Oaks, CA: SAGE Publications Inc.

Hofstede, G. 1993. Cultural Constraints on Management Theories. Executive, 7(1): 81-94. https://www.jstor.org/stable/4165110

Hofstede, G. 1980. Culture's Consequences: International Differences in Work-Related Values. Beverly Hills, CA: SAGE.

Kellogg, K. C., Orlikowski, W. J., \& Yates, J. 2006. Life in the Trading Zone: Structuring Coordination Across Boundaries in Postbureaucratic Organizations. Organization Science, 17(1): 22-44.

https://doi.org/10.1287/orsc.1050.0157

Li, J. H., Chang, X. R., Lin, L., \& Ma, L. Y. 2014. Meta-Analytic Comparison Influencing Factors of Knowledge Transfer in Different Cultural Contexts. Journal of Knowledge Management, 18(2): 278-306.

https://doi.org/10.1108/JKM-08-2013-0316

Lloyd, S., \& Hartel, C. 2010. Intercultural Competencies for Culturally Diverse Work Teams. Journal of Managerial Psychology, 25(8): 845-875.

https://doi.org/10.1108/02683941011089125

McTaggart, R. 1997. Guiding Principles for Participatory Action Research. In R. McTaggart (Ed.), Participatory Action Research: 25-43. Albany, NY: University of New York Press.

Oreszczyn, S., Lane, A., \& Carr, S. 2010. The Role of Networks of Practice and Webs of Influencers on Farmers' Engagement with and Learning about Agricultural Innovations. Journal of Rural Studies, 26(4): 404-417.

https://doi.org/10.1016/j.jrurstud.2010.03.003

Perkmann, M., \& Walsh, K. 2007. University-Industry Relationships and Open Innovation: Towards a Research Agenda. International Journal of Management Reviews, 9(4): 259-280. https://doi.org/10.1111/j.1468-2370.2007.00225.x 


\section{Using Action Research to Organize Technology Transfer in Complex Innovation \\ Contexts Armando Machevo Ussivane and Paul Ellwood}

Polanyi, M. 1966. The Tacit Dimension. New York: Anchor Day Books.

Powell, W. W. 1990. Neither Market nor Hierarchy: Network Forms of Organisation. Research in Organisational Behaviour, 12: 295-336.

Rivera, W. M., \& Sulaiman, V. R. 2009. Extension: Object of Reform, Engine for Innovation. Outlook on Agriculture, 38(3): 267-273. https://doi.org/10.5367/000000009789396810

Rogers, E. M. 2003. Diffusion of Innovation (5th ed). New York: Free Press.

Rogers, E. M. 1962. Diffusion of Innovations. New York: The Free Press of Glencoe.

Rogers, E. M., \& Shoemaker, F. F. 1971. Communication of Innovations: A Cross Cultural Approach. New York: Free Press.

Thomson, A. M., \& Perry, J. L. 2006. Collaboration Processes: Inside the Black Box. Public Administration Review, 66(1): 20-32. https://doi.org/10.1111/j.1540-6210.2006.00663.x

Torbert, W. R. and Associates 2004. Action Inquiry. San Francisco, CA: Berret-Koehler Publishers.

West, J., \& Bogers, M. 2017. Open Innovation: Current Status and Research Opportunities. Innovation: Organization \& Management, 19(1): 43-50. https://doi.org/10.1080/14479338.2016.1258995

Whyte, W. F. 1991. Conclusions. In W. F. Whyte (Ed.), Participatory Action Research: 237-241. Thousand Oaks, CA: SAGE Publications.
Citation: Ussivane, A. M., \& Ellwood, P. 2019. Using Action Research to Organize Technology Transfer in Complex Innovation Contexts. Technology Innovation Management Review, 9(4): 17-26.

http://doi.org/10.22215/timreview/ 1230

Keywords: action research, technology transfer, boundaries, international collaboration, agricultural innovation 


\title{
Bridging Participatory Policy Trends and Research Traditions through Social Innovation Malin Lindberg, Daniel Hallencreutz, and Anna Tengqvist
}

\author{
"The ability to perform innovation is dependent upon the way") \\ in which the relevant actors are organized. This becomes of \\ particular importance when emphasis is on experience- \\ based innovation, on the ability of the wider social context to \\ support innovation, and on the need to create innovation \\ that can meet the demand for social responsibility.
}

Bjørn Gustavsen (1938-2018)

In "Social Innovation and Action Research" (2012)

\begin{abstract}
This study explores whether social innovation may serve as a bridge between participatory policy trends and research traditions when striving for improved societal relevance and impact of research and innovation (R\&I). Despite their shared aim of relevance and impact through civic involvement, European R\&I policies and participatory action research approaches seldom refer to each other or harness each other's resources. The study advances the knowledge regarding how the participatory elements in the policies and research approaches relate through a participatory case study of a joint R\&I process to develop a model for social innovation support in Sweden. The case study helps distinguish potential synergies between various degrees of involvement advocated in the policies and research approaches, as well as between the reliance on trending policy concepts vs. scientific notions of validity. Social innovation is perceived as a potential bridge between these elements, as it draws upon participatory academic traditions, while simultaneously tapping into current policy trends of co-creation, in the development of new approaches and solutions to societal challenges.
\end{abstract}

\section{Introduction}

Improved societal relevance and societal impact are increasingly called for in European Union (EU) policies on research and innovation (R\&I) (European Union, 2014, 2016, 2017; Grimm et al., 2013). This is because R\&I is seen as a key to tackling societal challenges and fulfilling the global goals of sustainable development in the 2030 Agenda (European Union, 2017). The EU policies argue that the fulfillment of such societal expectations on R\&I requires cross-disciplinary, cross-sectorial, cross-institutional, and cross-border collaboration. Further, the EU policies contend that dialogue and active cooperation between science and society help achieve socially responsible R\&I policies and processes that are also more relevant to citizens (European Union, 2014). Consequently, the EU policies advocate for co-creative approaches where researchers and societal stakeholders jointly develop new knowledge and solutions in various formats (European Union, 2017; Science Europe, 2017). In parallel to these policy trends, participatory action research has a long tradition of elaborating and validating methods, criteria, and ethics for joint knowledge production, with the dual aim of scientific and societal relevance and progress (Aagaard Nielsen \& Svensson, 2006; Foote Whyte, 1991; Gunnarsson et al., 2015; Reason \& Bradbury, 2008). By involving societal stakeholders - especially those being underprivileged in matters related to their lives and futures - in the whole research process from initiation to implementation, participatory action research aspires equal participation, empowerment, and emancipation.

Despite their shared aspirations of improved societal relevance and impact through science-society collaboration, the EU policy trends and the participatory action research approaches seldom refer to each other or harness each other's resources, in terms of methods, 


\section{Bridging Participatory Policy Trends and Research Traditions through Social Innovation Malin Lindberg, Daniel Hallencreutz, and Anna Tengqvist}

strategies, legitimacy, etc. This raises questions of potential, underexploited synergies between the public legitimacy of the policy trends and the scientific legitimacy of the academic traditions that could improve their relevance and impact. The main aim of this study is thus to advance the knowledge regarding how the participatory elements in EU policies and participatory action research approaches relate in regard to how societal relevance and impact are achieved and ensured. A participatory case study helps distinguish this relation, focusing a joint process for developing a guiding model for social innovation support, involving Swedish innovation researchers, innovation promoters, and other innovation experts. As we will discuss in the article, the case's focus on social innovation reveals a potential bridge between policies and research by empowering stakeholders to foster new approaches and solutions to societal challenges (Anheier et al., 2019; Franz et al., 2012; Howaldt et al., 2018; Moulaert et al., 2013; Nicholls et al., 2015).

\section{Participatory Policy Trends and Academic Traditions}

In this section, the main participatory elements in the EU policy trends and the participatory action research approach are outlined, alongside an introduction to social innovation, as a springboard for the subsequent empirical analysis of how they relate in regard to societal relevance and impact.

\section{Co-creation in European policies}

Calls for improved societal relevance and societal impact in European R\&I policies recurrently refer to policy concepts such as open science, open innovation, science with and for society (SwafS), and responsible research and innovation (RRI) (European Union, 2014, 2016, 2017; Science Europe, 2017; The Knowledge Coalition, 2016). Open science aspires toward more "reliable, efficient, and responsive" science, by making the scientific processes more open, inclusive, and interdisciplinary, with open access to both data and publications as well as collaborative interaction with societal stakeholders (European Union, 2016). Open innovation aspires toward new social and technological solutions to societal and industrial challenges through user involvement and cross-industrial/sectoral collaboration (European Union, 2016). Science with and for society envisions responsible and societally relevant research and innovation through dialogue and active cooperation between science and society (European Union, 2014). In order to "better align both the process and its outcomes with the values, needs and expectations of
European society", responsible research and innovation advocates for the practical involvement of society, increased public access to scientific results, and considerations of ethical dimensions (European Union, 2014).

The policy concepts prescribe societal involvement in R\&I processes, turning society into "a living laboratory for innovative solutions to the many challenges we face in Europe - be they economic, environmental or social" (European Union, 2017). In EU policies, these solutions are frequently referred to in terms of social innovation, defined as new ways to tackle the major societal challenges and of meeting social needs that are not adequately met by the market or the public sector (European Union, 2010, 2014, 2017; The Knowledge Coalition, 2016). The societal involvement in the development of such solutions will allow "all societal actors (researchers, citizens, policy makers, business, third sector organisations etc.) to work together during the whole research and innovation process" (European Union, 2014). The civil society - individual citizens and nonprofit organizations - is singled out as especially important to involve, allowing citizens to be producers of new insights and solutions, to create a demand for innovative results, and to have a say in what research and innovations that should be prioritized (European Union, 2016).

Four approaches to citizen involvement are delineated in the policy discourse: co-operation, collaboration, coproduction, and co-design (Science Europe, 2017). Cooperation implies the lowest degree of involvement, where citizens passively give researchers access to data collection through their phones, computers, or other devices. Collaboration implies a more active contribution, where citizens assist in the collection of data demanded by researchers, for example through observations of flora, fauna, pollution, etc. Co-production allows citizen participation not only in the data collection but also in the analysis of the collected data. Co-design entails the most comprehensive involvement, allowing citizens to actively contribute to the agenda-setting, funding, design, implementation, and evaluation of R\&I projects, programs, and policies. Codesign thus involves citizens in all R\&I phases, from the selection of topics and challenges to address, to the planning and implementation of data collection and ideation, and further to the analysis, dissemination, and implementation of the results (European Union, 2016).

Various methods for citizen involvement are prescribed in relation to the mentioned policy concepts (European Union, 2014, 2016, 2017; Science Europe, 2017). A digital 


\section{Bridging Participatory Policy Trends and Research Traditions through Social Innovation Malin Lindberg, Daniel Hallencreutz, and Anna Tengqvist}

"RRI Toolkit” (rri-tools.eu) provides over 100 methods for public engagement, including frameworks, science communication, joint reflection, multi-stakeholder dialogues, co-creative workshops, university-society partnerships, etc. Interactive exhibitions, digital and physical knowledge-sharing platforms, science cafés, and future workshops are also promoted (European Union, 2014). Laboratories represent a recurring format where researchers and societal stakeholders jointly explore and address scientifically and societally relevant topics in temporary or permanent settings (European Union, 2017; The Knowledge Coalition, 2016). One example is "innovation laboratories of change", where new ideas and concepts are piloted by all kinds of societal stakeholders, but especially "new actors of innovation and change" (European Union, 2017). Other examples are citizen labs and citizen observatories, where citizens help capture, evaluate, and communicate data in physical settings (European Union, 2016). Living labs, science shops, and open innovation platforms are other promoted formats where citizens, companies, public authorities, students, and researchers jointly generate new insights and innovations (European Union, 2014, 2016; The Knowledge Coalition, 2016). In relation to social innovation, living labs are perceived to both "contribute to social innovation and themselves represent a form of social innovation" (The Knowledge Coalition, 2016).

\section{Participatory action research}

Participatory action research aspires to the joint development of new insights and solutions by researchers and societal stakeholders, where academic and societal perspectives, relevance, and progress are aligned (Aagaard Nielsen \& Svensson, 2006; Foote Whyte, 1991; Gunnarsson et al., 2015; Reason \& Bradbury, 2008). Participatory action research provides participatory methodologies and arenas for "high-grade collaboration" with joint planning and execution of the whole research process - from problem formulation to research design, data collection, data analysis, result dissemination, and result implementation (Aagaard Nielsen \& Svensson, 2006; Foote Whyte, 1991). It sets out to challenge the traditional expert-novice and observer-observed relationships between researchers and societal stakeholders by acknowledging the expertise and competences of both groups and enhancing equal participation in the development process (Aagaard Nielsen \& Svensson, 2006; Gunnarsson et al., 2015; Reason \& Bradbury, 2008). Empowerment and emancipation are thus crucial aspirations in participatory action research, especially in relation to underprivileged stakeholders in matters related to their lives and futures (Foote Whyte, 1991).
The wider area of action research, of which participatory action research is a part, has been described as "an orientation to (scientific) inquiry that seeks to create participative communities of inquiry in which qualities of engagement, curiosity and question are brought to bear on significant practical issues" (Reason \& Bradbury, 2008). Its democratic agenda sets out "not only to achieve specific social improvements and reforms, but a more profound need to transform political culture, generally in society and specifically within science and research institutions and practices" (Gunnarsson et al., 2015). Action research is generally traced back to the American social psychologist Kurt Lewin, who in the late 1930s and onwards involved minority groups in social science knowledge production to counter exploitation and colonialism (Adelman, 1993). It has thereafter been further developed in various streams throughout the world - for example through participatory action research, pragmatic action research, emancipatory action research, community action research, etc. - with recurrent references to additional scholars such as John Dewey, Paulo Freire, and William Foote Whyte (Aagaard Nielsen \& Svensson, 2006; Gunnarsson et al., 2015; Reason \& Bradbury, 2008).

In order to specify the relationship between action research and participatory action research, a distinction can be made between doing research "on", "for", and "with" societal stakeholders (Aagaard Nielsen \& Svensson, 2006; Gunnarsson et al., 2015). Research “on” implies a clear distinction between scientific and practical knowledge production, where the researcher acts as an expert observer, mainly aspiring for scientifically useful results. Action research - and subsequently participatory action research - were developed as a reaction to this approach, introducing research "for" and "with" that challenge the scientific-practical distinction, expert-novice relation and scope of beneficiaries. Research "for" - encompassed by action research implies a blurred distinction between scientific and practical knowledge production, where the researcher still acts as an expert observer, but with a pronounced agenda to contribute to practical benefit for a particular group of people. Research "with" - encompassed by both action research and participatory action research - interweaves scientific and practical knowledge production by actively involving both researchers and stakeholders in the generation of scientifically and practically useful results.

Sharing an agenda of empowerment and emancipation among underprivileged stakeholders through joint development of new approaches and solutions to societal 


\section{Bridging Participatory Policy Trends and Research Traditions through Social Innovation Malin Lindberg, Daniel Hallencreutz, and Anna Tengqvist}

challenges, social innovation is considered relevant for action research and participatory action research by an increasing number of scholars (e.g., Andersen \& Bilfeldt, 2017; Estensoro, 2015; Gustavsen, 2012; Mazigo, 2017; Yang \& Sung, 2016). Methods for practicing participatory action research include, for example, empowering dialogues, dialogue seminars/conferences, future creating workshops, and research circles (Aagaard Nielsen \& Svensson, 2006; Gunnarsson et al., 2015; Reason \& Bradbury, 2008). Participatory action research implies elaborated reflections on proper criteria for esteeming and ensuring the validity - the trustworthiness - of both process and results. It underlines the need for socially contextualized knowledge, where the intersection of academic and societal knowledge is meant to ensure a multifaceted scrutiny of methods and conclusions (Gibbons et al., 1994; Nowotny et al., 2001). This is expected to contribute to processual validity, with constantly evolving insights through the joint planning and execution in all phases (Aagaard Nielsen \& Svensson, 2006). Pragmatic validity is also anticipated, as the socially contextualized knowledge development is meant to ensure that the process and results are relevant and useful in the particular context. These two validity criteria - pragmatic and processual validity - are in participatory action research aligned by the notion of democratic validity, which refers to engagement, empowerment, and emancipation of underprivileged stakeholders (Aagaard Nielsen \& Svensson, 2006; Gunnarsson et al., 2015). These criteria and effects are not automatically fulfilled in participatory action research processes, however, since social structures and interactions are inherently complex.

\section{Social innovation}

Social innovation, in terms of new social solutions to societal challenges and other needs for social progress, has received increasing attention from researchers, policymakers, innovation promoters, and innovators during the last decade due to its perceived potential to empower stakeholders to foster new approaches and solutions to societal challenges (Anheier et al., 2019; Franz et al., 2012; Howaldt et al., 2018; Moulaert et al., 2013; Nicholls et al., 2015). Social innovations may take the form of new services, activities, methods, establishments, alliances, etc. intended to improve welfare, wellbeing, and quality of life, especially among groups who are disadvantaged or underrepresented in specific societal areas. In order to transform complex societal structures, social innovations need to create synergies between established institutions, regulations, and norms, on the one hand, and people's individual and collective capacity to change these structures, on the other. The desired transformation requires active involvement of those groups that are to benefit from the developed solutions, making both individual and collective empowerment a crucial component of social innovation.

Social innovation further requires multi-actor and multi-level mobilization, where public, private, and civil society actors interact on various organizational and geographical levels in order to match the complexity of the addressed societal challenges (Anheier et al., 2019; Franz et al., 2012; Howaldt et al., 2018; Moulaert et al., 2013; Nicholls et al., 2015). A mapping of 1000 social innovations across the globe reveals that public authorities and civil society organizations are most frequently involved, whereas private companies are somewhat less frequently involved (Howaldt et al., 2018). Researchers and other university officials are least frequently involved, since users and beneficiaries tend to replace them as knowledge providers in social innovation. Almost half of the mapped cases in that global study directly involve users or beneficiaries, in line with the empowerment ambitions of social innovation.

\section{Research Design}

A participatory case study of an R\&I project in Sweden helps distinguish the relationship and potential synergies between EU R\&I policies and participatory action research approaches. A single case study design has an esteemed potential to enhance multifaceted insights by combining various types of data, which has previously been proven fruitful when exploring new complex topics with multiple dimensions (Wiebe et al., 2010; Yin, 2009). Relevance is the most crucial criterion for case selection, rather than a random selection, which is why the study is based on a case that is esteemed as most likely to provide valuable insights into the relationship between participatory elements in EU policies and participatory action research approaches. The studied case is constituted by a process of joint development of a guiding model for social innovation support, involving Swedish innovation researchers, innovation promoters, and other innovation experts. The process was carried out as part of an R\&I project that took place from 2016 to 2017 and was funded by Sweden's national innovation agency VINNOVA.

The process aspired to meet the unmet need of validated, practical tools for improving the support to innovations with high societal relevance and impact among Swedish innovation promoters, such as innovation offices, science parks, and incubators. This need had been 


\section{Bridging Participatory Policy Trends and Research Traditions through Social Innovation Malin Lindberg, Daniel Hallencreutz, and Anna Tengqvist}

evoked by articulated demands from financiers, managers, and clients to broaden the innovation promoters' traditional focus on technological and industrial innovations to innovative solutions to current societal challenges and the United Nation's global sustainability goals (Lindberg, 2014, 2018). In order to enhance both societally relevant and scientifically valid results, a participatory action research approach was used in the process, where researchers and stakeholders were aspired to jointly develop new knowledge and solutions (cf. Aagaard Nielsen \& Svensson, 2006; Foote Whyte, 1991; Gunnarsson et al., 2015; Reason \& Bradbury, 2008). The process was coordinated by an innovation researcher from Luleå University of Technology and innovation experts from the consultancy agency Kontigo, who also jointly authored this article.

The involved stakeholders were representatives from Sweden's major innovation promoters, including the Swedish Network for Innovation and Technology Transfer Support (SNITTS), Swedish Incubators and Science Parks (SISP), Sweden's national hub for social innovation (Mötesplats Social Innovation), Sweden's national promoter of social businesses (Coompanion), and the Swedish Association of Local Authorities and Regions (Sveriges Kommuner och Landsting). Some of these (e.g., Coompanion and Mötesplats Social Innovation) were more experienced in supporting social innovation than others (e.g., SISP and SNITTS), which was seen as an opportunity for peer-to-peer learning. Additional researchers with expertise in innovation were also involved from Chalmers University of Technology and Halmstad University, as well as design experts from Geektown Kommunikationsbyrå, who designed the model. The stakeholder involvement was intended to ensure socially robust knowledge, where both the process and results are validated through continuous dialogue between those who possess various experiences and expertise in the studied area (cf. Nowotny et al., 2001). This implied simultaneous and intertwined development of the model and the study of its development, as common in participatory action research (cf. Aagaard Nielsen \& Svensson, 2006; Gunnarsson et al., 2015; Reason \& Bradbury, 2008).

The process took place during more than a full year, with chronological steps of joint planning of the process, mapping of pre-existing studies and models, outline of practically and scientifically validated model components, incremental design of a graphic model with these components, and dissemination of the model to innovation promoters in Sweden and internationally. The forms of engagement in these steps encompassed participatory dialogues at individual and collective meetings, workshops, and digital correspondence. The process was initiated through a series of initial meetings between the coordinating researcher and experts, and each of the involved innovation promoters and additional researchers, in order to plan the process and map their experiences of and approaches to social innovation support. Potential model components were thereafter delineated and validated through a series of meetings and workshops with all stakeholders. Based on this input, the model was incrementally designed and refined through a series of meetings and digital correspondence with all stakeholders. The finalized model was thereafter jointly disseminated through workshops and digital platforms.

Throughout this process, data was collected for this article by the coordinating researcher and experts in order to further intertwine scientific and societal progress. The process was documented through field notes, photographs, and PowerPoint presentations from meetings and workshops, as well as emails and model outlines from the digital correspondence. The collected data was analyzed in the light of previous studies on basic characteristics and logics of social innovation processes and support. A thematic analysis approach was used to distinguish the most pivotal components and mechanisms of such a model and how these were ranked and refined based on the participants' expertise and experiences (cf. Guest et al., 2012). In the analysis process, it was distinguished that the case's focus on social innovation introduces a potential bridge between policies and research, which will be further elaborated in the subsequent sections.

\section{Results}

As outlined above, participatory approaches to research and innovation are advocated both in EU policies and the participatory action research tradition. In these approaches, researchers and societal stakeholders jointly develop new knowledge and solutions for improved societal impact and relevance. A participatory approach was also prominent in this case study, which illustrates how innovation researchers, innovation promoters, and other innovation experts jointly developed a model for social innovation support (Figure 1).

Similar to the EU policies, the studied process was motivated by current societal challenges and the global sustainability goals in the 2030 Agenda, urging innovation promoters to widen their focus from technological and commercial innovations to social innovation, where 


\section{Bridging Participatory Policy Trends and Research Traditions through Social \\ Innovation Malin Lindberg, Daniel Hallencreutz, and Anna Tengqvist}

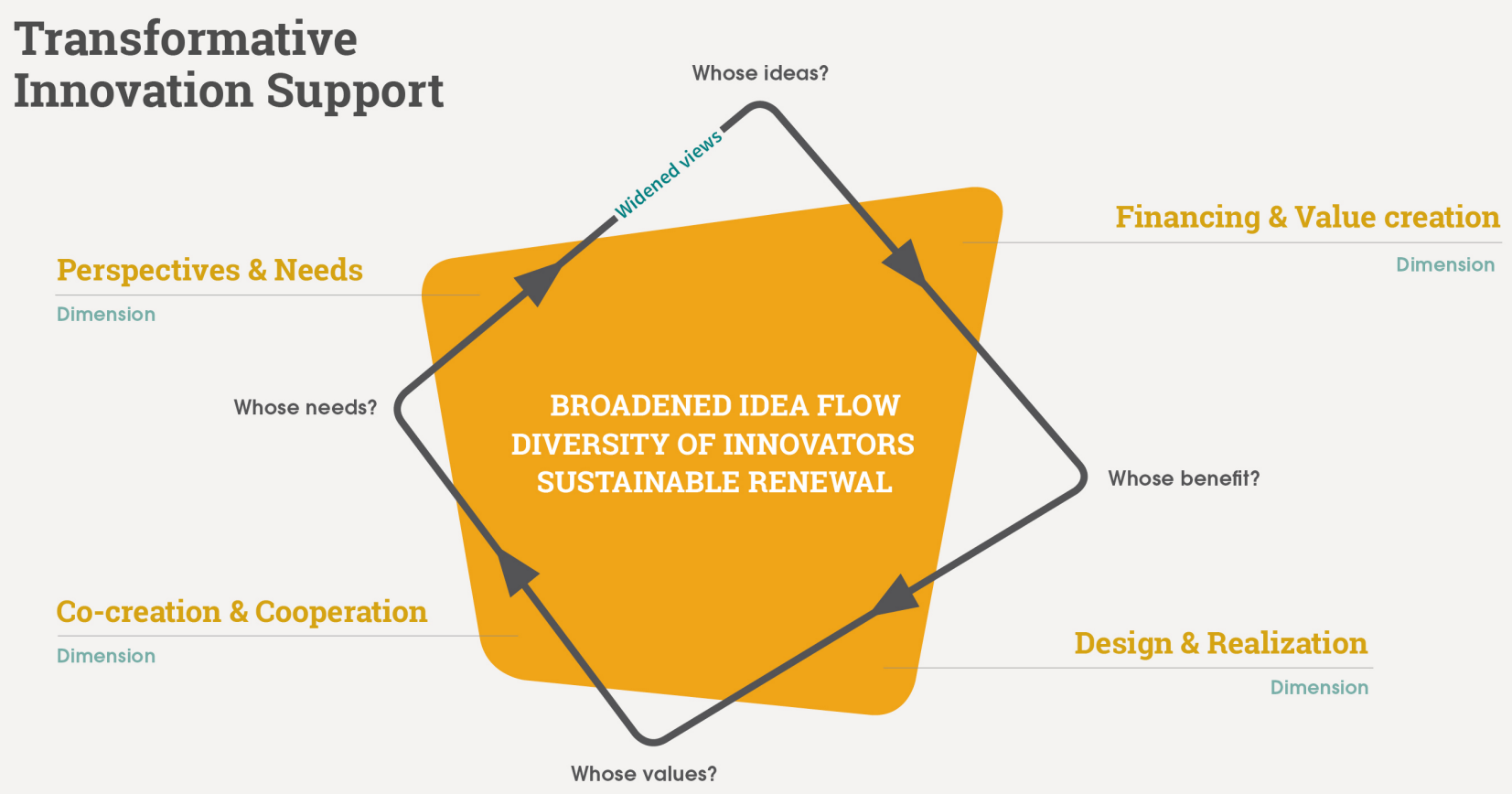

Figure 1. Model for social innovation support (see transformativeinnovation.se)

social improvement and social inclusion are essential. The case also reflects the fact that social innovation is increasingly referred to in participatory action research studies, as a way to open up R\&I to societal stakeholders and concerns. As some of the involved innovation promoters were more experienced in social innovation support than others, their initial insights varied with respect to what kinds of issues that the process would address.

\section{Degrees of involvement}

In the EU policies, various degrees of citizen involvement are conceptualized in terms of cooperation, collaboration, co-production, and co-design, corresponding to the degrees of research "on", "for", and "with" according to the academic participatory action research tradition. In each tradition, co-design and research "with" refer to the most comprehensive involvement, aiming for active contribution of citizens to all phases of the R\&I process from planning to implementation. This is reflected in the studied model development for social innovation support, involving stakeholders in joint planning, mapping, component outline, model design, and results dissemination. As the involvement in each step was designed and managed by the coordinating re- searcher and experts, their relationships to the stakeholders were, however, not fully equal. It was also difficult for the stakeholders to find the time for continuous engagement, in the midst of their primary work obligations.

Each step nevertheless implied a continuous dialogue between the researchers and stakeholders at meetings and workshops and during digital correspondence. In order to enhance stakeholder participation despite busy calendars, these engagement formats were more flexible and less formalized than those promoted in the EU policies and participatory action research approaches. They were rather organized in line with the most fundamental ambition of the participatory action research approach: to provide methodologies and arenas for high-grade collaboration. In regard to the EU policies, the process may nevertheless be understood as a type of living lab or open innovation platform, where stakeholders and researchers jointly generate new insights and innovations. This conclusion is further substantiated by the perception of living labs as both a generator and example of social innovation, as also focused in the studied case. 


\section{Bridging Participatory Policy Trends and Research Traditions through Social Innovation Malin Lindberg, Daniel Hallencreutz, and Anna Tengqvist}

\section{Reliance on policy concepts $v$ scientific notions}

The reliance on various policy concepts - such as open science, open innovation, responsible research and innovation, and science with and for society - in the EU policies is matched by a reliance on scientific notions of socially contextualized knowledge and democratic validity in participatory action research. These policy concepts and scientific notions share the ambition to open up R\&I processes to societal concerns and stakeholders. This is also reflected in the studied case, in its ambition to develop a model for supporting the realization of new solutions to societal challenges and other needs of social progress. The model was consequently named "Transformative Innovation Support" and highlighted three main incentives for supporting social innovation: Broadened inflow of ideas, Increased diversity of innovators, and Improved societal impact. It further delineated four specific dimensions to support: Perspectives and Needs, Co-creation and Collaboration, Design and Realization, Financing and Value Creation. It thereby encompassed a cross-cutting dimension of widened views, highlighting norm-critical queries regarding whose needs and perspectives are allowed to guide the development of innovations.

The model's transformative incentives and dimensions reflect the empowering agenda of social innovation, participatory action research, and EU policies, engaging in inquiries regarding how social and political conditions may be changed through cross-organizational and cross-sectoral interactions. This relates to the criterium of democratic validity applied in participatory action research, where the trustworthiness of the process and results is esteemed by its engagement and empowerment of underprivileged stakeholders, with constantly evolving, joint insights that are relevant and useful in the particular context. By acknowledging the expertise and competences not only among the involved innovation researchers and experts, but also among the innovation promoters - and indirectly among their target groups of social innovators and, in turn, their target groups of underprivileged people - the traditional expert-novice and observer-observed relationships between researchers and stakeholders were challenged. The coordinating role of the researcher and experts did, however, grant them major influence over the process management and model design.

The policy concepts promoted in the EU policies share this democratic agenda to open up R\&I processes to societal concerns and stakeholders, but generally lack discussions on proper validity criteria for achieving and esteeming this in the participatory processes and res- ults. They rather rely on more abstract notions of reliable, inclusive, and ethical R\&I related to societal values, needs, and expectations. The academic participatory action research tradition may help substantiate and validate these notions through socially contextualized knowledge, ensuring a multifaceted, localized scrutiny of the process and results through intertwining academic and societal knowledge. In the studied model development, scientific and societal relevance and trustworthiness was correspondingly applied as a consistent criterion when selecting and formulating model components. This implied constant deliberations among the innovation promoters, researchers, and experts, regarding the relevance and validity of various components, where the coordinating researcher and experts nevertheless held the ultimate decision-making power. The innovation promoters who were less experienced in supporting social innovation expressed concerns over being too ambitious in regard to their established services, tailored to technological and industrial innovations. While the more experienced innovation promoters, as well as the innovation researchers and experts, advocated for a design with maximized transformative potential.

\section{Discussion and Conclusions}

In order to advance the knowledge regarding how the participatory elements in EU policies and participatory action research approaches relate in regard to how societal relevance and impact are achieved and ensured, the study has scrutinized evidence from policy documents, academic studies, and a case study of a Swedish participatory process of model development for social innovation support.

The results expose potential synergies between the various degrees of involvement highlighted in the EU policy approach to co-creation - cooperation, collaboration, co-production, and co-design - and the participatory action research tradition - research "on", "for", and "with". The degrees of co-design and research aspire to the most comprehensive involvement in each tradition, where citizens are expected to actively contribute to all phases of the R\&I process and jointly develop new knowledge and solutions with researchers. This is also reflected in the studied model development, where stakeholders were actively involved in each step of planning, mapping, component outline, model design, and results dissemination, even if full equality was limited by the coordinating researcher's unilateral control over the process design and management. Less formalized co-creation methods were used 


\section{Bridging Participatory Policy Trends and Research Traditions through Social Innovation Malin Lindberg, Daniel Hallencreutz, and Anna Tengquist}

in the studied case than those promoted in the EU policies and the participatory action research tradition, rather organized in line with the most fundamental function of participatory action research - to provide methodologies and arenas for high-grade collaboration - as well as the living lab format highlighted in the EU policies, where various stakeholders jointly generate new insights and innovations.

The results further expose potential synergies between the reliance on policy concepts such as open science, open innovation, responsible research and innovation, and science with and for society in EU policies and the reliance on scientific notions of socially contextualized knowledge and democratic validity in participatory action research. The policy concepts and scientific notions address the same democratic agenda of opening up R\&I processes to societal concerns and stakeholders, but the former generally lacks the latter's reflection on proper validity criteria for achieving this in the participatory processes and results. The focus on democratic validity and socially contextualized knowledge in participatory action research aspires a multifaceted, localized scrutiny of the process and results through intertwining academic and societal knowledge. This is reflected in the studied case's transformative incentives and dimensions, engaging researchers and societal stakeholders in continuous reflections on how excluding social and political conditions in innovation support may be changed.

The identified, untapped potential for improved synergies between the participatory elements in EU policies and participatory action research approaches seems to be bridged by the notion of social innovation. Generally understood as new ways to meet societal challenges and other needs of social progress - especially among disadvantaged and marginalized groups - social innovation is highlighted in the studied case, in EU policies, and in participatory action research studies. There, it serves to motivate and guide broad societal involvement, across societal sectors and groups - especially the civil society through the entire R\&I process from problem formulation to implemented solutions. It further helps establish and manage practical participatory formats, such as living labs, both as social innovations in themselves and as arenas for producing social innovations. The main bridging function of social innovation seems, however, to lie in its transformative mechanisms, which aspire to empower researchers and societal stakeholders to jointly challenge and change organizational and societal structures. This bridging function is most explicitly stated in the very name of the developed model for social innovation support: Transformative Innovation Support. 


\section{Bridging Participatory Policy Trends and Research Traditions through Social \\ Innovation Malin Lindberg, Daniel Hallencreutz, and Anna Tengquist}

\section{About the Authors}

Malin Lindberg is a Professor at Luleå University of Technology, Sweden, where he specializes in participatory action research, in which knowledge is developed jointly by researchers and societal stakeholders. Her main topic of interest is inclusive forms of innovation and organization, with specific focus on social innovation, participatory innovation, and sustainable development. She has published several studies on policies, support, and management of inclusive innovation and organization in international anthologies and journals, for example, the International Journal of Innovation Management, the International Journal of Innovation and Regional Development, the International Journal of Social Entrepreneurship and Innovation, and the European Public \& Social Innovation Review.

Daniel Hallencreutz is a Senior Consultant for WSP in Sweden. He specializes in participatory processes of regional development with a scholarly base in human geography. His main topic of interest is mechanisms of growth and societal change in clusters and innovation systems in various industrial and geographical contexts. His $\mathrm{PhD}$ thesis scrutinized growth patterns in Swedish clusters of design-intensive and cultural-products industries, such as multimedia, fashion, and music. He has managed several participatory evaluation processes of regional and national clusters and innovation systems, for example, in the European Regional Development Fund.

Anna Tengqvist is a Senior Consultant for WSP in Sweden. She specializes in participatory processes of social sustainability, equality management, and gender mainstreaming. One of her main topics of interest is social innovation development and support, and in this area she has managed several co-creative evaluations of multi-actor platforms and projects on regional level. She has also managed several participatory model development processes for gender equality, equal opportunities, intersectionality, and accessibility in the private, public, and nonprofit sectors. This work includes the development of a European standard for gender mainstreaming in the European Social Fund.

\section{References}

Aagaard Nielsen, K., \& Svensson, L. (Eds.) 2006. Action Research and Participatory Research. Maastricht, Netherlands: Shaker Publishing.

Adelman, C. 1993. Kurt Lewin and the Origins of Action Research. Educational Action Research, 1(1): 7-24. https://doi.org/10.1080/0965079930010102

Andersen, J., \& Bilfeldt, A. 2017. Transforming welfare Institutions through Social Innovation and Action Research in Denmark. International Journal of Action Research, 13(3): 201-220. https://doi.org/10.3224/ijar.v13i3.02

Anheier, H., Krlev, G., \& Mildenberger, G. (Eds.) 2019. Social Innovation - Comparative Perspectives. New York: Routledge.

Estensoro, M. 2015. How Can Social Innovation be Facilitated? Experiences from an Action Research Process in a Local Network. Systemic Practice \& Action Research, 28(6): 527-545. https://doi.org/10.1007/s11213-015-9347-2

European Union. 2017. $L A B-F A B-A P P$ - Investing in the European Future We Want. Report of the Independent High Level Group on Maximising the Impact of EU Research \& Innovation Programmes. Brussels: European Commission.

European Union. 2016. Open Innovation, Open Science, Open to the World -A Vision for Europe. Brussels: European Commission.

European Union. 2014. Science with and for Society. HORIZON 2020 Work Programme 2014-2015. Brussels: European Commission.

European Union. 2010. Europe 2020 Flagship Initiative Innovation Union. Brussels: European Commission.

Foote Whyte, W. (Ed.) 1991. Participatory Action Research. Newbury Park, CA: SAGE. https://dx.doi.org/10.4135/9781412985383

Franz, H., Hochgerner, J., \& Howaldt, J. (Eds.) 2012. Challenge Social Innovation - Potentials for Business, Social Entrepreneurship, Welfare and Civil Society. Berlin/Heidelberg: Springer.

Gibbons, M., Limoges, C., Nowotny, H., Schwartzman, S., Scott, P., \& Trow, M. 1994. The New Production of Knowledge: The Dynamics of Science and Research in Contemporary Societies. London: SAGE.

Grimm, R., Fox, C., Baines, S., \& Albertson, K. 2013. Social Innovation, an Answer to Contemporary Societal Challenges? Locating the Concept in Theory and Practice. Innovation: The European Journal of Social Sciences, 26(4): 436-455. https://doi.org/10.1080/13511610.2013.848163

Gunnarsson, E., Hansen, H. P., Steen Nielsen, B., \& Sriskandarajah, N. (Eds.) 2015. Action Research for Democracy - New Ideas and Perspectives from Scandinavia. New York: Routledge.

Gustavsen, B. 2012. Social Innovation and Action Research. In H. Franz, J. Hochgerner, \& J. Howaldt (Eds.), Challenge Social Innovation - Potentials for Business, Social Entrepreneurship, Welfare and Civil Society: 353-366. Berlin/Heidelberg: Springer.

Howaldt, J., Kaletka, C., Schröder, A., \& Zirngiebl, M. 2018. Atlas of Social Innovation - New Practices for a Better Future. Dortmund: Sozialforschungsstelle, TU Dortmund University. 


\section{Bridging Participatory Policy Trends and Research Traditions through Social Innovation Malin Lindberg, Daniel Hallencreutz, and Anna Tengqvist}

Lindberg, M. 2014. From Exclusion to Inclusion in Public Innovation Support? Innovative Practices in Bottom-Up Networks. Scandinavian Journal of Public Administration, 18(4): 91-107.

Lindberg, M. 2018. Relating Inclusiveness and Innovativeness in Inclusive Innovation. International Journal of Innovation and Regional Development, 8(2): 103-119.

Mazigo, A. F. 2017. Promoting Social Innovation through Action Research: Evidence from an Empirical Study in the Fisheries Sector of Ukerewe District in Tanzania. Journal of Human Development and Capabilities, 18(2):239-257. https://doi.org/10.1080/19452829.2016.1256276

Moulaert, F., MacCallum, D., Mehmood, A., \& Hamdouch, A. (Eds.) 2013. The International Handbook on Social Innovation: Collective Action, Social Learning and Transdisciplinary Research. Cheltenham, UK: Edward Elgar.

Nicholls, A., Simon, J., \& Gabriel, M. (Eds.) 2015. New Frontiers in Social Innovation Research. New York: Palgrave Macmillan.

Nowotny, H., Scott, P., \& Gibbons, M. 2001. Re-Thinking Science Knowledge and the Public in an Age of Uncertainty. Cambridge: Polity Press.

Reason, P., \& Bradbury, H. (Eds.) 2008. The Sage Handbook of Action Research. Participatory Inquiry and Practice. London: SAGE Publications.

Science Europe. 2017. The Rationales of Open Science: Digitalisation and Democratisation in Research. Science Europe High-Level Workshop, September 14, 2017, Berlin.

The Knowledge Coalition. 2016. Portfolio for Research and Innovation: Cooperation, Creativity, Game Changers. Amsterdam: The Knowledge Coalition.

Yang, C-F., \& Sung, T-J. 2016. Service Design for Social Innovation through Participatory Action Research. International Journal of Design, 10(1): 21-36.
Citation: Lindberg, M., Hallencreutz, D., \& Tengqvist, A. 2019. Bridging Participatory Policy Trends and Research Traditions through Social Innovation. Technology Innovation Management Review, 9(4): 27-36. http://doi.org/10.22215/timreview/1231

Keywords: action research, co-creation, innovation, participatory research, social innovation 


\title{
Increasing the Impact of Industry-Academia Collaboration through Co-Production
}

\author{
Anna Sannö, Anna Ericson Öberg, Erik Flores-Garcia, and Mats Jackson
}

\author{
(6rom an academic perspective, it can be more interesting" \\ when things are not working than when they are. In \\ industry, we don't find that interesting, only frustrating. \\ Industrial manager in this study, \\ reflecting on university collaboration
}

\begin{abstract}
Increased competition and globalization motivate us to join forces to enhance the impact of the research conducted. Collaboration between organizations with different views can, however, be difficult to manage and needs awareness and skills to meet different expectations. This article will consider both a mutual industrial and academic perspective into the development of action research and, in six research project cases, empirically explore how the impact can be enhanced by considering certain key factors in the research process. How the phases of problem formulation, methodology, and results are managed is critical for the success of a collaboration and, thereby, its impact. Counter-productive forces that could dilute the progress over time need to be considered given that combining practical relevance and scientific rigour comes with challenges.
\end{abstract}

\section{Introduction}

Conducting research that is both practically relevant and scientifically rigorous, while also making a great societal impact, is a continuous challenge for scholars and universities (Bartunek \& Rynes, 2014; Coughlan et al., 2016; Ellström, 2008; Starkey \& Madan, 2001). In today's society, we live in a time with a high pace of changes leading to a constant need for new competences and skills. The mobility of scientific competences from universities to industrial firms enables firms to absorb and utilize the knowledge developed in academia (Kunttu et al., 2018). Increased competition and globalization in engineering communities are motivating industrial and academic institutions to improve their collaborations (Sandberg et al., 2011).

Embedded in the discussion of making societal impact is the character of knowledge, and this leads to realizing a new process for producing knowledge for change (Pettigrew, 2011). Several more practice-oriented methods have been developed over the years, such as action research (Coughlan \& Coghlan, 2002), collaboration research (Adler et al., 2004), collaborative management research (Coghlan et al., 2012), interactive research (Ellström, 2008; Svensson et al., 2007), cooperative inquiry
(Reason, 2006), and engaged research (Van de Ven, 2007). Nevertheless, collaboration is far from easy to manage, and scholars continue to address the question of how to involve practitioners. For example, boundaryspanning activities, such as appointing doctoral students, have been proposed (Kunttu et al., 2018). Further topics have been identified, such as exploring factors hindering collaboration (Kaymaz \& Eryiğit, 2011), reviewing success factors powering collaboration (Wohlin et al., 2012), and identifying where challenges may be found in the literature (Garousi et al., 2016). In such studies, however, it is typically the scholar's viewpoint that is considered (Kaymaz \& Eryiğit, 2011).

This article will, however, consider both a mutual industrial and academic perspective, and empirically explore how the impact can be enhanced by considering certain key factors in the research process. The context of the research conducted and presented in this article is in Sweden, where universities and international industrial companies are encouraged to conduct research together. The article highlights some of the major challenges when co-producing knowledge. Six research project cases will be presented and analyzed based on how different key factors are linked to the perceived impact of the projects. 


\title{
Increasing the Impact of Industry-Academia Collaboration through Co-Production
}

\author{
Anna Sannö, Anna Ericson Öberg, Erik Flores-Garcia, and Mats Jackson
}

The article is outlined as follows: after the introduction, the theoretical framework related to co-production and impact is presented, followed by a section on the research approach. Thereafter, the identified key factors and cases are presented. Further, the implications are discussed, concluding with how different elements and categories of impact relate to the management of the identified key factors.

\section{Background}

\section{Research positioning}

Before proceeding, we should clarify the epistemological assumptions that underlie our recommendations. This underlying assumption influences how we perceive the quality of research. We adopt the perspective that the purpose of management research is to generate knowledge that is valid as well as relevant from a practical standpoint inspired by Aguinis and Edwards (2014). The questions pursued by management research should draw from relevant theory and be anchored in issues relevant to the practice of management. Management research is here viewed as a scientific discipline that concerns methodological issues neighbouring on the social sciences, rooted in the complexity of change phenomena. It is not expected that management research will match the rigour and precision of research in the basic sciences. In applied science, the progress in management research depends rather on applying the best methods and is a continuous improvement of the methodological tools. In the theoretical framework, we will present how we have interpreted the important term of impact, starting with collaborative research.

\section{Collaborative research}

Collaboration with industry is critical for academia to create scientific knowledge and obtain industrial data. In turn, collaboration with universities is crucial for organizations in joint, scientific-based research projects in order to develop solutions for production-sourced problems (Kaymaz \& Eryiğit, 2011). When entering this kind of research project, the expectations of the contribution, not only to an academic audience but also to the organization where the problem exists, makes participatory research a suitable approach. The Knowledge Foundation in Sweden uses co-production as their way to adapt knowledge production to a more participatory way to conduct research. Co-production can be seen to exist when a research problem is framed in the context of the application and allows diffusion during knowledge production.
Coghlan and Coughlan (2008) identified three particular insights into collaborative research from their experience of designing, conducting, and publishing their collaborative research. In short, these are: 1) linking theory, practice, and collaboration; 2) capturing differences while sustaining collaboration; and 3) managing quality. This points towards more complex management when conducting the research, which is further discussed below. With the complexity arising from combining two differently organized systems, it is clear that multiple versions of collaboration exist, and these are dependent on too many factors to point towards one overall methodology. However, we have found Figure 1 to be a useful guide for us when discussing co-production.

The co-production process illustrated in Figure 1 has been developed from the Knowledge Foundation and further developed by the research group at Mälardalen University. First of all, trust and relations have to exist among the persons and organizations involved. The motivation to conduct co-creative research is triggered by the results and values that have been generated from earlier research or from people seeing the potential for new collaboration projects.

The conceptual co-creating model is based on three phases. It starts with formulating a common problem that both the academic and industrial representatives are interested in from their respective perspectives. The funding and resources phase is important in securing involvement and participation in the research from both industry and academia. Finally, in the collaborative work phase, the actual research needs to be conducted collaboratively, demanding relevant research methodologies and project management.

One of the goals of collaborative research is the generation of new knowledge that is of value to the participants, and to society at large. However, one challenge in working towards this goal is that practitioners and researchers develop a discrete understanding separately; each needs the other in the generation of a shared understanding. The fact that researchers investigate a topic important to practitioners does not necessarily mean that the researchers are to apprehend what that topic means to practitioners, and vice versa. Both parties work to different timescales, objectives, reward systems, and perceptions, and they understand each other's practice differently (Garousi et al., 2016). Each has to train and educate others both to think and to apply that thinking systematically and even creatively to the 


\section{Increasing the Impact of Industry-Academia Collaboration through Co-Production} Anna Sannö, Anna Ericson Öberg, Erik Flores-Garcia, and Mats Jackson

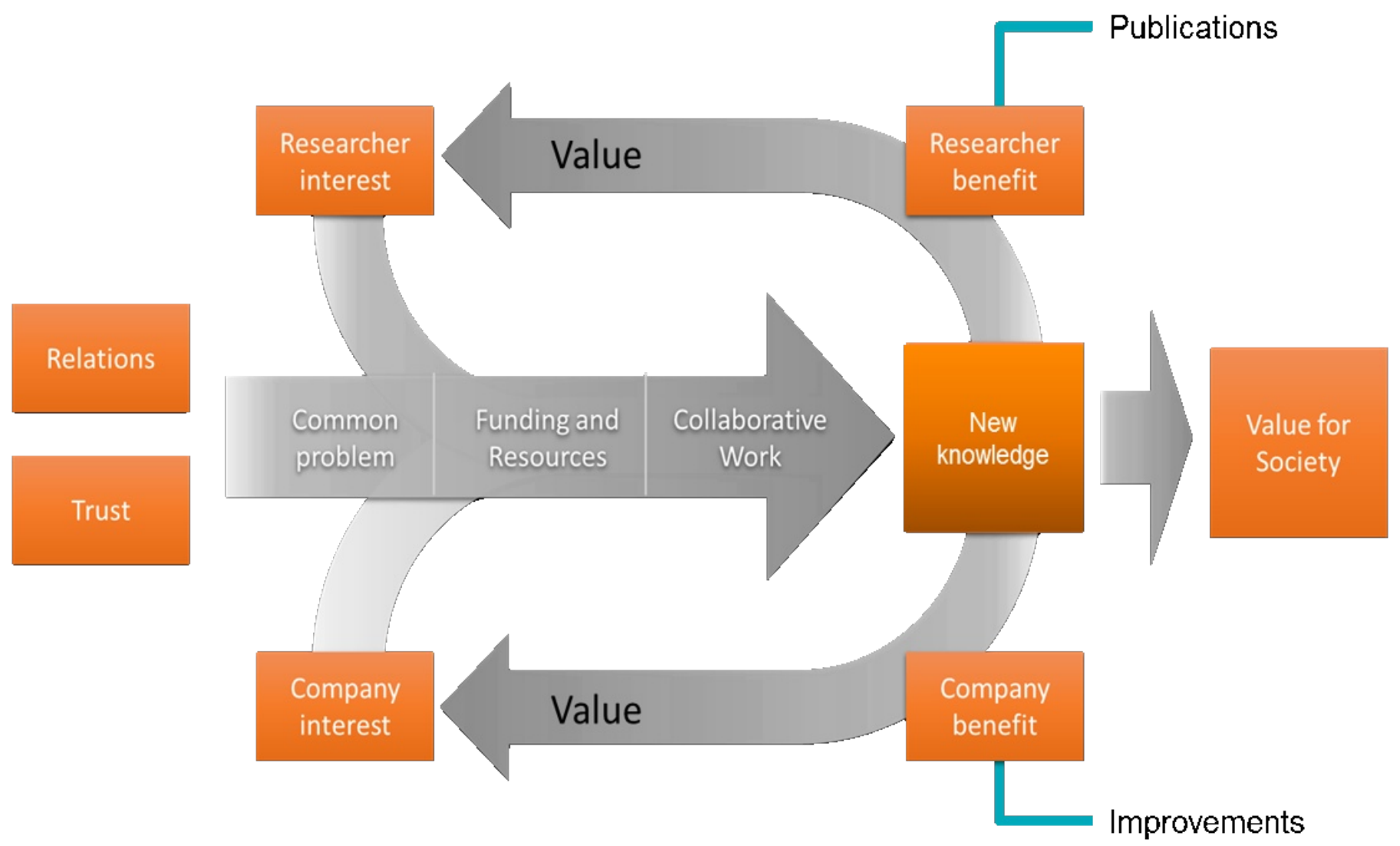

Figure 1. A Co-production process based on the Knowledge Foundation co-production model

design, running, and improvement of operations (Coughlan et al., 2016). A classical criticism towards collaborative research concerns the potential threats to "objectivity", and thereby also to the validity of the research results, due to the involvement of the researcher in practical activities. On the other hand, there are also counter-arguments that a collaborative relationship may contribute to better access to important processes, but also to more valid data compared with traditional research (Argyris, 1980). The process of co-creating research questions needs to expose the tensions in the process of learning to collaborate and to accommodate different perspectives of research partners (Shani et al., 2007). Scientific knowledge that does not make the required contribution seriously hinders university-industry collaboration. If the universities are not creating knowledge to solve industry problems, industry will have less regard for the knowledge provided by the universities (Kaymaz \& Eryiğit, 2011).

\section{Impact}

The concerns in the literature often come back to the terms of rigorous and relevant research. The research process itself should be transparent and carefully considered in order to create rigorous research. Its usefulness indicates the need for relevance and rather addresses the question of how we conduct relevant research. Some streams in research argue that the relevance should come from the gap of existing knowledge in research (Mohrman et al., 2001)

The rigour and relevance gaps are said to stem from the alienation of practitioners from formal academic styles and lead to substantial stylistic differences (Kelemen \& Bansal, 2002). This issue is related to knowledge transfer and interpretation, with the problem lying in the inability or unwillingness of academic researchers to translate their insights for practitioners (Chen et al., 2013). Further, Antonacopoulou (2009) argued that impact does matter in management scholarship, because it is a means of demonstrating the transformation of general information into meaningful knowledge enabling purposeful action. The impact matters because it demonstrates what can happen when research brings attention to neglected issues, it poses different questions, and it builds confidence to experiment. 


\title{
Increasing the Impact of Industry-Academia Collaboration through Co-Production
}

\author{
Anna Sannö, Anna Ericson Öberg, Erik Flores-Garcia, and Mats Jackson
}

Nor is the impact factor well-defined when conducting collaborative research, as the objective is more complex with more stakeholders aligned in the process. Meagher (2009) identified categories of impact, published by Pettigrew, 2011:

- Instrumental impacts: tangible products or services

- Conceptual impacts: scholarly contribution

- Capacity-building impacts: training and collaborative activities

- Cultural changes: achieved in the organizations

- Enduring connectivity impacts: knowledge exchange activities and relationships

According to Antonacopoulou (2009), one of the factors contributing to the tension between rigour and relevance of management scholarship relates to the questions we ask and the way we ask them. Learning to ask the "right" questions is fundamentally more important than a "right" answer. For management scholarship to be impactful, rigour and relevance must be connected so that the questions capture the interests and concerns of different users.

Antonacopoulou (2009) describes impact as having six elements (I-M-P-A-C-T):

I = Influential
(technical, scientific, and practical)
M = Memorable
(lasting experience, "measurable" outcome)
P = Practical
(integrating knowledge about the practitioner)
$\begin{aligned} & \text { A = Actionable } \\ & \text { (connections based on authenticity) }\end{aligned}$
$\begin{aligned} & \text { C = Co-created } \\ & \text { (through learning-driven collaborations) }\end{aligned}$
T = Transformational
(create new questions and possibilities)

Pettigrew (2001) has argued that the elements needed for the research to accomplish high impact and change are many, but the most frequently debated features include:
- a more porous boundary between science and society

- a resultant loss of research autonomy

- a breakdown of assumptions about unitary views of science

- greater range of participants and research practice

- greater recognition of the character of research practice and outcomes

- recognition of the complex interactions between multiple stakeholders in the research process and evaluation of the quality and relevance of research processes, outputs, and outcomes

The literature presented here is further related to the empirical data in the results and analysis described later in this article. The research approach is described in the next section.

\section{Research Approach}

The research projects described in this article have been conducted over five years in a co-production setting between universities and companies in Sweden. The participating companies are global companies within the automotive and pharmaceutical industry segment. The cases were selected based on companies who developed synergy projects with the universities in the past. Therefore, they also had an equal voice in terms of expecting research resulting in impact for them, too. They were interested in further collaboration with universities, which made it relevant to them to discuss the impact of the research. The purpose of this analysis is to capture important factors influencing the research process enabling enhanced impact.

While conducting co-production research, the authors identified certain key factors and challenges. Two of the authors were externally-employed doctoral students at the Innofacture Research School at Mälardalen University in Sweden. At the manufacturing company, a department with 10 researchers was established for manufacturing research with strategic and long-term academic partnership. Two of the authors managed the department, and two other universities had $\mathrm{PhD}$ students in the department. The steps leading to the results in this article are described in Table 1 and are inspired by Kolb's learning cycle (Kolb, 2014). 


\title{
Increasing the Impact of Industry-Academia Collaboration through Co-Production
}

\author{
Anna Sannö, Anna Ericson Öberg, Erik Flores-Garcia, and Mats Jackson
}

Table 1. The steps leading to the identified challenges, key factors, and analysis of impact in this study

\begin{tabular}{lll}
\hline Steps & Method & Participants \\
\hline Data collection & $\begin{array}{l}\text { Concrete experience by planning and } \\
\text { conducting co-creative research through } \\
\text { case studies, interactive research, and } \\
\text { participatory research approaches }\end{array}$ & $\begin{array}{l}\text { Three senior researchers; } \\
\text { seven active PhD students }\end{array}$ \\
\hline Reflective observation & Workshop, documentation, and analysis & $\begin{array}{l}\text { Three senior researchers; } \\
\text { seven active PhD students }\end{array}$ \\
\hline Abstract conceptualization & $\begin{array}{l}\text { Analyzing and concluding experiences, } \\
\text { capturing the findings in a practical } \\
\text { handbook (Sannö et al., 2018) }\end{array}$ & $\begin{array}{l}\text { Review from 30 industrial } \\
\text { managers and academic } \\
\text { researchers }\end{array}$ \\
\hline Active experimentation & $\begin{array}{l}\text { Analysis of impact and retrospectively } \\
\text { describing specific cases }\end{array}$ & Three former PhD students \\
\hline
\end{tabular}

The factors are summarized in Table 2 and Table 3 . The projects had been carried out in close collaboration with academia and industry, and all were related to technology management and innovation. The cases were selected on the basis that they all resulted in new knowledge for the researchers and the organizations.

\section{Co-Production in Industrial Cases}

Key factors related to perspectives from the co-production process

The different perspectives of the co-production research process, as described in the practical handbook (Sannö et al., 2018), are briefly described in Table 2. These process perspectives are further used to describe the six cases in the next section.

\section{The key factors as counterproductive forces influencing} the projects

Details of the identified counterproductive forces are presented in Table 3 (Sannö et al., 2018). These counterproductive forces are later used to further describe six cases.

\section{Case description and key factors related to impact}

The cases individually described below are analyzed from the literature in the impact section (Antonacopoulou, 2009; Meagher, 2009). The cases are then consolidated in the section that follows.

- Case A - "Disagreement on deliverables": This project studied variation when creating welding procedures; one university and four companies participated. The project management was run by a consultant who was hired by the university. However, during the early phases, the expectations of the project were never discussed. When publications were discussed after two years, the expectations of the participants differed, leading to mistrust. The result became useful for the industrial partners in capacity-building impacts but it also resulted in two publications written by the company. The lesson learned was the importance of gaining an understanding of what the respective participants want to get from the project, in line with driving forces and rewards, since it influences, for example, methodology and prioritization. Unfortunately, relations were broken and research in the same constellation did not happen again. The industrial company managed to produce actionable results and raised new questions with other partners.

- Case B - "Manufacturing of new product": This subproject was an externally-employed doctoral student project that investigated how to manufacture a new type of highly innovative product. The externally-employed doctoral student and the participants were employed at the company involved in the project. In the main project, other parties were also involved. Early on, the researchers in the project communicated effectively and received positive attention from the top management, competitors, as well as the media. The methodology was described in the research proposal and the result became useful for the company with instrumental impacts (products and services taken up by the company) as well as capacity-building impacts with training (sessions), and sustainable relationships. 


\title{
Increasing the Impact of Industry-Academia Collaboration through Co-Production
}

\author{
Anna Sannö, Anna Ericson Öberg, Erik Flores-Garcia, and Mats Jackson
}

Table 2. The different perspectives in the research process that were identified as key factors to manage

\begin{tabular}{|c|c|c|c|}
\hline & Definition & Industrial Perspective & Academic Perspective \\
\hline \multirow[t]{2}{*}{$\begin{array}{l}\text { Problem } \\
\text { formulation }\end{array}$} & $\begin{array}{l}\text { Stakeholders identify a } \\
\text { knowledge gap to fill. }\end{array}$ & $\begin{array}{l}\text { Often desired to solve a current problem } \\
\text { that is explicit and identified by the } \\
\text { organization. }\end{array}$ & \multirow{2}{*}{$\begin{array}{l}\text { Find a research gap based on previous } \\
\text { knowledge. Whether it works in } \\
\text { practice or not is not the primary goal, } \\
\text { but knowing why is. }\end{array}$} \\
\hline & & $\begin{array}{l}\text { Short-term problems are often easier to } \\
\text { prioritize. }\end{array}$ & \\
\hline Methodology & $\begin{array}{l}\text { The fundamental } \\
\text { strategy that outlines } \\
\text { the research as well as } \\
\text { methods to collect and } \\
\text { analyze the data. }\end{array}$ & $\begin{array}{l}\text { To solve problems using organizationally } \\
\text { experience, best practice, or traditional } \\
\text { methods. }\end{array}$ & $\begin{array}{l}\text { Key features to legitimize and describe } \\
\text { how the researcher has arrived at the } \\
\text { result to critically review the research } \\
\text { process. Research ethics are also } \\
\text { fundamental. }\end{array}$ \\
\hline Result & $\begin{array}{l}\text { The expected and } \\
\text { realized outcome of } \\
\text { the project. }\end{array}$ & $\begin{array}{l}\text { A solution to an existing problem and } \\
\text { preferably possible to demonstrate. } \\
\text { Newness of less importance compared to } \\
\text { the effect and ease of implementation. }\end{array}$ & $\begin{array}{l}\text { Contribute to the educational system } \\
\text { by providing and adding new } \\
\text { knowledge by publishing, and training } \\
\text { students. }\end{array}$ \\
\hline
\end{tabular}

Several publications such as conceptual impacts with unique material "from inside" an organization also had high academic value and interest. The project became influential, memorable, practical, actionable, cocreated, and transformational (i.e., it had I-M-P-A-C-T, as described earlier), with new questions leading to new research projects.

- Case C - "Development of a new production system": This project developed a production system where five different families of powertrains for the automotive industry could be assembled in one line. The company co-employed academic staff. The academic researchers formulated the aim of the project as a practical need. The academics also announced that, in addition to this, their objective was to collect material for scientific publications and hold presentations, seminars, or workshops to disseminate knowledge on the use of simulation technique in the organization. One of the success factors was that the time plan was based on estimates from previous projects, which did not involve changes of equal magnitude to the production processes. The project involved the externally-employed participants in a number of joint activities during the course of the project, with high attendance because of the good formulation of the practical needs, and tangible products and services. The project led to the implementation of the new production system. Access to data enabled joint learning and conceptual impact with robust evidence-based data achieved from a research point of view as well, fulfilling the influential, memorable, practical, actionable, co-created, and transformational objectives. This conceptual knowledge also led to further research questions and projects.

- Case D - "Simulation in the development of production systems": This project aimed at acquiring knowledge about simulation for the development of production systems, including challenges and benefits. Researchers presented past and ongoing simulation-related projects to members of the manufacturing organization at university premises and at different manufacturing sites as well as workshop series developed on the topics. Company representatives and graduate students identified areas and evaluated the consequences of solutions through simulation. A similar approach was taken initially as in case C. The only difference was that the organization and academic institution did not know each other at the start of co-production. Cases given to academic partners were initially small in scope and involved decisions that had already been taken. Therefore, it took time and several joint activities before the participants of the project became aligned to expectations of knowledge. Cases to base this knowledge on were presented as examples, and practical solutions were important, but in the end, the expectations that emerged from the industry side went beyond solving an immediate issue. After building trust and relations, the project started to deliver rigorous data as well and co-created learning, leading to capacity-building impacts and further connectivity impacts. 


\section{Increasing the Impact of Industry-Academia Collaboration through Co-Production} Anna Sannö, Anna Ericson Öberg, Erik Flores-Garcia, and Mats Jackson

Table 3. Counterproductive forces from an academic and industrial perspective

\begin{tabular}{|c|c|c|c|}
\hline Key Factors & Definition & Industrial Perspective & Academic Perspective \\
\hline Reflections of time & $\begin{array}{l}\text { Not only measurable } \\
\text { but a perception that } \\
\text { can be different and } \\
\text { dependent on the } \\
\text { person. }\end{array}$ & $\begin{array}{l}\text { - Aiming at time reduction in } \\
\text { production or the } \\
\text { development process. } \\
\text { - Often a short-term focus. } \\
\text { - Time for reflection is often } \\
\text { rare. }\end{array}$ & $\begin{array}{l}\text { - Enabler for reflection connected to } \\
\text { building knowledge. } \\
\text { - Learning and understanding is a non- } \\
\text { linear process; they need to develop over } \\
\text { time. } \\
\text { - The publications system has a long-term } \\
\text { perspective; it might take years to publish. }\end{array}$ \\
\hline View on knowledge & $\begin{array}{l}\text { Many definitions } \\
\text { (e.g., context- } \\
\text { specific, relational, } \\
\text { tacit, explicit, or as a } \\
\text { process). }\end{array}$ & $\begin{array}{l}\text { - Diffuse term, often related to } \\
\text { the degree of education, } \\
\text { assignment, experience, or } \\
\text { years in the company. } \\
\text { - Competitive advantage; } \\
\text { included in their systems. }\end{array}$ & $\begin{array}{l}\text { - The core (the criterion) is to add new } \\
\text { knowledge by building new theory, } \\
\text { expanding, qualifying, reporting, or } \\
\text { testing existing theory. }\end{array}$ \\
\hline $\begin{array}{l}\text { Driving forces and } \\
\text { rewards }\end{array}$ & $\begin{array}{l}\text { Motivation for the } \\
\text { participants; what } \\
\text { you get } \\
\text { acknowledged for. }\end{array}$ & $\begin{array}{l}\text { - Mainly connected to a } \\
\text { problem; if related to } \\
\text { financial importance often } \\
\text { more prioritized, indicator } \\
\text { focused. } \\
\text { - Influenced by the culture. }\end{array}$ & $\begin{array}{l}\text { - Ability to identify a relevant problem, to } \\
\text { get funding, to conduct the research and } \\
\text { explicitly express your contribution in a } \\
\text { scientific way. } \\
\text { - Striving for publication in highly ranked } \\
\text { journals. }\end{array}$ \\
\hline Power dynamics & $\begin{array}{l}\text { Organizational as } \\
\text { well the perceived } \\
\text { differences in power } \\
\text { between people. }\end{array}$ & $\begin{array}{l}\text { - Often multiple career paths } \\
\text { - The position and title can be } \\
\text { the initial viewpoint, but } \\
\text { behind is rather personality, } \\
\text { previous achievements, ideas, } \\
\text { and experience. }\end{array}$ & $\begin{array}{l}\text { - Fewer career paths. } \\
\text { - Hierarchy is clearer. } \\
\text { - The titles are important because they } \\
\text { signal the level of achievement in } \\
\text { contributing to knowledge. }\end{array}$ \\
\hline Communication & $\begin{array}{l}\text { The exchange of } \\
\text { information by } \\
\text { speaking, writing, or } \\
\text { using other media to } \\
\text { communicate. }\end{array}$ & $\begin{array}{l}\text { - Important to understand the } \\
\text { local, cultural language (e.g., } \\
\text { the loudest voice is the only } \\
\text { voice heard or first speaker } \\
\text { advantage). } \\
\text { - Influences how to act, dress, } \\
\text { and behave. }\end{array}$ & $\begin{array}{l}\text { - Terminology is important; using } \\
\text { definitions. } \\
\text { - Argumentation is important to show the } \\
\text { value of the research; how and why you } \\
\text { have arrived at your findings. } \\
\text { - Ability to write and to publish is } \\
\text { important. }\end{array}$ \\
\hline
\end{tabular}




\title{
Increasing the Impact of Industry-Academia Collaboration through Co-Production
}

\author{
Anna Sannö, Anna Ericson Öberg, Erik Flores-Garcia, and Mats Jackson
}

- Case E - "Technology change with insights": This case was initiated as a project to upgrade a technology to improve the environmental impact of a process in a manufacturing plant. The team consisted of the researcher employed by the organization, a researcher from a university observing the other researcher, as well as the company team and suppliers. The researcher used visualization to communicate the role of the researcher and, early on, discussion concerning the methodology. The expectations of the technical support were at first higher than those of the management research. After implementing the technology, with several issues along the way, the organization realized that the need for knowledge had to be built upon their own competence, not by the knowledge of external parties. The co-production initiated a learning process inside the organization by asking research-related questions and by giving support to find solutions in the literature. The researcher built up knowledge about how different factors in the organization influenced the project while the participants learned how to manage the change process. It also led to mutual understanding of problems and how to develop a collaborative methodology to enhance learning in the organization. The project was influential, memorable as "before and after" memory, practical, actionable, co-created, and transformational, leading to several new questions and possibilities. Its conceptual impact was the scholarly contribution of innovation theory related to time and contexts, cultural change and enduring connectivity impacts, as well as capacity-building impacts of learning.

- Case F- "Study of re-used material with project cooperation issues": An evaluation was made concerning whether parts could be re-used, leading to a new technology to be used in the value chain. Several actors from different companies and universities joined the project, with the research leader acting as project manager. The project was sold to the companies as a practical problem where all the different perspectives were also taken into account. However, the driving forces of business interests by partners in the project misdirected the purpose and the methodology. The expected result was not achieved. The main finding was that a common problem formulation was missing and a failure to make sure, by communication and management, that all the actors were aligned through the process. In order to have done so, it would have been necessary to realize the driving forces and motivation for the project and what to expect from the actors. The project was hardly influential; it became less practical or academically rigorous and did not lead to further projects.

\section{Discussion}

Effective management of the phases of problem formulation, methodology, and results is important for successful collaboration and thereby impact. From the different cases, we can conclude that, even if there is not one methodology or research process, these phases are still important to clarify and manage when initiating a collaborative research project. The research should not be based on the interest of only one of the stakeholders; communication and mutual interest in a driving force are important key factors during all stages, opening up a more porous boundary between science and society (Pettigrew, 2011).

The summary of the cases presented in Table 4 shows the identified factors that influence the impact/implications of co-produced research. If we were to grade the perspectives by importance, we would see that the driving forces that motivate engagement in a project as well as communication are particularly important in terms of achieving impact, which is in accordance with previous findings (Garousi et al., 2016; Kaymaz \& Eryiğit, 2011; Sandberg et al., 2011). The cases were evaluated from the perspective of the different factors. Each case was assigned a grading for each factor according to the I-M-P-A-C-T elements described by Antonacopoulou (2009):

+ Several elements with a positive impact

$+\quad$ A few elements with a slightly positive impact

- A few elements with a slightly negative impact

-- Several elements with a negative impact

Further, the different categories of impact (Meagher, 2009) for each case were evaluated by the academic and industrial perception of the outcome.

\section{Positive impact

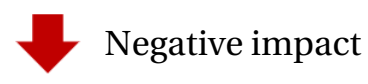

Just as Coghlan and Coughlan (2008) highlighted the insights of linking theory, practice, and collaboration, differences were encountered while sustaining the collaboration by managing the counterproductive forces. Built on trust and relationships, progress is facilitated and can lead to several impacts, as seen in the difference between Case C and Case D. If trust and relationships are built, the practical and scholarly results are 


\section{Increasing the Impact of Industry-Academia Collaboration through Co-Production}

Anna Sannö, Anna Ericson Öberg, Erik Flores-Garcia, and Mats Jackson

Table 4. Categories of impact and influence by the identified key factors for each case

\begin{tabular}{|c|c|c|c|c|c|c|}
\hline \multirow[b]{2}{*}{ Key Factor/Category of Impact } & \multicolumn{6}{|c|}{ Case } \\
\hline & $\mathbf{A}$ & B & $\mathbf{C}$ & $\mathbf{D}$ & $\mathbf{E}$ & $\mathbf{F}$ \\
\hline Problem formulation & ++ & ++ & ++ & ++ & + & - \\
\hline Methodology & - & ++ & ++ & ++ & ++ & - \\
\hline Result & -- & ++ & ++ & ++ & + & -- \\
\hline Reflections of time & - & - & + & + & + & -- \\
\hline View of knowledge & -- & ++ & - & ++ & + & -- \\
\hline Driving forces and rewards & -- & ++ & ++ & ++ & + & - \\
\hline Power dynamics & - & + & ++ & + & ++ & - \\
\hline Communication & - & ++ & ++ & ++ & + & -- \\
\hline Instrumental impacts & & & & & & \\
\hline Conceptual impacts & & & & & & \\
\hline Capacity-building impacts & & & & & & \\
\hline Cultural change & & & & & & \\
\hline Enduring connectivity impacts & & & & & & \\
\hline
\end{tabular}

likely to be equally balanced. A greater range of participants in the knowledge development process will require adaptation of the methodology (Pettigrew, 2011), and this will lead to cultural changes in both systems.

One limitation of the cases investigated is whether research funding was secured, because the driving force of obtaining funding will likely impact the project. We see the result of decades of emphasis on the co-production of knowledge in Sweden, but the study is limited to doctoral students in this environment and the international industrial companies involved. This article does not look toward theory development, nor method development, but rather creates a voice of experiences of scholars aiming for practical relevance in the academic system. We encourage the inclusion of other stakeholders from companies and academia to reflect on the characteristics and challenges addressed.

Today, several terms and definitions of quality and impact exist, but it is still difficult for academics to agree on these definitions and improve collaboration. Therefore, it is necessary to have tools, measurements, and methods to evaluate co-production and the impact it gives. We would like to emphasize the need for involving the participant stakeholders in the discussion. We therefore propose that greater emphasis should be placed on the Implications for Practice section (Bartunek \& Rynes, 


\title{
Increasing the Impact of Industry-Academia Collaboration through Co-Production
}

\author{
Anna Sannö, Anna Ericson Öberg, Erik Flores-Garcia, and Mats Jackson
}

2014), but also greater emphasis should be placed in the introduction and methodology parts of the resulting journal publications. By using the findings from this article, these can more explicitly be discussed by the collaborating organizations. As Adler and Harzing (2009) wrote, presenting research findings as if other researchers are the only end users is hardly an ideal situation for addressing complex questions in a way that contributes to society.

\section{Conclusion}

To do collaborative research requires awareness and certain skills from the participating organizations. In this article, we have used different forms of action research, and from the different industry-academic collaborations we have identified key factors influencing different elements - and categories of impact. We are contributing to the continuous discussion by scholars by including the academic and industrial views, seen as fundamental to fully realizing the research impact potential. How we manage the phases of problem formulation, methodology, and results is critical for successful collaboration and thereby its impact. Counter-productive forces that could dilute the progress also need to be considered since combining practical relevance and scientific rigour comes with challenges. A research gap concerning how to assess co-production was identified and further research on assessment models including impact needs to be conducted.
Citation: Sannö, A., Ericson Öberg, A., Flores-Garcia, E.,

\& Jackson., M.. 2019. Increasing the Impact of

Industry-Academia Collaboration through Co-

Production. Technology Innovation Management Review,

9(4): 37-47. http://doi.org/10.22215/timreview/1232

Keywords: action research, industry-academia collaboration, co-production, impact, collaboration, rigour, relevance, key factors

\section{About the Authors}

Anna Sannö is the Research Strategy Manager at Volvo CE, previously working as a Senior Lecturer in External Collaboration at Örebro University in Sweden. Her research focus is on sustainable operations management. Anna received her PhD in Innovation and Design from Mälardalen University where she belonged to the research school Innofacture. Anna has an industrial background in surface treatment and the automotive industry. She holds a BSc in Chemical Engineering from Chalmers University of Technology in Gothenburg, Sweden.

Anna Ericson Öberg is the Management System and Data Analysis Director at Volvo Construction Equipment and has been working with production, welding, and management since 2004. She has a PhD in Manufacturing Technology from Chalmers University of Technology in Gothenburg, Sweden. Her research interest lies in manufacturing improvements in the intersection between the research areas of quality, welding, and production and is managing and participating in several research projects. Anna holds an MSc in Manufacturing Management from Loughborough University in England and is Six Sigma Black Belt certified.

Erik Flores-Garcia is a doctoral student at Mälardalen University, Sweden. His research interests include discrete event simulation and decision-making. He holds an MSc in Production and Logistics from Mälardalen University and a BSc in Mechatronics from the Monterrey Institute of Technology and Higher Education in Mexico.

Mats Jackson is Professor of Innovative Production at Jönköping University, Sweden and is the Programme Manager of SPARK, their research and education environment focusing on knowledge-intensive product realization. He was previously the Professor of Innovation and Product Realisation at Mälardalen University in Sweden and the Manufacturing Research Manager at Volvo Construction Equipment. $\mathrm{He}$ was also the Project Manager for the research school Innofacture at Mälardalen University. He received his $\mathrm{PhD}$ in 2000 in Production System Development at Linköping University and has a background as a production engineer and management consultant in industry. 


\section{Increasing the Impact of Industry-Academia Collaboration through Co-Production}

\section{Anna Sannö, Anna Ericson Öberg, Erik Flores-Garcia, and Mats Jackson}

\section{References}

Adler, N., Shani, A. R., \& Styhre, A. 2004. Collaborative Research in Organizations: Foundations for Learning, Change, and Theoretical Development. Thousand Oaks, CA: Sage Publications.

Adler, N. J., \& Harzing, A.-W. 2009. When Knowledge Wins: Transcending the Sense and Nonsense of Academic Rankings. Academy of Management Learning \& Education, 8(1): 72-95. http://doi.org./10.5465/amle.2009.37012181

Aguinis, H., \& Edwards, J. R. 2014. Methodological Wishes for the Next Decade and How to Make Wishes Come True. Journal of Management Studies, 51(1): 143-174. http://doi.org/10.1111/joms.12058

Antonacopoulou, E. P. 2009. Impact and Scholarship: Unlearning and Practising to Co-Create Actionable Knowledge. Management Learning, 40(4): 421-430. http://doi.org/10.1177/1350507609336708

Argyris, C. 1980. Inner Contradictions of Rigorous Research. New York, NY: Academic Press.

Bartunek, J. M., \& Rynes, S. L. 2014. Academics and Practitioners Are Alike and Unlike:The Paradoxes of Academic-Practitioner Relationships. Journal of Management, 40(5): 1181-1201. http://doi.org/10.1177/0149206314529160

Chen, C. Y., Jim Wu, Y. C., \& Wu, W. H. 2013. A Sustainable Collaborative Research Dialogue between Practitioners and Academics. Management Decision, 51(3): 566-593. http://doi.org/10.1108/00251741311309661

Coghlan, D., Cirella, S., \& Shani, A. 2012. Action Research and Collaborative Management Research: More Than Meets the Eye? International Journal of Action Research, 8(1): 45-67. http://doi.org/10.1688/1861-9916_IJAR_2012_01_Shani

Coghlan, D., \& Coughlan, P. 2008. Action Learning and Action Research (ALAR): A Methodological Integration in an InterOrganizational Setting. Systemic Practice and Action Research, 21(2): 97-104.

http://doi.org/10.1007/s11213-007-9086-0

Coughlan, P., \& Coghlan, D. 2002. Action Research for Operations Management. International. Journal of Operations \& Production Management, 22(2): 220-240.

https://doi.org/10.1108/01443570210417515

Coughlan, P., Draaijer, D., Godsell, J., \& Boer, H. 2016. Operations and Supply Chain Management: The Role of Academics and Practitioners in the Development of Research and Practice. International Journal of Operations \& Production Management, 36(12): 1673-1695.

http://doi.org/10.1108/IJOPM-11-2015-0721

Ellström, P.-E. 2008. Knowledge Creation through Interactive Research: A Learning Approach. Paper presented at the Proceedings of the ECER Conference, September 8-12, 2008, University of Göteburg, Sweden.

Garousi, V., Petersen, K., \& Ozkan, B. 2016. Challenges and Best Practices in Industry-Academia Collaborations in Software Engineering: A Systematic Literature Review. Information and Software Technology, 79: 106-127. https://doi.org/10.1016/j.infsof.2016.07.006
Kaymaz, K., \& Eryiğit, K. Y. 2011. Determining Factors Hindering University-Industry Collaboration: An Analysis from the Perspective of Academicians in the Context of Entrepreneurial Science Paradigm. International Journal of Social Inquiry, 4(1).

Kelemen, M., \& Bansal, P. 2002. The Conventions of Management Research and Their Relevance to Management Practice. British Journal of Management, 13(2): 97-108. http://doi.org/10.1111/1467-8551.00225

Kolb, D. A. 2014. Experiential Learning: Experience as the Source of Learning and Development. Indianapolis, IN: Pearson.

Kunttu, L., Huttu, E., \& Neuvo, Y. 2018. How Doctoral Students and Graduates Can Facilitate Boundary Spanning between Academia and Industry. Technology Innovation Management Review, 8(6): 48-49.

http://doi.org/10.22215/timreview/1164

Meagher, L. 2009. Impact Evaluation of the Paccit Programme. Swindon, UK: Economic and Social Research Council.

Mohrman, S. A., Gibson, C. B., \& Allan M. Mohrman, J. 2001. Doing Research That Is Useful to Practice a Model and Empirical Exploration. Academy of Management Journal, 44(2): 357-375. http://doi.org/10.5465/3069461

Pettigrew, A. M. 2001. Management Research after Modernism. British Journal of Management, 12(1): 61-70. http://doi.org/10.1111/1467-8551.12.s1.8

Pettigrew, A. M. 2011. Scholarship with Impact. British Journal of Management, 22(3): 347-354. http://doi.org/10.1111/j.1467-8551.2011.00769.x

Reason, P. 2006. Choice and Quality in Action Research Practice. Journal of Management Inquiry, 15(2): 187-203. https://doi.org/10.1177\%2F1056492606288074

Sandberg, A., Pareto, L., \& Arts, T. 2011. Agile Collaborative Research: Action Principles for Industry-Academia Collaboration. IEEE Software, 28(4): 74-83. http://doi.org/10.1109/MS.2011.49

Sannö, A., Ericson Öberg, A., \& Jackson, M. 2018. How to Succeed with Co-Production: Experiences from Industrial Researchers. Eskilstuna, Sweden: Mälardalen University.

Shani, A. B., Mohrman, S. A., Pasmore, W. A., Stymne, B., \& Adler, N. (Eds.) 2007. Handbook of Collaborative Management Research. London: SAGE Publications.

Starkey, K., \& Madan, P. 2001. Bridging the Relevance Gap: Aligning Stakeholders in the Future of Management Research. British Journal of Management, 12(1): 3-26. http://doi.org/10.1111/1467-8551.12.s1.2

Svensson, L., Ellström, P.-E., \& Brulin, G. 2007. Introduction - On Interactive Research. International Journal of Action Research, 3(3): 233-249.

Van de Ven, A. H. 2007. Engaged Scholarship: A Guide for Organizational and Social Research. Oxford, UK: Oxford University Press.

Wohlin, C., Aurum, A., Angelis, L., Phillips, L., Dittrich, Y., Gorschek, T., Grahn, H., Henningsson, K., Kagstrom, S., Low, G., Rovegard, P., Tomaszewski, P., van Toorn, C., \& Winter, J. 2012. The Success Factors Powering Industry-Academia Collaboration. IEEE Software, 29(2): 67-73.

http://doi.org/10.1109/MS.2011.92 


\title{
A Discipline-Spanning Overview of Action Research and Its Implications for Technology and Innovation Management
}

\author{
Matthias Guertler, Nathalie Sick, and Anton Kriz
}

\author{
(6 If you want truly to understand something, try to change it. ") \\ Kurt Lewin \\ Psychologist, considered the founder of social psychology
}

\begin{abstract}
The iterative and learning character of action research is particularly beneficial for exploring complex socio-technical problems in technology and innovation management (TIM). In this respect, action research allows both rigorous and relevant research due to parallel solving of real-world problems, capability building, and gaining scientific insights. However, the use of action research within TIM research is surprisingly limited. Action research also is not a homogeneous research methodology since each research discipline, such as education and organizational science, has its own action research streams, which are often only loosely linked. A systematic overview of those action research traditions and specific best practices is still missing, which complicates a systematic transfer and use of action research in TIM. This article addresses this essential gap by building a cross-disciplinary overview of action research streams based on a bibliometric analysis using Scopus. The analysis includes relevant disciplines with action research traditions, their development over time, and the most influential journals, authors, institutions, and countries. Along with this discipline-spanning analysis, the article investigates particular TIM benefits and challenges of action research. The two key contributions of this article are: 1) a discipline-spanning overview of action research and its evolution and 2) an analysis of its implications for TIM research. These contributions build the basis for strengthening the use of action research in TIM. In the medium-term, action research has the capacity to link academia and industry more closely and, in doing so, assists important endeavours of translating more of our research outcomes into practice.
\end{abstract}

\section{Introduction}

This study provides a discipline-spanning overview of action research and its implications for technology and innovation management (TIM). TIM is characterized by complex socio-technical problems which include the involvement of a large variety of different stakeholders across the entire lifecycle of a product-service system (Kralisch et al., 2018). Moreover, innovation is multi-faceted and can be an outcome, a process, and a capability (D'Alvano \& Hidalgo, 2012; Hauschildt \& Salomo, 2007; Hidalgo \& Albors, 2008). Due to the socio-technical complexity and novelty of innovations, innovation management also faces high levels of uncertainty (D'Alvano \& Hidalgo, 2012).
The iterative learning and human-centred character of action research is particularly beneficial for exploring the complex socio-technical problems in TIM. Understanding the complex systems of technical and social elements, their relationships, and their dynamics can benefit from applied approaches such as action research (Benner \& Tushman, 2015; Ottosson, 2003). In this respect, action research allows both rigorous and relevant research due to parallel resolving of realworld problems, capability building, and gaining scientific insights (Brydon-Miller et al., 2003). However, despite these benefits and successful applications in other disciplines such as education (Hult \& Lennung, 1980), sociology, and experimental psychology (Burnes, 2004), the use of action research within TIM 


\section{A Discipline-Spanning Overview of Action Research and Its Implications for Technology and Innovation Management Matthias Guertler, Nathalie Sick, and Anton Kriz}

research is surprisingly limited. A Scopus search in November 2018, using the terms "action research" and "innovation management" linked to title, abstract, and keywords (before 2018), yielded only 19 journal articles. Action research itself is also not methodologically homogeneous since each research discipline, such as education and organizational science, has their own action research streams, which are often only loosely linked. A systematic overview of those action research streams and specific best practices is still missing, which complicates a systematic transfer and use of action research in TIM.

To allow a successful application of action research in TIM and a systematic transfer of approaches from other disciplines, it is important to build a detailed understanding about the "where" and "why" of action research for TIM as well as "which" and "how" cross-disciplinary approaches can be transferred and adapted. This article contributes to this overarching goal by focusing on the following fundamental questions: Which disciplines have successfully applied action research to date? Which benefits can action research provide to TIM but also which potential barriers might it face?

The present article addresses this essential gap by building a discipline-spanning overview of action research streams based on a bibliometric analysis using Scopus. The analysis includes relevant disciplines with action research traditions, their development over time, and the most influential journals, authors, institutions, and countries. Along with this discipline-spanning analysis, the article investigates and reviews important benefits and challenges of action research for TIM.

The key contributions of this article are twofold. First, the discipline-spanning overview of action research and its evolution provide insights into different disciplinary streams of action research as a basis to deepen and stretch the thinking between TIM and other disciplines applying action research. Second, opportunities and pathways to further discuss and establish the use of action research within the TIM discipline are identified based on the analysis of benefits and challenges for TIM research. In the medium-term, this enables greater academic and industry linkage for more rigorous research and in so doing helps strengthen the translation of research outcomes into practice.

The remainder of this article is structured as follows. The next section provides an overview of the bibliometric analysis including data collection and measures used. Next, findings of the bibliometric analysis are presented, followed by a discussion of the benefits and challenges of action research for technology and innovation management. The study closes with a summary of the main insights and limitations and an outlook on further research.

\section{Research Method}

In order to map the research landscape of action research, a bibliometric analysis of discipline-spanning contributions to the field of action research has been conducted. Bibliometrics as a quantitative statistical analysis originated in library and information science (Broadus, 1987; Pritchard, 1969). The method is now increasingly used in other research areas to map a certain field from a macro-perspective (Zhang et al., 2010).

The bibliometric analysis is based on Scopus, provided by Elsevier B.V., a global database with more than 71 million records, which is a well-established data source for bibliometric analyses (Harzing \& Alakangas, 2016). To cover a broad and particularly discipline-spanning range of contributions, the search term "action research" was used for title, abstract, and keywords. As different disciplines show varying patterns of publishing research results, particularly concerning journal articles, conference proceedings, and books, no limitations were implemented in terms of document types. The search was conducted in November 2018 with results including all material up until the end of 2017. The search resulted in 16,946 documents related to action research. Medicine was excluded as a discipline of analysis due to the high number of false positives, such as "action research arm", "action research aim", and other topics around genetics and stroke therapy. This reduced the sample to 13,727 documents.

In a first step, the disciplines involved in action research were analyzed as well as their respective publication outlets, more specifically peer-reviewed articles and reviews as well as conferences and books or book chapters. In a second step, the sample was reduced to peer-reviewed articles (i.e., articles, articles in press, reviews, editorials, and notes). These articles were analyzed in terms of the most influential journals, authors, contributions, as well as institutions and countries, while providing additional disciplinary insights. Measures used in this study, and established as well as widespread in bibliometrics, are contributions and citations as well as h-index (Hirsch, 2005; Merigó et al., 2015). Using the total number of contributions in combination with citations and h-index captures the extent as well as 


\section{A Discipline-Spanning Overview of Action Research and Its Implications for Technology and Innovation Management Matthias Guertler, Nathalie Sick, and Anton Kriz}

the outreach and influence of contributions in the field (Ding et al., 2014).

In addition to the quantitative bibliometric analysis, qualitative insights are added to complete the discipline-spanning review of action research with a discussion of benefits and challenges particularly to TIM.

\section{Discipline-Spanning Bibliometric Overview of Action Research Literature}

\section{General overview}

As of November 2018, 13,727 documents on action research have been published. Peer-reviewed articles hold the biggest share with $79 \%$, followed by conference papers with $14 \%$ and books, as well as book chapters with $7 \%$. Table 1 provides an overview of the most relevant disciplines with more than 500 publications on action research. A disciplinary analysis reveals that social science is the dominant discipline,

Table 1. Overview of central disciplines in action research

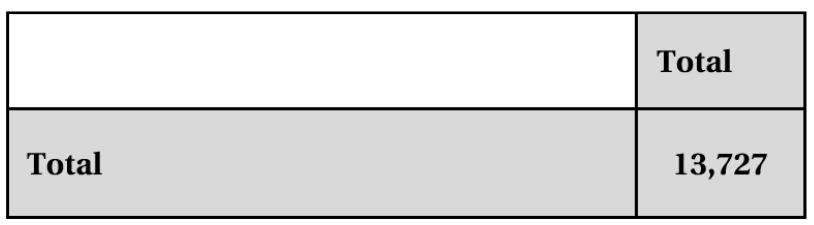

\begin{tabular}{|l|c|}
\hline Social Science & 7,924 \\
\hline Business, Management, and Accounting & 2,829 \\
\hline Computer Science & $20.6 \%$ \\
\hline Engineering & $15.2 \%$ \\
\hline Art and Humanities & 1,288 \\
\hline Psychology & 1,280 \\
\hline Nursing & $9.4 \%$ \\
\hline Decision Science & 1,051 \\
\hline Environmental Science & 897 \\
\hline & $6.7 \%$ \\
\hline & 682 \\
\hline & 673 \\
\hline
\end{tabular}

contributing $58 \%$ of all publications. Business, management, and accounting - including TIM - follows with $21 \%$, while computer science and engineering account for $15 \%$ and $9 \%$, respectively. As publication structure and strategies can vary across disciplines, a detailed analysis of three key outlets of scientific research is given: 1) peer-reviewed articles (i.e., articles, articles in press, reviews, editorials, and notes), 2) conference papers, and 3) books and book chapters. Unsurprisingly, peer-reviewed articles are the key outlet for most disciplines, ranging from $64 \%$ in decision science to $98 \%$ in nursing with an overall average of $79 \%$. Exceptions, as Table 1 highlights, are computer science and engineering, with conference papers the dominant or at least equal outlet for research publication. This might be due to a more prominent role of conferences in these disciplines, which might mean that conference papers need to be considered when analyzing these disciplines, but this requires further research.

\begin{tabular}{|r|r|r|}
\hline $\begin{array}{c}\text { Peer-Reviewed } \\
\text { Articles }\end{array}$ & \multicolumn{1}{c|}{$\begin{array}{c}\text { Conference } \\
\text { Papers }\end{array}$} & $\begin{array}{c}\text { Books \& Book } \\
\text { Chapters }\end{array}$ \\
\hline 10,792 & 1,905 & 953 \\
$78.6 \%$ & $13.9 \%$ & $6.9 \%$ \\
\hline
\end{tabular}

\begin{tabular}{|c|c|c|}
\hline 6,789 & 493 & 624 \\
\hline $85.7 \%$ & $6.2 \%$ & $7.9 \%$ \\
\hline 2,481 & 182 & 152 \\
\hline $87.7 \%$ & $6.4 \%$ & $5.4 \%$ \\
\hline 865 & 1,114 & 71 \\
\hline $41.5 \%$ & $53.4 \%$ & $3.4 \%$ \\
\hline 651 & 548 & 67 \\
\hline $50.5 \%$ & $42.5 \%$ & $5.2 \%$ \\
\hline 1,152 & 15 & 110 \\
\hline $90.0 \%$ & $1.2 \%$ & $8.6 \%$ \\
\hline 924 & 74 & 52 \\
\hline $87.9 \%$ & $7.0 \%$ & $4.9 \%$ \\
\hline 880 & 4 & 12 \\
\hline $98.1 \%$ & $0.4 \%$ & $1.3 \%$ \\
\hline 434 & 230 & 3 \\
\hline $63.6 \%$ & $33.7 \%$ & $0.4 \%$ \\
\hline 599 & 30 & 42 \\
\hline $89.0 \%$ & $4.5 \%$ & $6.2 \%$ \\
\hline
\end{tabular}

timreview.ca 


\section{A Discipline-Spanning Overview of Action Research and Its Implications for Technology and Innovation Management Matthias Guertler, Nathalie Sick, and Anton Kriz}

\section{Evolution of action research in different disciplines}

Analyzing the year-by-year evolution of action research articles published in each discipline reveals a long "incubation phase" between the first publication and an increased publication momentum (Figure 1). The start of a publication stream is considered as two consecutive publications with no more than three gap years. The seminal paper on action research by Kurt Lewin dates back to 1946. This social sciences action research article is seen as the start of all publication streams (Burnes, 2004) and is still seen as seminal in today's action research landscape. In the following five years, the disciplines of business, management, and accounting; arts and humanities; psychology; as well as nursing started publication activities on action research. However, it was not until around the beginning of the 1970s that action research led to a continuous publication stream and began to develop additional intensity. In 1974, decision science published the first action research art- icles with consecutive contributions. Later disciplines are computer science and engineering with smaller gaps of eight and 12 years, with action research only gaining real momentum from the early $80 \mathrm{~s}$. The most recent discipline in our analysis is environmental science starting in 1980.

Figure 1 highlights a marked incline in publications in social sciences from the 1980s with this catapulting after 2004. A more general incline across respective disciplines is observed with the turn of the millennium. The growth factor of the annual publication rates from 2000 until 2017 ranges from 1.0 for nursing and 2.5 for psychology up to 32.0 for engineering. Decision science and business, management, and accounting represent the lower middle field with a growth factor of 3.5 and 4.2 respectively. The upper middle field is formed by social science (7.4), computer science (7.7), environmental science (8.8), and arts and humanities (9.6).

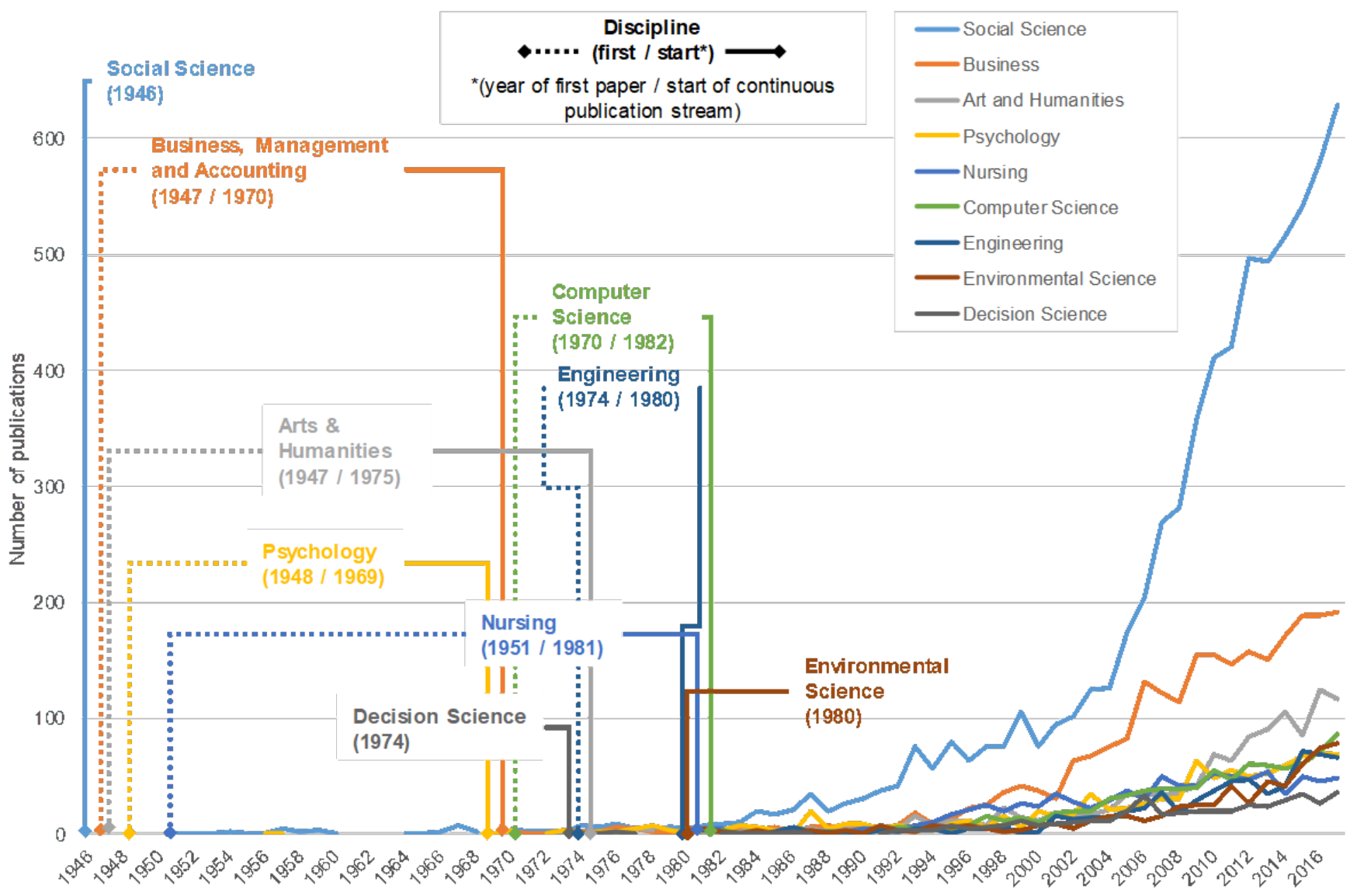

Figure 1. Evolution of new action research publications in the key disciplines 


\section{A Discipline-Spanning Overview of Action Research and Its Implications for Technology and Innovation Management Matthias Guertler, Nathalie Sick, and Anton Kriz}

The most influential journals

Another key aspect of a bibliometric overview of action research is where studies on or involving action research are published, particularly concerning the focus and disciplines. It is striking that the most productive action research journals are specifically dedicated to action research as a research method, for example, Educa- tional Action Research (445 articles), Action Research (298 articles), Systemic Practice and Action Research (221 articles), and the International Journal of Action Research (76 articles) (Table 2). The aforementioned journals are either associated with social science or business, management, and accounting, the two major disciplines in action research (Table 1).

Table 2. Most productive and influential journals publishing action research

\begin{tabular}{|c|c|c|c|c|c|}
\hline & Journal & 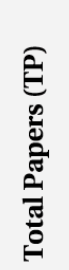 & 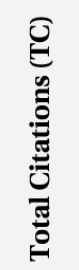 & TC/TP & 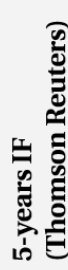 \\
\hline 1 & Educational Action Research & 445 & 3136 & 7.0 & N/A \\
\hline 2 & Action Research & 298 & 3627 & 12.2 & 0.83 \\
\hline 3 & Systemic Practice and Action Research & 221 & 1876 & 8.5 & 0.88 \\
\hline 4 & Journal of Advanced Nursing & 102 & 3137 & 30.8 & 2.76 \\
\hline 5 & Journal of Clinical Nursing & 84 & 1317 & 15.7 & 1.98 \\
\hline 6 & International Journal of Action Research & 76 & 235 & 3.1 & N/A \\
\hline 7 & Teaching and Teacher Education & 52 & 1749 & 33.6 & 3.34 \\
\hline 8 & Nurse Education Today & 47 & 480 & 10.2 & 2.43 \\
\hline 9 & Journal of Applied Behavioral Science & 41 & 954 & 23.3 & 2.18 \\
\hline 10 & Human Relations & 40 & 2486 & 62.2 & 4.35 \\
\hline 11 & Espacios & 36 & 16 & 0.4 & N/A \\
\hline 12 & Learning Organization & 34 & 651 & 19.1 & N/A \\
\hline 13 & AI and Society & 33 & 71 & 2.2 & N/A \\
\hline 14 & British Educational Research Journal & 33 & 718 & 21.8 & 2.29 \\
\hline 15 & Journal of Social Issues & 32 & 2689 & 84.0 & 3.26 \\
\hline 16 & Social Science and Medicine & 32 & 2071 & 64.7 & 3.84 \\
\hline 17 & $\begin{array}{l}\text { International Journal of Operations and } \\
\text { Production Management }\end{array}$ & 31 & 1921 & 62.0 & 4.37 \\
\hline 18 & International Journal of Learning & 30 & 19 & 0.6 & $N / A$ \\
\hline 19 & Management Learning & 30 & 780 & 26.0 & 2.46 \\
\hline 20 & British Journal of Occupational Therapy & 29 & 209 & 7.2 & 0.97 \\
\hline
\end{tabular}

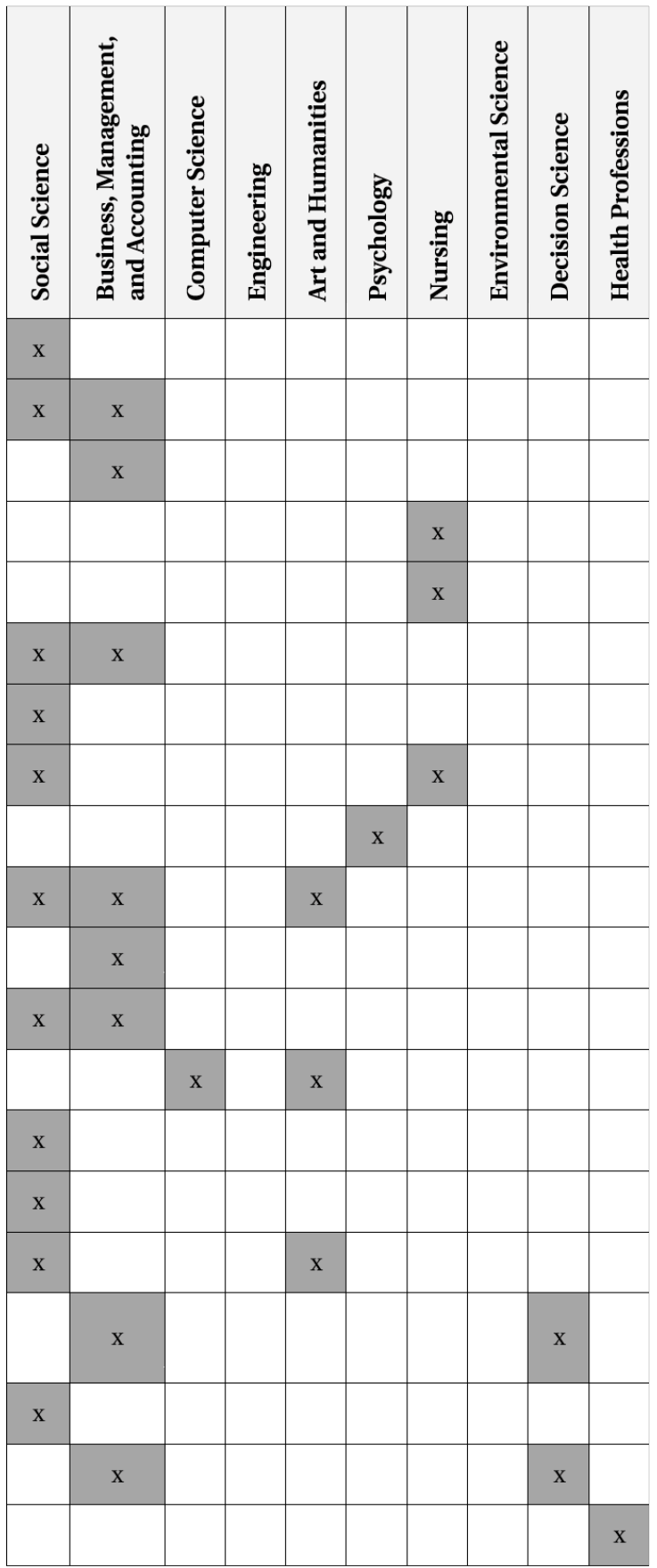




\section{A Discipline-Spanning Overview of Action Research and Its Implications for Technology and Innovation Management Matthias Guertler, Nathalie Sick, and Anton Kriz}

Notably, these more dedicated action research journals are not amongst the most influential journals in terms of citations and impact factor. The highest number of citations per paper (number of total citations "TC" divided by number of total papers "TP") is held by the Journal of Social Issues (84 TC/TP) with the seminal paper by Kurt Lewin from 1946 with 1796 citations, followed by Social Science and Medicine (65 TC/TP), Human Relations (62 TC/TP), and the International Journal of Operations and Production Management (62 TC/TP). Similar to the most productive journals, the most influential ones are attached to social science and business, management, and accounting, but also to arts and humanities and decision science. Underlining the interdisciplinary nature of action research, many journals show affiliations to more than one discipline.

However, no TIM journal can be found amongst the most productive or influential journals. Two findings need to be highlighted in this context: On the one hand, there are very productive dedicated action research journals that focus on action research as a research method. On the other hand, highly influential discipline-specific journals are identified without a particular focus on action research. Despite the inferiority in numbers, it seems that a discussion on the application as well as advantages and challenges of action research is happening on a discipline-specific level. One reason might be that the discussion on when and how to apply action research needs to consider the characteristics and boundary conditions of each discipline, which require and are crucial for discipline-specific action research models.

\section{The most influential articles}

Sorted by average annual citations, Table 3 presents the most influential articles on action research. The work of Israel and co-authors (1998) on community-based research to improve public health is a standout with the highest number of annual citations (125 TC/year). What is striking about the remainder of the articles is the high representation of management and, more specifically, TIM-related topics. In light of the fact that no TIM journal was found amongst the most productive outlets for action research, TIM-related topics and authors seem to be active but are publishing in different domains. "Action Design Research" by Sein and co-authors (2011) is a seminal work published in MIS Quarterly in the management information systems domain. Kaplan's (1999) "Innovation Action Research" is distributed through the Journal of Management Accounting Research in the accounting domain while Linder and Williander's (2017) "Circular Business Model Innovation" is published in
Business Strategy and the Environment in the strategic management domain. More distantly related examples from general management are the study by Kieser and Leiner (2009) on "Why the rigor-relevance in management gap in is unbridgeable" in the Journal of Management Studies or Luescher and Lewis (2008) on "Organizational change and managerial sense making" in the Academy of Management Journal. This dispersion of TIM-related action research articles across non-TIM outlets reinforces the need for a disciplinespanning analysis of action research, in order to build a deep understanding of a successful application and the benefits and challenges of action research for TIM.

\section{The most productive and influential authors (peer-} reviewed)

Nineteen authors with more than ten publications can be found in the action research arena, with David Coghlan the most productive with 44 papers (Table 4). Beyond being productive, he is one of the authors of "Action research for operations management", and in doing so laid the foundation for using action research in operations management (Table 3). Chris Huxham, with a total of 11 contributions, is the most cited and influential author with 112 citations per paper. Reviewing the disciplines associated with the authors' publications in Scopus, it is striking that all authors are linked to social science, the originating and dominant discipline shaping action research. Moreover, most authors have published in a wider variety of disciplines, including medicine; business management, and accounting; arts and humanities; as well as psychology. In contrast, only two authors - John Elliott and Karen Goognough - show a discipline-specific profile with their respective focus on social science and psychology.

\section{The most productive and influential institutions and countries}

The analysis of the most productive and influential institutions and countries reveals that Australia and the UK show strong streams of action research with eight and respectively six institutions in the TOP 20 (Table 5). Major contributions are also available from Brazil, Canada, Denmark, Ireland, and Sweden. Compared to other areas, the country profile seems to be quite specific, with powerful streams of action research in a small number of countries. Interestingly, the research output does not show a high variety between 72 contributions for first ranked Monash University in Australia compared to 51 contributions of Goteborgs Universitet in Sweden on rank 20. While citations per paper are also rather equally distributed, the University of 


\section{A Discipline-Spanning Overview of Action Research and Its Implications for Technology and Innovation Management Matthias Guertler, Nathalie Sick, and Anton Kriz}

Table 3. Overview of most influential articles

\begin{tabular}{|c|c|c|c|c|c|c|}
\hline$\#$ & Authors & Year & Title & Cited By & $\begin{array}{l}\text { Avg. Annual } \\
\text { Citations }\end{array}$ & Journal \\
\hline 1 & $\begin{array}{l}\text { Israel, B.A., Schulz, A.J., } \\
\text { Parker, E.A., Becker, A.B. }\end{array}$ & 1998 & $\begin{array}{l}\text { Review of community-based research: } \\
\text { Assessing partnership approaches to } \\
\text { improve public health }\end{array}$ & 2507 & 125.4 & $\begin{array}{l}\text { Annual Review of Public } \\
\text { Health }\end{array}$ \\
\hline 2 & $\begin{array}{l}\text { Sein, M.K., Henfridsson, } \\
\text { O., Purao, S., Rossi, M., } \\
\text { Lindgren, R. }\end{array}$ & 2011 & Action design research & 555 & 79.3 & $\begin{array}{l}\text { MIS Quarterly: } \\
\text { Management } \\
\text { Information Systems }\end{array}$ \\
\hline 3 & Montero, I., León, O.G. & 2007 & $\begin{array}{l}\text { A guide for naming research studies in } \\
\text { Psychology }\end{array}$ & 582 & 52.9 & $\begin{array}{l}\text { International Journal of } \\
\text { Clinical and Health } \\
\text { Psychology }\end{array}$ \\
\hline 4 & $\begin{array}{l}\text { Linder, M., Williander, } \\
\text { M. }\end{array}$ & 2017 & $\begin{array}{l}\text { Circular business model innovation: } \\
\text { Inherent uncertainties }\end{array}$ & 47 & 47.0 & $\begin{array}{l}\text { Business Strategy and } \\
\text { the Environment }\end{array}$ \\
\hline 5 & $\begin{array}{l}\text { Shirk, J.L., Ballard, H.L., } \\
\text { Wilderman, C.C., } \\
\text { Phillips, T., et al. }\end{array}$ & 2012 & $\begin{array}{l}\text { Public participation in scientific research: A } \\
\text { framework for deliberate design }\end{array}$ & 261 & 43.5 & Ecology and Society \\
\hline 6 & Bock, G.W., Kim, Y.-G. & 2002 & $\begin{array}{l}\text { Breaking the myths of rewards: An } \\
\text { exploratory study of attitudes about } \\
\text { knowledge sharing }\end{array}$ & 681 & 42.6 & $\begin{array}{l}\text { Information Resources } \\
\text { Management Journal } \\
\text { (IRMJ) }\end{array}$ \\
\hline 7 & Catalani, C., Minkler, M. & 2010 & $\begin{array}{l}\text { Photovoice: A review of the literature in } \\
\text { health and public health }\end{array}$ & 310 & 38.8 & $\begin{array}{l}\text { Health Education and } \\
\text { Behavior }\end{array}$ \\
\hline 8 & $\begin{array}{l}\text { Jagosh, J., MacAulay, } \\
\text { A.C., Pluye, P., Salsberg, } \\
\text { J., et al. }\end{array}$ & 2012 & $\begin{array}{l}\text { Uncovering the benefits of participatory } \\
\text { research: Implications of a realist review for } \\
\text { health research and practice }\end{array}$ & 216 & 36.0 & Milbank Quarterly \\
\hline 9 & $\begin{array}{l}\text { Geels, F.W., Berkhout, F., } \\
\text { Van Vuuren, D.P. }\end{array}$ & 2016 & $\begin{array}{l}\text { Bridging analytical approaches for low- } \\
\text { carbon transitions }\end{array}$ & 71 & 35.5 & Nature Climate Change \\
\hline 10 & Cornwall, A., Jewkes, R. & 1995 & What is participatory research? & 809 & 35.2 & $\begin{array}{l}\text { Social Science and } \\
\text { Medicine }\end{array}$ \\
\hline 11 & $\begin{array}{l}\text { Coughlan, P., Coghlan, } \\
\text { D. }\end{array}$ & 2002 & Action research for operations management & 537 & 33.6 & $\begin{array}{l}\text { International Journal of } \\
\text { Operations and } \\
\text { Production } \\
\text { Management }\end{array}$ \\
\hline 12 & *Kaplan, R. S. & 1998 & $\begin{array}{l}\text { Innovation action research: creating new } \\
\text { management theory and practice }\end{array}$ & $668^{*}$ & 33.4 & $\begin{array}{l}\text { Journal of Management } \\
\text { Accounting Research }\end{array}$ \\
\hline 13 & Myers, M.D. & 1997 & Qualitative research in information systems & 688 & 32.8 & $\begin{array}{l}\text { MIS Quarterly: } \\
\text { Management } \\
\text { Information Systems }\end{array}$ \\
\hline 14 & $\begin{array}{l}\text { Lüscher, L.S., Lewis, } \\
\text { M.W. }\end{array}$ & 2008 & $\begin{array}{l}\text { Organizational change and managerial } \\
\text { sensemaking: Working through paradox }\end{array}$ & 326 & 32.6 & $\begin{array}{l}\text { Academy of } \\
\text { Management Journal }\end{array}$ \\
\hline 15 & $\begin{array}{l}\text { Kurtz, C.F., Snowden, } \\
\text { D.J. }\end{array}$ & 2003 & $\begin{array}{l}\text { The new dynamics of strategy: Sense- } \\
\text { making in a complex and complicated } \\
\text { world }\end{array}$ & 489 & 32.6 & IBM Systems Journal \\
\hline 16 & Straub, D.W., Welke, R.J. & 1998 & $\begin{array}{l}\text { Coping with systems risk: Security planning } \\
\text { models for management decision making }\end{array}$ & 614 & 30.7 & $\begin{array}{l}\text { MIS Quarterly: } \\
\text { Management } \\
\text { Information Systems }\end{array}$ \\
\hline
\end{tabular}




\section{A Discipline-Spanning Overview of Action Research and Its Implications for Technology and Innovation Management Matthias Guertler, Nathalie Sick, and Anton Kriz}

Table 3 (continued). Overview of most influential articles

\begin{tabular}{|c|c|c|c|c|c|c|}
\hline \# & Authors & Year & Title & Cited By & $\begin{array}{l}\text { Avg. Annual } \\
\text { Citations }\end{array}$ & Journal \\
\hline 17 & $\begin{array}{l}\text { Avison, D.E., Lau, F., } \\
\text { Myers, M.D., Nielsen, } \\
\text { P.A. }\end{array}$ & 1999 & Action research & 581 & 30.6 & $\begin{array}{l}\text { Communications of the } \\
\text { ACM }\end{array}$ \\
\hline 18 & $\begin{array}{l}\text { Sedlmair, M., Meyer, M., } \\
\text { Munzner, T. }\end{array}$ & 2012 & $\begin{array}{l}\text { Design study methodology: Reflections } \\
\text { from the trenches and the stacks }\end{array}$ & 177 & 29.5 & $\begin{array}{l}\text { IEEE Transactions on } \\
\text { Visualization and } \\
\text { Computer Graphics }\end{array}$ \\
\hline 19 & $\begin{array}{l}\text { Chatti, M.A., Dyckhoff, } \\
\text { A.L., Schroeder, U., Thüs, } \\
\text { H. }\end{array}$ & 2012 & A reference model for learning analytics & 173 & 28.8 & $\begin{array}{l}\text { International Journal of } \\
\text { Technology Enhanced } \\
\text { Learning }\end{array}$ \\
\hline 20 & $\begin{array}{l}\text { Puhakainen, P., Siponen, } \\
\text { M. }\end{array}$ & 2010 & $\begin{array}{l}\text { Improving employees' compliance through } \\
\text { information systems security training: An } \\
\text { action research study }\end{array}$ & 216 & 27.0 & $\begin{array}{l}\text { MIS Quarterly: } \\
\text { Management } \\
\text { Information Systems }\end{array}$ \\
\hline 21 & $\begin{array}{l}\text { Jacobs, S., Dendoncker, } \\
\text { N., Martín-López, B., } \\
\text { Barton, D.N., Gomez- } \\
\text { Baggethun, E., et al. }\end{array}$ & 2016 & $\begin{array}{l}\text { A new valuation school: Integrating diverse } \\
\text { values of nature in resource and land use } \\
\text { decisions }\end{array}$ & 52 & 26.0 & Ecosystem Services \\
\hline 22 & Sebanz, N., Knoblich, G. & 2009 & $\begin{array}{l}\text { Prediction in joint action: What, when, and } \\
\text { where }\end{array}$ & 231 & 25.7 & $\begin{array}{l}\text { Topics in Cognitive } \\
\text { Science }\end{array}$ \\
\hline 23 & $\begin{array}{l}\text { Baum, F., MacDougall, } \\
\text { C., Smith, D. }\end{array}$ & 2006 & Participatory action research & 303 & 25.3 & $\begin{array}{l}\text { Journal of Epidemiology } \\
\text { and Community Health }\end{array}$ \\
\hline 24 & $\begin{array}{l}\text { Shannon, K., Kerr, T., } \\
\text { Allinott, S., Chettiar, J., } \\
\text { Shoveller, J., Tyndall, } \\
\text { M.W. }\end{array}$ & 2008 & $\begin{array}{l}\text { Social and structural violence and power } \\
\text { relations in mitigating HIV risk of drug- } \\
\text { using women in survival sex work }\end{array}$ & 252 & 25.2 & $\begin{array}{l}\text { Social Science and } \\
\text { Medicine }\end{array}$ \\
\hline 25 & $\begin{array}{l}\text { Baskerville, R.L., Wood- } \\
\text { Harper, A.T. }\end{array}$ & 1996 & $\begin{array}{l}\text { A critical perspective on action research as a } \\
\text { method for information systems research }\end{array}$ & 550 & 25.0 & $\begin{array}{l}\text { Journal of Information } \\
\text { Technology }\end{array}$ \\
\hline 26 & Lewin, K. & 1946 & Action research and minority problems & 1792 & 24.9 & Journal of Social Issues \\
\hline 27 & Wang, C.C. & 1999 & $\begin{array}{l}\text { Photovoice: A participatory action research } \\
\text { strategy applied to women's health }\end{array}$ & 469 & 24.7 & $\begin{array}{l}\text { Journal of Women's } \\
\text { Health }\end{array}$ \\
\hline 28 & Case, J.M., Light, G. & 2011 & $\begin{array}{l}\text { Emerging methodologies in engineering } \\
\text { education research }\end{array}$ & 172 & 24.6 & $\begin{array}{l}\text { Journal of Engineering } \\
\text { Education }\end{array}$ \\
\hline 29 & $\begin{array}{l}\text { Davison, R.M., } \\
\text { Martinsons, M.G., Kock, } \\
\text { N. }\end{array}$ & 2004 & Principles of canonical action research & 344 & 24.6 & $\begin{array}{l}\text { Information Systems } \\
\text { Journal }\end{array}$ \\
\hline 30 & $\begin{array}{l}\text { Kohler, T., Fueller, J., } \\
\text { Matzler, K., Stieger, D. }\end{array}$ & 2011 & $\begin{array}{l}\text { Co-creation in virtual worlds: The design of } \\
\text { the user experience }\end{array}$ & 165 & 23.6 & $\begin{array}{l}\text { MIS Quarterly: } \\
\text { Management } \\
\text { Information Systems }\end{array}$ \\
\hline 31 & Kieser, A., Leiner, L. & 2009 & $\begin{array}{l}\text { Why the rigour-relevance gap in } \\
\text { management research is unbridgeable }\end{array}$ & 212 & 23.6 & $\begin{array}{l}\text { Journal of Management } \\
\text { Studies }\end{array}$ \\
\hline
\end{tabular}




\section{A Discipline-Spanning Overview of Action Research and Its Implications for Technology and Innovation Management Matthias Guertler, Nathalie Sick, and Anton Kriz}

Table 4. The most productive and influential authors

\begin{tabular}{|c|c|c|c|c|c|c|}
\hline & Author & 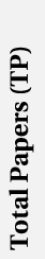 & 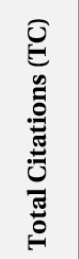 & TC/TP & $\mathbf{h}$ & Organization \\
\hline 1 & Coghlan, David & 44 & 1462 & 33.2 & 19 & $\begin{array}{l}\text { Trinity College Dublin, } \\
\text { Ireland }\end{array}$ \\
\hline 2 & Flood, Robert Louis & 23 & 157 & 6.8 & 15 & $\begin{array}{l}\text { Norges Teknisk- } \\
\text { Naturvitenskapelige } \\
\text { Universitet, Norway }\end{array}$ \\
\hline 3 & Kock, Ned Florencio & 20 & 831 & 41.6 & 30 & $\begin{array}{l}\text { Texas A and M International } \\
\text { University, USA }\end{array}$ \\
\hline 4 & Eilks, Ingo & 17 & 326 & 19.2 & 17 & $\begin{array}{l}\text { University of Bremen, } \\
\text { Germany }\end{array}$ \\
\hline 5 & Zuber-Skerritt, Ortrun & 17 & 403 & 23.7 & 13 & Griffith University, Australia \\
\hline 6 & Koch, Tina & 16 & 454 & 28.4 & 28 & $\begin{array}{l}\text { University of Newcastle, } \\
\text { Australia }\end{array}$ \\
\hline 7 & Elliott, John & 13 & 316 & 24.3 & 16 & $\begin{array}{l}\text { University of East Anglia, } \\
\text { UK }\end{array}$ \\
\hline 8 & Mathiassen, Lars & 13 & 487 & 37.5 & 29 & $\begin{array}{l}\text { Georgia State University, } \\
\text { USA }\end{array}$ \\
\hline 9 & Robinson, Andrew Lyle & 13 & 150 & 11.5 & 18 & $\begin{array}{l}\text { University of Tasmania, } \\
\text { Australia }\end{array}$ \\
\hline 10 & Dick, Bob & 12 & 241 & 20.1 & 8 & $\begin{array}{l}\text { Southern Cross University, } \\
\text { Australia }\end{array}$ \\
\hline 11 & Lykes, M. Brinton M. & 12 & 213 & 17.8 & 15 & Boston College, USA \\
\hline 12 & Wood, Lesley A. & 13 & 36 & 2.8 & 6 & $\begin{array}{l}\text { North-West University, } \\
\text { South Africa }\end{array}$ \\
\hline 13 & Brydon-Miller, Mary L. & 11 & 458 & 41.6 & 8 & University of Louisville, USA \\
\hline 14 & Fine, Michelle & 11 & 232 & 21.1 & 32 & $\begin{array}{l}\text { The Doctorate-Granting } \\
\text { Institution of the City } \\
\text { University of New York, USA }\end{array}$ \\
\hline 15 & Goodnough, Karen & 11 & 127 & 11.5 & 8 & $\begin{array}{l}\text { Memorial University of } \\
\text { Newfoundland, Canada }\end{array}$ \\
\hline 16 & Haslett, Tim & 11 & 94 & 8.5 & 8 & $\begin{array}{l}\text { University of Technology } \\
\text { Sydney, Australia }\end{array}$ \\
\hline 17 & Huxham, Chris & 11 & 1227 & 111.5 & 23 & $\begin{array}{l}\text { University of Strathclyde, } \\
\text { UK }\end{array}$ \\
\hline 18 & Reason, Peter & 11 & 458 & 41.6 & 14 & University of Bath, UK \\
\hline 19 & Spirig, Rebecca & 11 & 47 & 4.3 & 14 & $\begin{array}{l}\text { UniversitatsSpital Zurich, } \\
\text { Switzerland }\end{array}$ \\
\hline
\end{tabular}

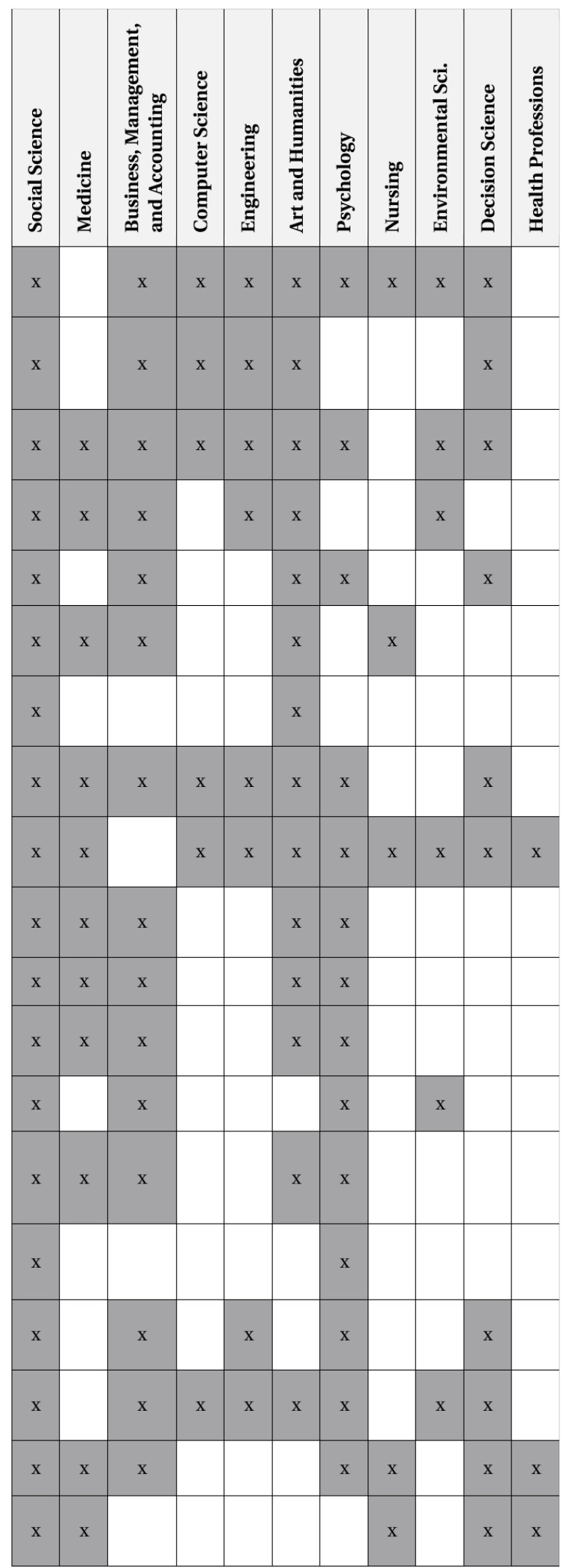




\section{A Discipline-Spanning Overview of Action Research and Its Implications for Technology and Innovation Management Matthias Guertler, Nathalie Sick, and Anton Kriz}

Table 5. Overview of institutions and countries

\begin{tabular}{|c|c|c|c|c|c|}
\hline & University / Institution & $\mathbf{T P}$ & TC & TC/TP & Country \\
\hline 1 & Monash University & 72 & 1449 & 20.1 & Australia \\
\hline 2 & The University of British Columbia & 71 & 1542 & 21.7 & Canada \\
\hline 3 & Queensland University of Technology & 71 & 830 & 11.7 & Australia \\
\hline 4 & Griffith University & 67 & 990 & 14.8 & Australia \\
\hline 5 & University of Manchester & 65 & 1651 & 25.4 & UK \\
\hline 6 & University of Queensland & 63 & 868 & 13.8 & Australia \\
\hline 7 & University of South Australia & 60 & 580 & 9.7 & Australia \\
\hline 8 & Universidade de Sao Paulo & 58 & 281 & 4.8 & Brazil \\
\hline 9 & University of Sheffield & 57 & 990 & 17.4 & UK \\
\hline 10 & University of Toronto & 57 & 1225 & 21.5 & Canada \\
\hline 11 & University of Technology Sydney & 56 & 512 & 9.1 & Australia \\
\hline 12 & Aalborg Universitet & 54 & 811 & 15.0 & Denmark \\
\hline 13 & University of Melbourne & 54 & 797 & 14.8 & Australia \\
\hline 14 & Curtin University & 54 & 291 & 5.4 & Australia \\
\hline 15 & Trinity College Dublin & 53 & 1531 & 28.9 & Ireland \\
\hline 16 & University of Leeds & 53 & 996 & 18.8 & UK \\
\hline 17 & University of Salford & 52 & 2164 & 41.6 & UK \\
\hline 18 & Loughborough University & 51 & 917 & 18.0 & UK \\
\hline 19 & Open University & 51 & 781 & 15.3 & UK \\
\hline 20 & Goteborgs Universitet & 51 & 1028 & 20.2 & Sweden \\
\hline
\end{tabular}

\begin{tabular}{|c|c|c|}
\hline & Country & TP \\
\hline 1 & USA & 2339 \\
\hline 2 & UK & 2203 \\
\hline 3 & Australia & 1168 \\
\hline 4 & Canada & 656 \\
\hline 5 & Brazil & 340 \\
\hline 6 & Sweden & 306 \\
\hline 7 & Spain & 291 \\
\hline 8 & South Africa & 282 \\
\hline 9 & Netherlands & 267 \\
\hline 10 & New Zealand & 244 \\
\hline 11 & Finland & 227 \\
\hline 12 & Italy & 205 \\
\hline 13 & Norway & 194 \\
\hline 14 & Germany & 191 \\
\hline 15 & Ireland & 179 \\
\hline 16 & France & 172 \\
\hline 17 & Denmark & 165 \\
\hline 18 & Thailand & 125 \\
\hline 19 & Taiwan & 124 \\
\hline 20 & China & 118 \\
\hline
\end{tabular}




\section{A Discipline-Spanning Overview of Action Research and Its Implications for Technology and Innovation Management Matthias Guertler, Nathalie Sick, and Anton Kriz}

Salford in the UK is the most influential institution with 42 citations per paper followed by Trinity College Dublin, Ireland, with 29. Although the USA show the highest number of articles per country (2339 articles), no US university/institution is amongst the TOP 20 universities. From a country perspective, the TOP 3 countries show a big lead to all following countries of the TOP 20.

\section{The most productive and influential institutions and countries}

Figure 2 presents the key institutions in the highlighted most active countries along with their most dominant disciplines. Social science and business, management, and accounting are well represented in the most active countries. Nursing, as well as arts and humanities, follow in the UK, Australia, and Canada, with the UK focusing on computer science in contrast to psychology in Australia and Canada. Action research in the US is positioned stronger in psychology, arts and humanities, and computer science. Brazil, in contrast, shows a slightly different profile. While social sciences and busi- ness, management, and accounting are less dominant, action research is also robust in engineering and decision science.

\section{Synthesis of findings}

The bibliometric analysis revealed that action research is applied in a variety of disciplines, with social science clearly the strongest and business, management, and accounting (including TIM) following in second. The first and seminal publication by Lewin (1946) started the action research journey with publication activity often exhibiting long incubation phases. Publications on action research gained real momentum after the turn of the millennium with the steepest increases in engineering. In addition to disciplinary streams, action research also shows particular strength in specific countries such as the USA, the UK, and Australia - although it might be interesting to investigate the influence of different cultural publication traditions onto these numbers. It is striking that the most productive journals (total number of articles) publishing action research are

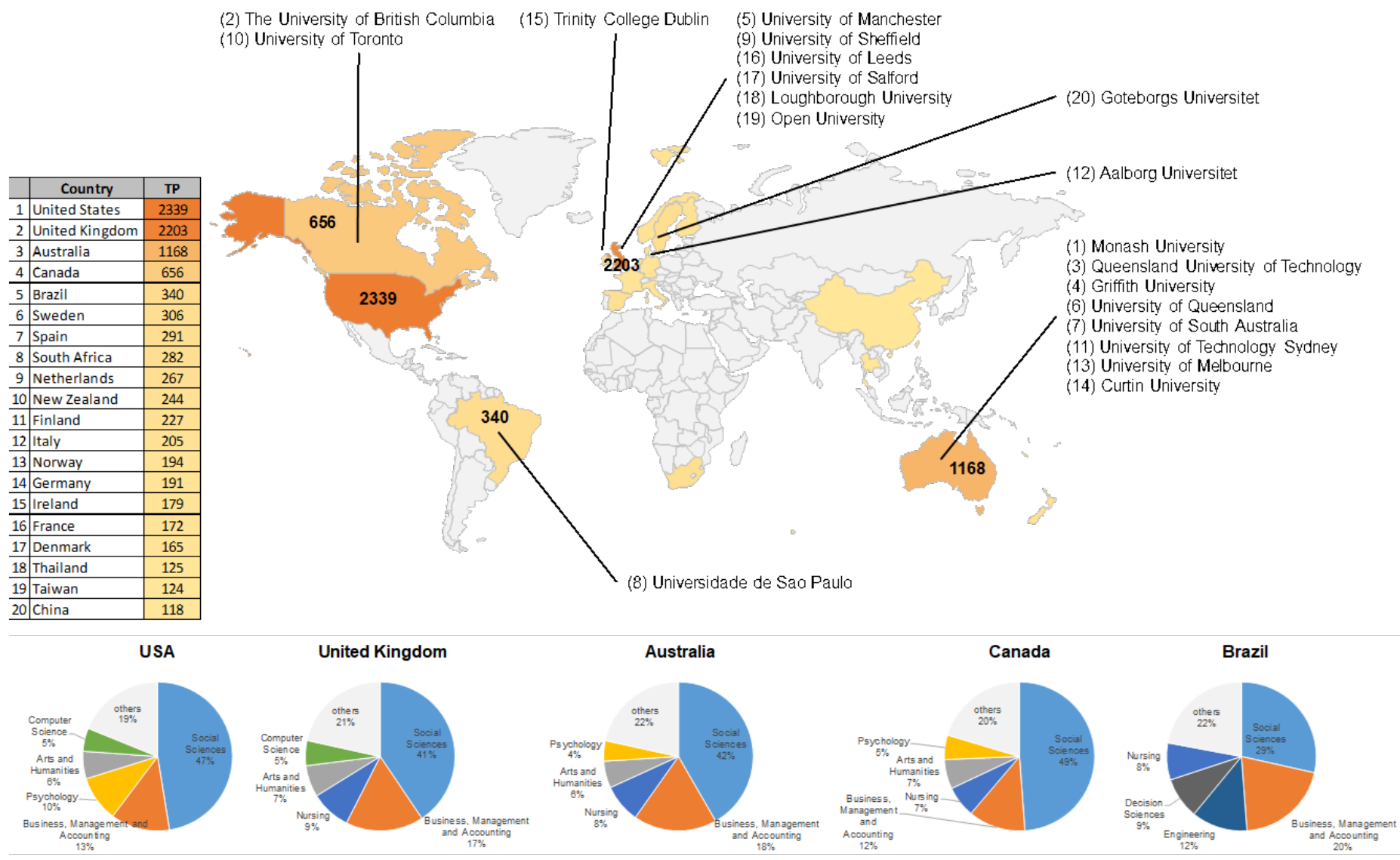

Figure 2. Global overview of most productive and influential institutions and authors 


\section{A Discipline-Spanning Overview of Action Research and Its Implications for Technology and Innovation Management Matthias Guertler, Nathalie Sick, and Anton Kriz}

discipline-spanning and action research specific, while the most influential journals as well as articles (impact factor, citations per article) are published in disciplinespecific journals. Although TIM journals are not represented among the most productive or influential journals, TIM-related topics hold a fair share of the most influential articles in the action research domain. Most of these articles were published in journals from other disciplines, which aligns with the small number of 19 dedicated action research articles in TIM or innovation management in general. This might indicate that researchers interested in publishing action research articles aim for journals in disciplines, where action research is more accepted. This stresses the need for a discipline-spanning analysis to understand the benefits and challenges of action research in TIM for a successful application. A subsequent qualitative analysis of action research literature reveals the benefits and challenges of action research for TIM.

\section{Action Research Benefits and Challenges for Technology and Innovation Management}

Following on from the bibliometric analysis, it became clear that action research approaches are scattered throughout a wide variety of disciplines, from which a TIM-specific model is yet to emerge. The specific developments of action research streams in different disciplines also highlighted the need for tailored approaches to account for the varying boundary conditions and requirements in each discipline. The following qualitative literature analysis aims to take an initial step towards a TIM-specific action research approach by discussing the benefits and challenges of action research highlighted in the different disciplinary streams from a TIM perspective (Table 6). For this purpose, the central elements of TIM mentioned in the introduction are related to the respective benefits and challenges of action research:

- Socio-technical character of innovation problems and systems

- Multi-faceted character of innovations and innovators

- Variety of innovation management stakeholders

- High levels of uncertainty around innovations

This discussion can serve as a foundation for developing a TIM-tailored action research approach based on insights and learnings from a variety of other disciplines.

\section{Benefits of action research}

Action research has an interdisciplinary character, which helps to overcome established discipline structures and "silos". This is necessary to deeply understand socio-technical innovation systems and different dimensions of innovators (Levin, 2012), which are characteristic of TIM. In this respect, the non-linear but iterative action research process spiraling around inherent learning and knowledge development (Herr \& Anderson, 2005; Lewin, 1946) helps to explore TIM problems with a high level of technological and human uncertainty and ambiguity.

Action research allows for the advancement of theory while solving real-world problems, as does TIM (Hult \& Lennung, 1980; Levin, 2012; Mumford, 2001; Ottosson, 2003). A central advantage is the capability of combining rigour and relevance as complementary rather than antitheses (Flyvbjerg \& Sampson, 2011; Levin, 2012; Mumford, 2001) with validity, depth, and a holistic research understanding identified as not necessarily compromising rigour (Eikeland, 2006). This overcomes the risk of basic or applied research being isolated and irrelevant (Flyvbjerg \& Sampson, 2011; Levin, 2012; Ottosson, 2003) including direct evaluation of research results and theories as well as in-depth insights around TIM-related company processes and structures (Susman \& Evered, 1978).

Like other research techniques, action research requires systematic fact finding, but it has particular strengths in aiding and supporting goal-directed actions for specific organizational contexts (Hult \& Lennung, 1980; Kaplan, 1998; Theodorakopoulos et al., 2012). Socio-technical systems (Levin, 2012), including organizational culture and behaviour as well as broad ranges of interdisciplinary stakeholders (Séror, 1996), demand rigour but also need to be reflective of the changing and ongoing realities. In a complex sociotechnical TIM context with different dimensions of innovators, action research, with its human-centered and client-empowering approach, enables deeper access and utilizes not only explicit but also implicit stakeholder knowledge and feedback on new approaches, interpretation of data, and identified research "anomalies", meaning unexpected findings (Eikeland, 2006; Flyvbjerg \& Sampson, 2011; Hult \& Lennung, 1980; Swann, 2002). These "anomalies" are common in highly uncertain TIM systems. Their systematic investigation sometimes might create better questions and lead to better research. This can reveal underlying cause-effect chains of phenomena and is the basis of improved understanding of TIM theory and models (Susman \& Evered, 1978). 


\section{A Discipline-Spanning Overview of Action Research and Its Implications for Technology and Innovation Management Matthias Guertler, Nathalie Sick, and Anton Kriz}

Lewin (1946) and Arens-Fischer and colleagues (2010) noted the importance of more applied theory when human agency is involved. This potentially generates new theory through practice but also incorporates "active evaluation" of both the "researched" and "researchers" (Brydon-Miller et al., 2003). Closely working with clients also allows for a better understanding of organizational group dynamics and underlying power structures, interests, and interdependencies (cf. Arieli et al., 2009; Flyvbjerg \& Sampson, 2011; Ottosson, 2003). Competence building is a real advantage of action research in TIM since clients are often beneficiaries of training insights - sometimes direct or alternatively through osmosis - while also engaging in the problem-solving process. This has spill-over advantages with potential to increase client commitment. Building trust sets the basis for more sustaining cooperative efforts between academia and clients and inevitably helps transition TIM knowledge and approaches into practice (Kaplan, 1998).

\section{Challenges of action research}

Action research has potential for "shining a light" on real-world and real-time business and industry nuances, yet it still has important challenges. A pertinent issue hampering such a method relates to limited precision in interventions including sub-optimal or non-existent research and research design quality (cf. van Aken, 2004) with increased relevance not sufficient in compensating for poor research design (Eden \& Huxham, 1996; Levin, 2012). Applied TIM research projects often bear the risk of focusing too strongly on a technology development part and neglecting an overarching methodological perspective. Like commensurate methods and designs, action research requires deep expertise and adequate verification and justification of empirical efforts. An inordinate focus around "action", particularly of practitioners consulting in "the field" (e.g. McNiff \& Whitehead, 2003; Starkey et al., 2009), without proper regard to "research" is arguably action research's most contentious challenge.

Another challenge with this form of application-oriented research is a need for researchers to have skilled facilitation, problem solving, and communicative capacity beyond less invasive TIM research methods such as surveys or interviews (cf. Hult \& Lennung, 1980; McGivern \& Fineman, 1983) with such expertise notably not easily acquired (Snoeren et al., 2012). Aligning interests of clients and researchers is a key challenge and is far from trivial. Action researchers exploring sociotechnical TIM problems with high levels of uncertainty also need to be aware and open to unforeseen events and unanticipated findings, which might contradict their prior experience (Hodgkinson \& Rousseau, 2009). This requires appropriate adjustments with trial and error and added time and potential additional resources (Burnes, 2004). Changing course requires researcher resilience due to a lack of a "neat step-by-step approach" (Herr \& Anderson, 2005) and loss of control over variables (McGivern \& Fineman, 1983). Interdependencies within socio-technical innovation systems are a crucial challenge that concomitantly makes prediction and specificity difficult (Burnes, 2004; Lewin, 1947; McGivern \& Fineman, 1983).

Effort, time, and cost of embedding researchers into a socio-technical innovation system with various innovators and stakeholders is a major challenge. Levin (2012) argues that this, along with a usually interdisciplinary character, adds to the complexity of a project. There is also a risk of getting lost in the problem-solving process (Hult \& Lennung, 1980) and getting too close to clients and stakeholders (Snoeren et al., 2012). Awareness of interests, power, and political games becomes critical where researchers are variously involved or embedded in these systems (Mumford, 2001). The variety of innovators and stakeholders requires a careful but challenging selection of willing and suitable project partners and definition of appropriate levels of involvement (Hult \& Lennung, 1980). Fincham and Clark (2009) subsequently argue "research" and "practice" are two distinctive domains with closeness often compromising independence with thorough research techniques actually the responsibility of academics, not practitioners.

Clearly, specialist social exchange competences such as building trust and avoiding controversies require experience and adequate capability (Arieli et al., 2009; Snoeren et al., 2012; Wicks \& Reason, 2009). Nurturing researchers with action research curiosity and capacity with skills in problem solving as well as methodical and social competences is important. It may mean, like anthropologists and ethnographers, TIM researchers need to be willing to "live in the field" (Levin, 2012: 134; McGivern \& Fineman, 1983; Susman \& Evered, 1978). Systematically reflecting on and challenging one's own research and context dependencies to avoid biases are crucial but also fundamental (Levin, 2012; Snoeren et al., 2012; Starkey et al., 2009). Action research also requires the communication of research findings to different communities and TIM stakeholders. Although it is essential, it requires additional effort and experience about how to purposefully present these findings to 


\section{A Discipline-Spanning Overview of Action Research and Its Implications for Technology and Innovation Management Matthias Guertler, Nathalie Sick, and Anton Kriz}

each community (Eikeland, 2006; Hult \& Lennung, 1980; Levin, 2012). In terms of academic publications, action research papers often struggle with word restrictions of journals as a detailed and transparent description of the study and its research design can be quite lengthy. Table 6 summarizes the key arguments above based on a substantive analysis and synthesis of the action research literature in relationship to TIM.

\section{Reflective Conclusion}

The study at hand contributes a quantitative disciplinespanning analysis of different action research streams across the globe as well as a qualitative analysis of benefits and challenges of action research for TIM. First, the close relationship between theory and practice in action research proves to be particularly beneficial to tackle socio-technical innovation problems and therefore bridge the rigour-relevance gap in TIM. However, in comparison to further TIM research methods, additional effort is required to prove the rigour and validity of the method. Second, the interdisciplinary nature of action research aligns well with the multi-faceted character of innovation and helps to span boundaries between disciplinary silos in TIM. On the other hand, TIM researchers need to be prepared and trained in how to take advantage of action research for boundaryspanning purposes. Third, the human-centred and client-empowering action research approach enables the inclusion of the TIM-specific wide variety of stakeholders and the continuous balancing of their interests and requirements. On the flip side, TIM researchers have the responsibility to ensure sufficient closeness between stakeholders and researchers, while maintaining independent research at the same time - which is less of an issue when using other TIM research methods. Fourth, the iterative action research process supports exploration in highly uncertain TIM environments, while the frequent pivots in action research projects are more likely to lead to more disruptive theory extensions. However, there is no TIM-specific action research methodology available that guides TIM researchers through the iterative steps of the action research process. In summary, these insights provide recommendations and avenues for further research on where, when, and how to purposefully use action research in TIM:

- The discipline-spanning bibliometric analysis in this study could be enlarged by using additional measures to identify linkages between TIM and other disciplines, such as co-citations or keyword analyses.
- A detailed qualitative analysis of TIM-specific contributions across journals from different disciplines could add to the current analysis and identify additional strengths and "white spots" of action research in TIM to date.

- Future research should further investigate the potential bidirectional dependencies between a limited acceptance of action research in TIM-related journals and the high number of TIM-related publications in journals from other disciplines. This also includes an analysis of if, where, and how actual action research articles might have been published under a different label. The analysis of the most productive and influential journals can also help researchers to select the most suitable outlet for their publications.

- The research design and study description of action research projects can often be quite lengthy and in conflict with word limitations of journals. The development of a standardized way of describing action research projects could help to save space while ensuring a transparent research description.

- Due to the combination of technological and social aspects of TIM, future studies could explore how action research can be used in interdisciplinary joint projects in combination with other research methodologies. An example might be the development of a product-service system, which brings together technical subject matter experts for developing the system and TIM as well as engineering design researchers exploring the overarching innovation processes.

- Another interesting field of research is how practitioners and their expertise can be utilized best to yield indepth insights and co-create knowledge to advance the TIM body of knowledge. This deep research "in the field" requires further investigations into how rigour and relevance can be combined most efficiently in a TIM environment.

- In the context of the capability building through action research, the link and potential synergies to action learning should be explored in the future. This could benefit teaching and practitioner training of TIM approaches as well as training of action researchers themselves.

- Based on the insights from the abovementioned research endeavours, a TIM-specific action research methodology needs to be developed. Although existing 


\section{A Discipline-Spanning Overview of Action Research and Its Implications for Technology and Innovation Management Matthias Guertler, Nathalie Sick, and Anton Kriz}

Table 6. Technology and innovation management specific benefits and challenges of action research

\begin{tabular}{|c|c|c|}
\hline & Benefits & Challenges \\
\hline $\begin{array}{l}\text { Socio-technical } \\
\text { character of TIM } \\
\text { problems and } \\
\text { contexts }\end{array}$ & $\begin{array}{l}\text { - Continuous alignment of theory and practice } \\
\text { creates holistic understanding of innovation as a } \\
\text { socio-technical system including its } \\
\text { organizational culture and behaviour (Kaplan, } \\
\text { 1998; Ottosson, 2003; Séror, 1996) } \\
\text { - Combination of rigour and relevance allows for } \\
\text { solving real-world TIM problems while } \\
\text { advancing TIM theory (Levin, 2012; Mumford, } \\
\text { 2001) } \\
\text { - Better diffusion of new TIM approaches in } \\
\text { practice to bridge the rigour-relevance gap in } \\
\text { TIM (Kaplan, 1998; Theodorakopoulos et al., } \\
\text { 2012; Yang \& Hsiao, 2009) }\end{array}$ & $\begin{array}{l}\text { - Effort, time, and cost to embed TIM researchers } \\
\text { into a socio-technical innovation system } \\
\text { (Sørensen, Mattsson, \& Sundbo, 2010) } \\
\text { - TIM researchers need to be willing to live “in the } \\
\text { field", which might contradict prior experience } \\
\text { (Levin, 2012; Susman \& Evered, 1978) } \\
\text { - Higher effort compared to further TIM research } \\
\text { methods to ensure and prove validity and rigour } \\
\text { of research (Coughlan \& Coghlan, 2002; Eikeland, } \\
\text { 2006) }\end{array}$ \\
\hline
\end{tabular}

Variety of TIM

stakeholders
- Competence building for clients and researchers (technical and social) for future TIM projects (for details: Arieli et al., 2009; Burnes, 2004; Hult \& Lennung, 1980)

- Human-centred and client-empowering approach enables access to tacit knowledge of TIM stakeholders (Eikeland, 2006; Flyvbjerg \& Sampson, 2011; Hult \& Lennung, 1980)

- Iterative and reflective action research approach allows for continuous balancing of TIM stakeholder needs
- Need to analyze TIM stakeholder networks, interests, and power requires experience and knowledge about individual needs of each community (Mumford, 2001)

- Requires purposeful processing and presentation for each TIM stakeholder community (Eikeland, 2006; Levin, 2012)

- Managing closeness, but also independence of research and practice as a responsibility of TIM researchers (Fincham \& Clark, 2009)
High levels of uncertainty around TIM
- Iterative action research process helps to explore highly uncertain and ambiguous TIM problems (Herr \& Anderson, 2005; Lewin, 1946)

- Alignment of the iterative action research process with the effectuation process in entrepreneurship and TIM (cf. Frederiksen \& Brem, 2017)

- Pivoting in action research projects allows for more disruptive theory improvements in highly uncertain TIM environments
- Iterative action research process and pivoting, including unexpected findings, might contradict TIM researchers' prior experience

- No TIM-specific action research methodology available providing a rigorous step-by-step process (Herr \& Anderson, 2005)

- A detailed description of a study's action research design can be lengthy and conflict with word limitations of journals 


\section{A Discipline-Spanning Overview of Action Research and Its Implications for Technology and Innovation Management Matthias Guertler, Nathalie Sick, and Anton Kriz}

action research methodologies from other disciplines such as "design science research" and "education action research" cannot directly be adopted, they should be carefully analyzed to use their experience and adapt suitable elements.

A better understanding of the application of action research in TIM along with new TIM-specific research methodologies has the potential to enhance academic standing in industry and strengthen the translation of research outcomes into practice. In general, it is crucial to avoid seeing and marketing action research as "the" new research paradigm for TIM. Instead, action research will be a valuable enhancement of the existing TIM research methodology toolbox.

\section{About the Authors}

Matthias Guertler is a Lecturer in Engineering Design at the University of Technology Sydney (UTS), Australia. He holds several degrees in Mechanical Engineering, Engineering Design, and Innovation Management from the Technical University of Munich, Germany. Matthias' transdisciplinary research is at the interface of engineering design and innovation management with a focus on managing open innovation. His action-research-based projects have been in close collaboration with various partners from industry and defense in Germany and Australia.

Nathalie Sick is a Senior Lecturer in Contemporary Technology Management in the Faculty of Engineering and IT at the University of Technology Sydney (UTS), Australia. Prior to joining UTS, she was a Young Research Group Leader with the Helmholtz Institute in Muenster, Germany, as well as a Junior Professor at the University of Muenster. She holds degrees in Management and Engineering as well as a $\mathrm{PhD}$ in Innovation Management. Her research revolves around innovation and technology management with a particular interest in disciplinespanning collaborations and industry convergence.

Anton Kriz is an Associate Professor at the Australian National University (ANU) specializing in the area of strategic innovation management and international marketing. His research focuses on advancing innovation management and innovation champions in enterprises, clusters, and regions through action research and action learning interventions. As part of the Research School of Management at ANU, he also teaches Innovation and New Venture Creation to executives at Tsinghua University in Beijing, China. 


\section{A Discipline-Spanning Overview of Action Research and Its Implications for Technology and Innovation Management Matthias Guertler, Nathalie Sick, and Anton Kriz}

\section{References}

Arens-Fischer, W., Duschek, S., Pfeiffer, S., Renvert, E., Ruping, B., \& Valcárcel, S. 2010. Aktionsforschung - Zeit für eine Neuentdeckung? Action Research - Time for a Rediscovery? In H. Jacobsen (Ed.), Innovationsstrategien jenseits traditionellen Managements. Beiträge zur ersten Tagung des Förderschwerpunkts des BMBF: 130-150. Stuttgart: Fraunhofer-Verlag.

Arieli, D., Friedman, V. J., \& Agbaria, K. 2009. The Paradox of Participation in Action Research. Action Research, 7(3): 263-290. https://doi.org/10.1177/1476750309336718

Benner, M. J., \& Tushman, M. L. 2015. Reflections on the 2013 Decade Award-"Exploitation, Exploration, and Process Management: The Productivity Dilemma Revisited" Ten Years Later. Academy of Management Review, 40(4): 497-514. https://doi.org/10.5465/amr.2015.0042

Broadus, R. N. 1987. Toward a Definition of "Bibliometrics". Scientometrics, 12(5-6): 373-379. https://doi.org/10.1007/BF02016680

Brydon-Miller, M., Greenwood, D., \& Maguire, P. 2003. Why Action Research? Action Research, 1(1): 9-28. https://doi.org/10.1177/14767503030011002

Burnes, B. 2004. Kurt Lewin and the Planned Approach to Change: A Re-appraisal. Journal of Management Studies, 41(6): 977-1002. https://doi.org/10.1111/j.1467-6486.2004.00463.x

Coughlan, P., \& Coghlan, D. 2002. Action Research for Operations Management. International Journal of Operations \& Production Management, 22(2): 220-240. https://doi.org/10.1108/01443570210417515

D’Alvano, L., \& Hidalgo, A. 2012. Innovation management Techniques and Development Degree of Innovation Process in Service Organizations. R\&D Management, 42(1): 60-70. https://doi.org/10.1111/j.1467-9310.2011.00663.x

Ding, Y., Rousseau, R., \& Wolfram, D. (Eds.) 2014. Measuring Scholarly Impact: Methods and Practice. Cham, Switzerland: Springer International Publishing.

Eden, C., \& Huxham, C. 1996. Action Research for Management Research. British Journal of Management, 7(1): 75-86. https://doi.org/10.1111/j.1467-8551.1996.tb00107.x

Eikeland, O. 2006. Validity in Action Research - Validity of Action Research. In K. A. Nielsen \& L. Svensson (Eds.), Action and Interactive Research - Beyond Practice and Theory: 193-240. Maastricht, Netherlands: Shaker.

Fincham, R., \& Clark, T. 2009. Introduction: Can We Bridge the Rigour-Relevance Gap? Journal of Management Studies, 46(3): 510-515.

https://doi.org/10.1111/j.1467-6486.2009.00834.x

Flyvbjerg, B., \& Sampson, S. 2011. Making Social Science Matter: Why Social Inquiry Fails and How It can Succeed Again (13th ed.). Cambridge: Cambridge University Press.

Frederiksen, D. L., \& Brem, A. 2017. How Do Entrepreneurs Think They Create Value?: A Scientific Reflection of Eric Ries? Lean Startup Approach. International Entrepreneurship and Management Journal, 13(1): 169-189. https://doi.org/10.1007/s11365-016-0411-x
Harzing, A.-W., \& Alakangas, S. 2016. Google Scholar, Scopus and the Web of Science: A Longitudinal and Cross-Disciplinary Comparison. Scientometrics, 106(2): 787-804. https://doi.org/10.1007/s11192-015-1798-9

Hauschildt, J., \& Salomo, S. 2007. Innovationsmanagement (4th ed.). Munich: Vahlen.

Herr, K., \& Anderson, G. L. 2005. The Action Research Dissertation: A Guide for Students and Faculty. Thousand Oaks, CA: SAGE Publications.

Hidalgo, A., \& Albors, J. 2008. Innovation Management Techniques and Tools: A Review from Theory and Practice. $R \& D$ Management, 38(2): 113-127. https://doi.org/10.1111/j.1467-9310.2008.00503.x

Hirsch, J. E. 2005. An Index to Quantify an Individual's Scientific Research Output. Proceedings of the National Academy of Sciences of the United States of America, 102(46): 16569-16572. https://doi.org/10.1073/pnas.0507655102

Hodgkinson, G. P., \& Rousseau, D. M. 2009. Bridging the RigourRelevance Gap in Management Research: It's Already Happening! Journal of Management Studies, 46(3): 534-546. https://doi.org/10.1111/j.1467-6486.2009.00832.x

Hult, M., \& Lennung, S.-Å. 1980. Towards a Definition of Action Research: A Note and Bibliography. Journal of Management Studies, 17(2): 241-250. https://doi.org/10.1111/j.1467-6486.1980.tb00087.x

Kaplan, R. S. 1998. Innovation Action Research: Creating New Management Theory and Practice. Journal of Management Accounting Research, 10: 89-118.

Kralisch, D., Ott, D., Lapkin, A. A., Yaseneva, P., Soete, W. de, Jones, M., Minkov, N., \& Finkbeiner, M. 2018. The Need for Innovation Management and Decision Guidance in Sustainable Process Design. Journal of Cleaner Production, 172: 2374-2388. https://doi.org/10.1016/j.jclepro.2017.11.173

Levin, M. 2012. Academic Integrity in Action Research. Action Research, 10(2): 133-149. https://doi.org/10.1177/1476750312445034

Lewin, K. 1946. Action Research and Minority Problems. Journal of Social Issues, 2(4): 34-46. https://doi.org/10.1111/j.1540-4560.1946.tb02295.x

Lewin, K. 1947. Frontiers in Group Dynamics. Human Relations, 1(1): $5-41$. https://doi.org/10.1177/001872674700100103

McGivern, C. K., \& Fineman, S. 1983. Research and Consultancy: Towards a Conceptual Synthesis. Journal of Management Studies, 20(4): 425-439. https://doi.org/10.1111/j.1467-6486.1983.tb00217.x

McNiff, J., \& Whitehead, J. 2003. Action Research: Principles and Practice (2nd ed.). London: Routledge Falmer.

Merigó, J. M., Gil-Lafuente, A. M., \& Yager, R. R. 2015. An Overview of Fuzzy Research with Bibliometric Indicators. Applied Soft Computing, 27: 420-433.

https://doi.org/10.1016/j.asoc.2014.10.035

Mumford, E. 2001. Advice for an Action Researcher. Information Technology \& People, 14(1): 12-27. https://doi.org/10.1108/09593840110384753 


\section{A Discipline-Spanning Overview of Action Research and Its Implications for Technology and Innovation Management Matthias Guertler, Nathalie Sick, and Anton Kriz}

Ottosson, S. 2003. Participation Action Research: A Key to Improved Knowledge of Management. Technovation, 23(2): 87-94. https://doi.org/10.1016/S0166-4972(01)00097-9

Pritchard, A. 1969. Statistical Bibliography or Bibliometrics. Journal of Documentation, 25(4): 348-349.

Séror, A. C. 1996. Action Research for International Information Technology Transfer: A Methodology and a Network Model. Technovation, 16(8): 421-448.

https://doi.org/10.1016/0166-4972(96)00032-6

Snoeren, M. M., Niessen, T. J. H., \& Abma, T. A. 2012. Engagement Enacted: Essentials of Initiating an Action Research Project. Action Research, 10(2): 189-204. https://doi.org/10.1177/1476750311426620

Sørensen, F., Mattsson, J., \& Sundbo, J. 2010. Experimental Methods in Innovation Research. Research Policy, 39(3): 313-322. https://doi.org/10.1016/j.respol.2010.01.006

Starkey, K., Hatchuel, A., \& Tempest, S. 2009. Management Research and the New Logics of Discovery and Engagement. Journal of Management Studies, 46(3): 547-558.

https://doi.org/10.1111/j.1467-6486.2009.00833.x

Susman, G. I., \& Evered, R. D. 1978. An Assessment of the Scientific Merits of Action Research. Administrative Science Quarterly, 23(4): 582.

https://doi.org/10.2307/2392581

Swann, C. 2002. Action Research and the Practice of Design. Design Issues, 18(1): 49-61. https://doi.org/10.1162/07479360252756287

Theodorakopoulos, N., Sánchez Preciado, D. J., \& Bennett, D. 2012. Transferring Technology from University to Rural Industry within a Developing Economy Context: The Case for Nurturing Communities of Practice. Technovation, 32(9-10): 550-559. https://doi.org/10.1016/j.technovation.2012.05.001

van Aken, J. E. 2004. Management Research Based on the Paradigm of the Design Sciences: The Quest for Field-Tested and Grounded Technological Rules. Journal of Management Studies, 41(2): 219-246.

https://doi.org/10.1111/j.1467-6486.2004.00430.x

Wicks, P. G., \& Reason, P. 2009. Initiating Action Research: Challenges and Paradoxes of Opening Communicative Space. Action Research, 7(3): 243-262.

https://doi.org/10.1177/1476750309336715

Yang, H.-L., \& Hsiao, S.-L. 2009. Mechanisms of Developing Innovative IT-Enabled Services: A Case Study of Taiwanese Healthcare Service. Technovation, 29(5): 327-337.

https://doi.org/10.1016/j.technovation.2009.01.006

Zhang, G., Xie, S., \& Ho, Y.-S. 2010. A Bibliometric Analysis of World Volatile Organic Compounds Research Trends. Scientometrics, 83(2): 477-492.

https://doi.org/10.1007/s11192-009-0065-3
Citation: Guertler, M., Sick, N., \& Kriz, A. 2019. A Discipline-Spanning Overview of Action Research and Its Implications for Technology and Innovation Management. Technology Innovation Management Review, 9(4): 48-65.

http://doi.org/10.22215/timreview/1233

Keywords: action research, discipline-spanning analysis, bibliometrics, literature review, technology and innovation management (cc) BY 


\title{
Choosing an Outlet for Action Research: Publication Patterns in Innovation Journals Magnus Hoppe
}

\author{
'Why not go out on a limb? Isn't that where the fruit is? \\ Frank Scully (1892-1964) \\ Journalist and author
}

\begin{abstract}
With the aim to help innovation researchers choose outlets for articles based on participatory and action research methods, this article describes and discusses publication patterns of action research. A bibliographic study of 33 innovation journals ranked 4, 3, 2, and 1 in the 2018 Academic Journal Guide is complemented by a case study of this journal, the Technology Innovation Management Review, as an example of an established open access journal in the field with a wider scope and target group. From these two studies, we learn that the overall trend is towards more publications of action research articles in a diversity of outlets. Indirectly, the study supports the general view that articles striving towards adding practical relevance to research are becoming more frequent. There is no support for the notion that more renowned and higher-ranked journals would be more hesitant to accept articles with action research methods. The study also notes that there are interesting outlets beside those highly ranked and indexed in more conventional ways. The conclusion reached is that we lack a clear answer to the question of what are the best outlets for those of us who are interested in both innovation and action research. Instead, the study invites us to reflect upon what kind of impact we want to have and then act accordingly.
\end{abstract}

\section{Introduction}

What are the best outlets for those of us who are both interested in innovation and action research? Especially for those of us who would like to combine practical impact with an academic career, this is an important question. Bibliometric rules and arguments from institutional managers often favour established procedures, demanding not just any publications, but publications in high-ranked journals, or "proper journals", as Shani and colleagues (2007) write. As an action researcher, this requirement can be cumbersome given that well-established and high-ranked journals might be hesitant to accept articles based on action research methods, according to MacIntosh and Wilson (2003) and Mathiassen, Chiasson, and Germonprez (2012), but at least "some good journals do sometimes publish action research" as Ahlstrom (2015) phrases it. However, for action researchers, this positive development is quite recent and specific to certain fields (e.g., education and health) and does not encompass technology and innovation, according to Flicker (2014).
What distinguishes action research from other research traditions are an interest to make a direct impact on practical problems, that is to create action, and the involvement of those concerned in problem definitions and knowledge constructions. It is based on democratic ideals, where the interests and demands on questions asked, methods used and results, sought from both researchers and those researched are equally respected (Dewey, 1937; Johansson \& Lindhult, 2008; Lewin, 1946). One-sided scientific control of the research process, including control of analyses and interpretations, will not do, and this approach therefore challenges dominating scientific ideals that rest on upholding the divide. The mutuality of action research is sometimes highlighted through adding the prefix participative or participatory to action research. Action research has slowly been gaining acceptance over the years, and there are now two well-established dedicated journals: Action Research (established in 2003 by SAGE) and the International Journal of Action Research (established in 2005 by Rainer Hampp Verlag). Browsing published titles, one can note that these two journals are dominated by health, education, 


\section{Choosing an Outlet for Action Research: Publication Patterns in Innovation Journals} Magnus Hoppe

and development studies, thus supporting Flicker's (2014) statement above. Technology and innovation are covered, but they are not part of the mainstream.

After researching what has been written on the publishing topic, there is no clear answer available to the initial question regarding the best publication outlets for action researchers. Instead, we are left with quite weak value-laden statements as those above. Answers are incomplete and concluding statements are mostly circumstantial, pointing to the fact that action research articles still do not match the standards of high-ranked journals, and thus are being rejected. Shani and colleagues (2007) suggest that these standards mainly are applied in order to protect the publishers' reputation, where action research has been considered questionable. Exactly what the standards are also varies from institution to institution and person to person (Shani et al., 2007), making it hard for an action researcher to judge the chances of being accepted. Schön (1995) provides us with a possible explanation to this problem, describing action research as scientifically different with an epistemology and standards of its own where practical relevance is part of the scientific rigour and not something that can be disregarded.

On the other hand, new research approaches and mixed methods are making their way into high-ranked journals, and among those, some rely on action research. The reason for this development, according to Rau, Goggins, and Fahy (2018), is the current societal demand for research to have social impact, not only scholarly impact. This demand also paves the way for publications in open access journals. When introduced, open access first appeared as another outlet option for researchers. Now, there are voices turning the optional outlet into the preferred outlet, even making it mandatory in certain circumstances. An example of this demand is an agreement from September 2018, when eleven European countries approved "Plan S", which requires that, "from 2020, scientific publications that result from research funded by public grants must be published in compliant Open Access journals or platforms" (cOAlition S, 2018). This development should come as no surprise, as there is general movement in society towards open approaches. Since the turn of the millennium, open approaches, where different actors get together in order to create change through active participation in knowledge building, culminating in some kind of action, appear to becoming the new norms that drive society (cf. Chesbrough, 2003). Action research is thus well in tune with the overall societal development, especially when the prefix participatory/participative is added to different knowledge processes.

Summing up, "open" as the new normal, the establishment of open access journals, and now public demands for open publishing, are growing concerns for both publishers and researchers. The former sees their traditional business models crumble, and several now offer open access for a fee. The latter are instead given more approved choices when looking for the best outlets. Even though there are many predatory journals luring researchers into low-quality outlets with mysterious payment schemes, there are also well-established open access journals that uphold scientific rigour through peer review, for example, and thus represent valid options for serious researchers. In the midst of this development, the initial question remains, and the purpose of this article has been specified to describe and discuss action research publication patterns in innovation journals.

In order to meet this purpose, a limited bibliographic review of 33 journals was undertaken. The bibliographic study was then complemented with a case study of the TIM Review in order to build an example of a contemporary journal with an agenda for bridging the knowledge gap between theory and practice (quite in line with the action research agenda of many researchers). In the remainder of this article, the results of both studies are described and analyzed with the aim of helping researchers choose outlets for articles based on participatory and action research methods.

\section{Bibliographic Study}

The bibliographic study consists of a limited review of all 33 journals listed in the innovation category of the Chartered Association of Business Schools' 2018 Academic Journal Guide (AJG; charteredabs.org/academic-journalguide-2018/). This study especially addresses questions of rank in relation to frequency of published action articles over the years.

The choice of the AJG as a base for the selection is explained by its well-established use in business schools. It is also quite stable. Compared to the 2015 AJG, the 2018 version used here displays just one change in ranking, which is that the journal Research Policy has moved up from 4 (top journals) to $4^{*}$ (journals of distinction). The 2018 edition also encompasses four new journals, all ranked 1, moving the index from a total of 29 journals to 33. The index is dominated by lower-ranked journals, as can be viewed in Figure 1 . 


\section{Choosing an Outlet for Action Research: Publication Patterns in Innovation Journals}

\section{Magnus Hoppe}

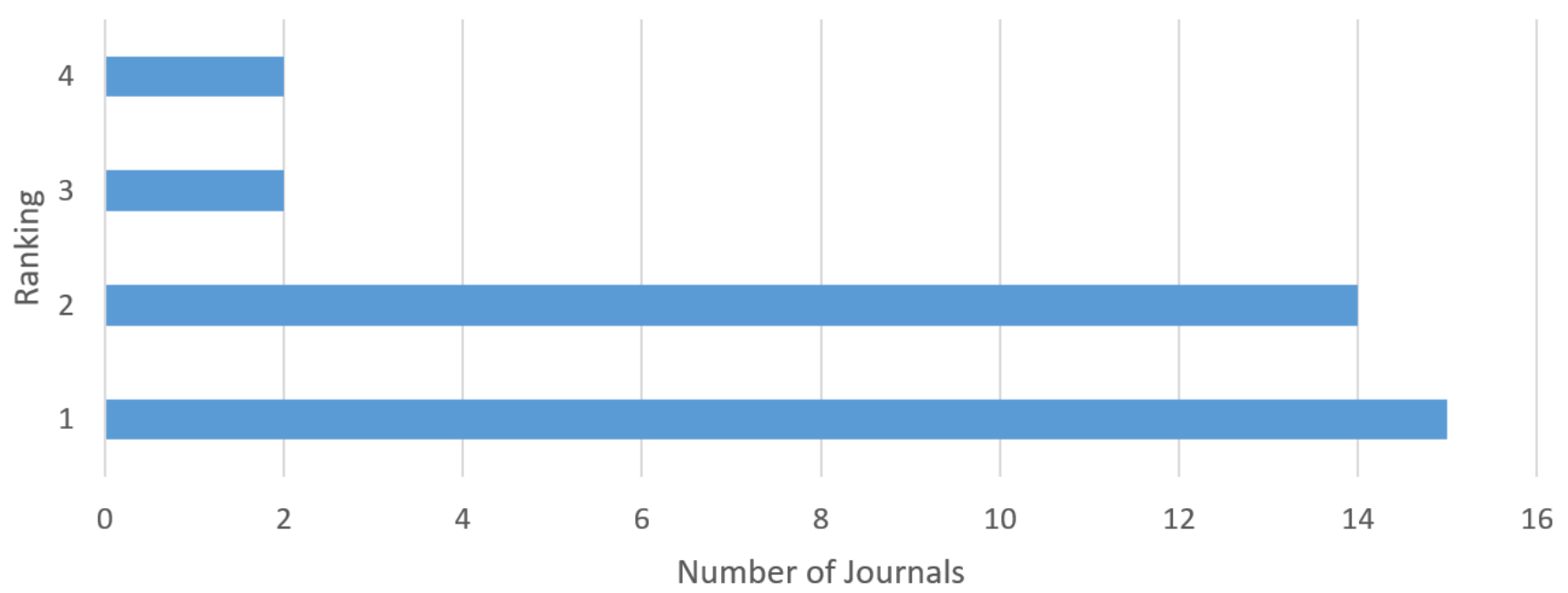

Figure 1. Number of innovation journals by ranking in the 2018 AJG

The ranking is described as follows in the AJG:

Rank $4^{*}$ Grade 4 journals that are recognized worldwide as exemplars of excellence

Rank 4 Journals that publish the most original and best-executed research

Rank 3 Journals that publish original and wellexecuted research papers and are highly regarded

Rank 2 Journals that publish original research of an acceptable standard

Rank 1 Journals that, in general, publish research of a recognized, but more modest standard in their field

\section{Data collection}

The bibliographic study is divided into two parts. The first part includes 18 journals ranked 4,3 , and 2, accessed through searches using academic library access and individual searches through the homepage of each journal. The second part includes 15 journals ranked 1, researched using Google Scholar. The different parts are presented separately. By doing this division, the influence of less established and novel journals will interfere less with the overall trend of more established journals.

The search terms used for the study are "action research", "participatory research", "participative research", "participatory action research", and "participative action research". In the analysis, the last four terms are grouped in pairs as they are judged to be synonyms, as follows: "participatory/participative research" and "participatory/participative action research".

The study encompasses the years from 1968 (the first mentioning of action research) to 2018, although most journals were not founded at the time of the first mentioning. The total tally for each year can thus not be compared straight off. The year 2018 is also included, although with incomplete records as the study was conducted in December of that year.

\section{Analytical approach}

For an article to qualify, it must exactly match one of the five search terms, where it is important to observe that "participatory/participative action research" also will show up in the more general search for "action research". Accordingly, the compilation does not claim to give the exact numbers of articles, instead it gives an overview of how many articles mention the five interrelated search terms. In this way, "participatory/participative action research" shall be regarded as a subcategory of "action research" that was extracted from the total number in the presentation, where the combined number gives us a total for all articles mentioning any form of "action research".

Furthermore, it should be noted that the study does not consider if there is just a brief mentioning of a term in passing or if it was a central term reoccurring throughout an article. The study does thus not reveal how many specifically claimed participatory and action research articles that are actually published by the journals. The mentioning of the terms should instead be seen as proxies for a publication pattern that would 


\section{Choosing an Outlet for Action Research: Publication Patterns in Innovation Journals} Magnus Hoppe

only be possible to assess through a qualitative study. This, in turn, would be dependent on full access to all articles in all journals, which we do not have at present. The results are thus more indications through proxies than complete or correct numbers.

As discussed by Reason and Bradbury (2008), there are many different names for action research, which means that a choice of other search phrases than the five mentioned would give different results. The choice of these specific five terms are, however, justified as follows. Our presumption is that "action research" will return articles expressly addressing expressed methodological choices, whereas "participatory/participative research" will return articles especially addressing the relationship between the researcher and the researched. The combined term "participatory/participative action research" will consequently return articles addressing both these angles. All this assumes that the authors have reflected on the terms used, which they should have given that information about methodological choices usually is prioritized in research articles.

Reflecting on these matters in the outset, we also hypothesized that the terms "participatory" and "participative" ought to be more commonly used as methodological descriptors in recent articles due to the popularization of open approaches and a movement toward dismantling borders between the researchers and the researched, as described by Rau and colleagues (2018).

\section{Complementary Case Study: The TIM Review}

The bibliographic study is built on an index constructed by an expert group, favouring a conventional way of ranking innovation journals that need to qualify to be included. However, newer journals emphasizing broader goals (including quality) are easily neglected and may remain unranked. As discussed in the introduction, an array of new journals has been launched outside the conventions that make the AJG possible. Still, one might wonder how the publishing patterns of a new type of journal compare to that of those in a traditional index. For comparative reasons, a singular case study of the journal Technology Innovation Management Review (TIM Review; timreview.ca) was conducted. The choice of TIM Review came naturally as it is the outlet for this article (as part of a pair of special issues dedicated to action research), but it also represents a well-established open access journal with an aim of spreading know- ledge across disciplines and to both scholars and practitioners. It should also be more interesting to the readers to have data on the very journal they are reading, instead of some other possibly just as relevant journal. In other words, including TIM Review invites the readers to directly reflect upon claims made in this article with their first-hand experiences of the journal.

For this complementary study, data was collected using Google Scholar's advanced search, but following the same pattern as for the bibliographic study. The analytical approach was also the same as for the bibliographic study but was complemented with a few qualitative additions made possible through open access to both articles and the Editor-in-Chief (quite in line with growing ideas of relevance and the epistemology that builds action research, one might add).

\section{Results}

The result section is divided into two sections. First, we present the findings and analysis of the bibliographic study's two parts: journals ranked 4, 3, and 2 and then journals ranked 1 . Second, we do a similar analysis for the TIM Review. This is followed by an analysis and a discussion that more specifically address publication patterns and the questions guiding this article.

\section{Journals ranked 4, 3, and 2}

The first part of the bibliographic study (journals ranked 4, 3, and 2) includes a total of 423 articles going back to the publication of the first action research article in 1968. Of these 423 articles, 319 contain the general term action research, 32 articles contain the more specific term participatory/participative action research, and 76 contain the term participatory/participative research. For the period between 2000 and 2018, these different categories amount to 228, 26, and 67 articles, respectively.

As visible in Figure 2, all researched terms show an increase over the studied period. For action research, this is continuous growth, whereas the other terms are more stochastically mentioned but reoccurring from about the year 2000. From 2000 onwards, there are about 13-14 action research and 3-4 participatory/participative research articles published each year within the innovation category of the AJG journals ranked 4, 3, and 2. Of the 13-14 action research articles published each year, typically only 1 or 2 use the more specific term participatory/participative action research. 


\title{
Choosing an Outlet for Action Research: Publication Patterns in Innovation Journals
}

\author{
Magnus Hoppe
}

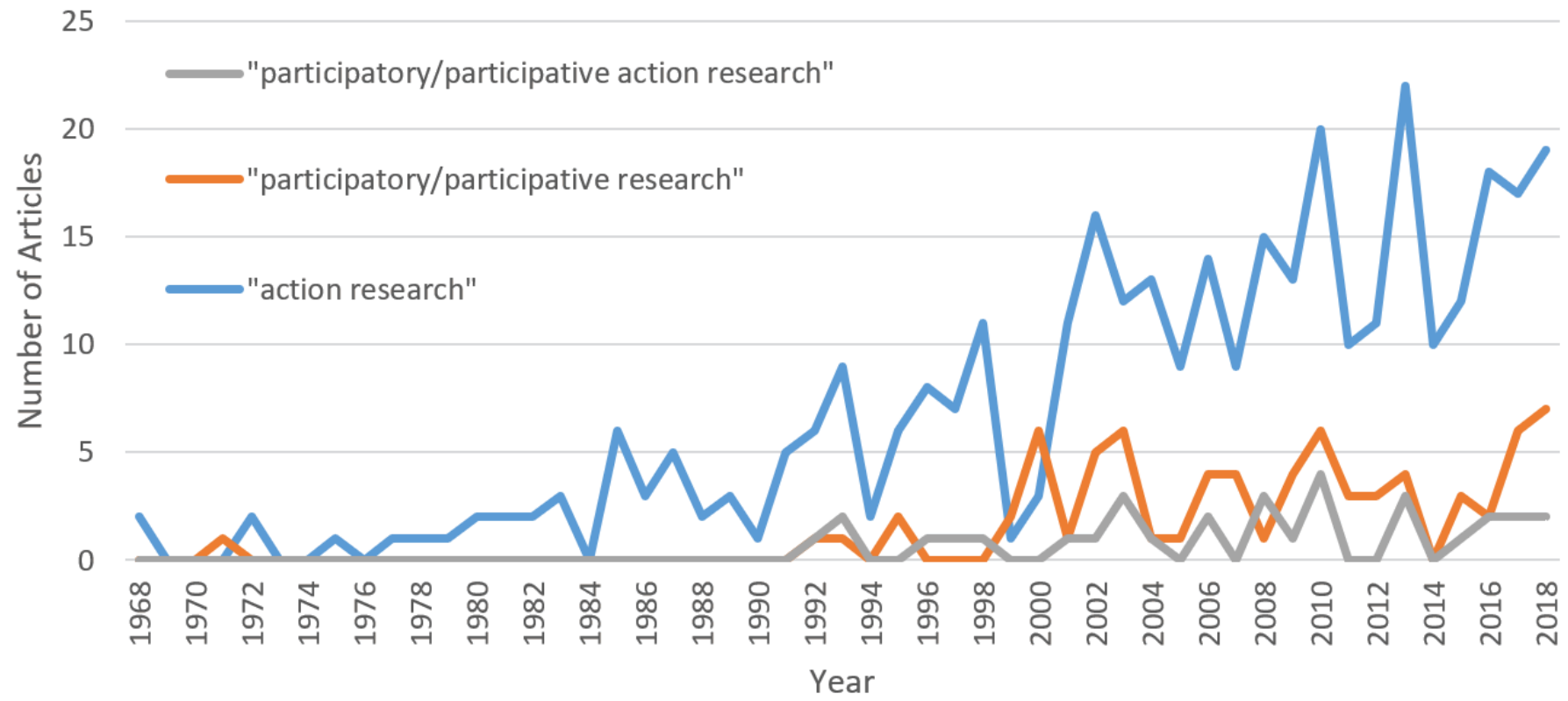

Figure 2. Total number of published articles in journals ranked 4, 3, and 2 included in the AJG mentioning action research, participatory/participative research, and participatory/participative action research between 1968 and 2018

There is no support for the notion that any of the examined terms have been used relatively more frequently over this 18-year period; instead, the terminology pattern seems quite stable from the year 2000 onwards. But, if we instead compare the periods before and after the year 2000, participatory/participative research has become more frequent, moving from 1 article out of 11 in the period before the new millennium to 1 article out of 5 in the period that follows.

A total of 311 articles were published since the year 2000, leaving a total of 106 articles published up until 1999. Hence, about three-quarters of all articles were published after the year 2000. The oldest articles mentioning action research are from 1968 (both of them in Research Technology Management: International Journal of Research Management) followed by one article from 1972 (in Research Policy). Complementary to this, there is an article in Social Studies of Science from 1971 that mentions participatory/participative research. Thus, there are articles published $45-50$ years ago that mentioned the central concepts of this study, although it is not until the 1990s that we see recurrent publication of the terms participatory/participative research and participatory/participative action research.

From the start in 1968, there was, on average, an article mentioning action research every second year until the 1980s where publications reach two articles a year. In the 1990s, it averaged a bit over six articles a year. From the year 2000, the relative development is slower, moving from about 10 articles a year at the beginning of the millennium to closing in on 20 the last three years, ending in 2018.

Journals that stand out with a long and relative extensive publication record for articles mentioning action research before the year 2000 are Technovation (27), $R \& D$ Management (11), Research Policy (10), and Creativity and Innovation Management (10). When it comes to the total number of published articles with the term action research since 1968, at the top of the list is Technovation (66), closely followed by Research Policy (63), and then Creativity and Innovation Management (47), and $R \& D$ Management (36). Of these four, it is only Creativity and Innovation Management that is ranked 2. The other three are ranked 3 or 4 . The remaining journal in the AJG ranked 4, the Journal of Product Innovation Management, displays a total of 15 action research articles, but all of them are from 2003 or later (even though the journal was instigated in 1984), and the journal is now averaging one action research article a year. The findings indicate a more open stance towards action research in recent years for this journal.

The latter part of the review, from the year 2000 to 2018, is summarized in Figure 3, where the journals are listed in the order of the AJG. The numbers at the top of the figure indicate the journals' 2018 rankings. 


\title{
Choosing an Outlet for Action Research: Publication Patterns in Innovation Journals
}

\author{
Magnus Hoppe
}

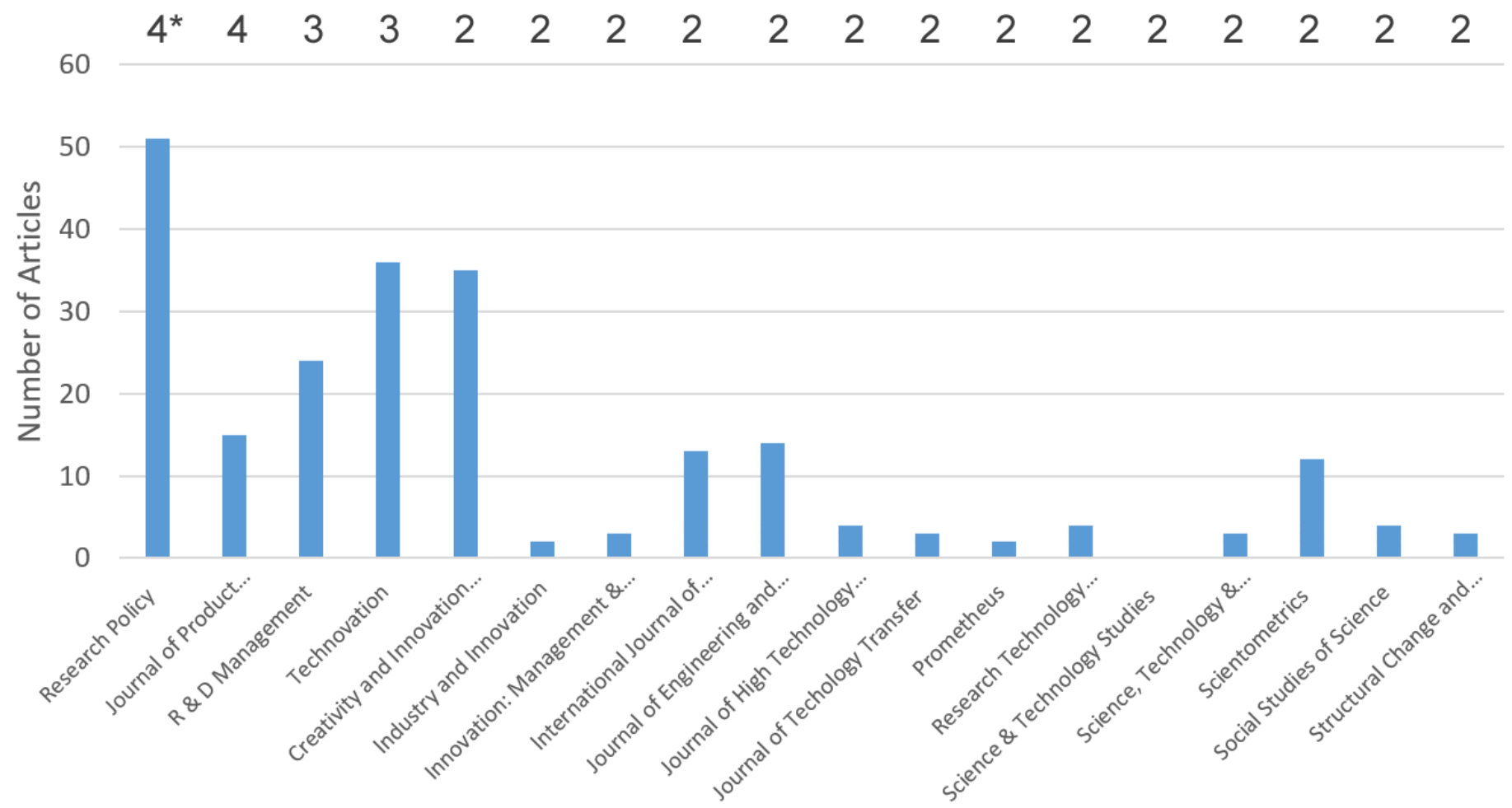

Figure 3. Number of articles mentioning action research published between 2000 and 2018 in individual innovation journals ranked 4,3 , or 2 in the AJG

Judging by Figure 3, the four journals ranked 4 and 3 appear to be the main outlets for action research articles, followed by Creativity and Innovation Management (35), the Journal of Engineering and Technology Management (14), the International Journal of Innovation Management (13), and Scientometrics (12).

Turning to participatory/participative research, most journals do occasionally publish articles using these terms, but one journal stands out. Science, Technology \& Human Values totals 18 articles since the year 2000, giving us a neat average of one article a year. Noticeably, there are no articles published in this journal before the year 2000 that mention participatory/participative research. Comparatively, when it comes to mentioning action research, there are eight articles in this journal before the year 2000 and nine articles after 2000, giving a total of 17. This finding indicates that, today, participatory/participative research articles are more likely to pass the review process of this journal than articles with action research, a tendency that has been pronounced since the year 2000. The journal Social Studies of Science has a similar but less distinct publication pattern, slightly favouring participatory/participative research over action research. Among the higher-ranked journ- als, Research Policy and Technovation (both from Elsevier) stand out as they have published articles with participatory/participative research since the early 1990s with a total of 16 articles for Research Policy and 13 articles for Technovation. These totals are quite high compared to the three articles in the Journal of Product Innovation Management (rank 4) and the one article in $R \& D$ Management (rank 3). Noteworthy, Research Policy has 5 recent publications, dating from 2017 and 2018.

Even though the numbers are generally not strong, there are a few interesting publication tendencies. For instance, Technovation has a long record of publishing articles mentioning action research, peaking between 2003 and 2006 with an average of four articles per year, but there is a decline in more recent years. Since 2014, it has published 1-2 articles a year. The other well-established journal with a higher track record compared to the others, Research Policy, does not have the same trajectory. Instead, is it quite stable with 3-4 articles a year. However, although 2018 was not complete at the time of the data collection for this study, a post hoc expansion of the search to include the full year revealed that $R e$ search Policy published six action research articles in 2018, thereby matching its 2010 record. With another 


\section{Choosing an Outlet for Action Research: Publication Patterns in Innovation Journals}

Magnus Hoppe

four open access articles published up until the July 2019 issue, Research Policy thus may be closing in on a new record.

Among the journals ranked 2, both the International Journal of Innovation Management and the Journal of Engineering and Technology Management are quite stable, with 1-2 articles mentioning action research each year. Comparatively, Scientometrics has a divergent publishing pattern. Going back to the period before the year 2000, it published an article mentioning action research every 2-3 years, but from 2000 until 2014 it published none. In 2015, a change came; since then, it has published three articles a year on average.

Finally, the results also show that some innovation journals do not publish much at all in any of the categories.

\section{Journals ranked 1}

The second part of the bibliographic study concerns journals ranked 1 in the AJG. The publication patterns of these journals in the rank 1 category are harder to assess, as many journals of these journals are quite new. There is a total of 149 articles mentioning "action research" for this group, where all were published between 2000 and 2018, save for one published in 1998 by the European Journal of Innovation Management, clearly indicating that this group is dominated by more novel journals. Thus, the unsettled character of this category of journals ranked 1 prevents us from being more specific in terms of yearly patterns, etc.

As can be expected, journals with a longer publication record within this category also display more articles mentioning "action research". Figure 4 gives an overview of the number of action research articles in each journal. At first glance, the pattern is similar to that of journals ranked 2 visible in Figure 3. Due to differences in the search methods and data available for the two categories, it would be hazardous to claim any major variance.

Journals ranked 1 also publish articles mentioning participatory/participative research at about the same rate as journals ranked 4,3 , or 2 , with a total of 40 articles for this period counting all journals. There is about one article mentioning participatory/participative research for every four articles mentioning action research.

Journals that stand out are the four with most articles mentioning action research: the International Journal of Innovation and Technology Management (27), the International Journal of Entrepreneurship and Innovation Management (24), the European Journal of Innovation Management (18), and the International Journal of

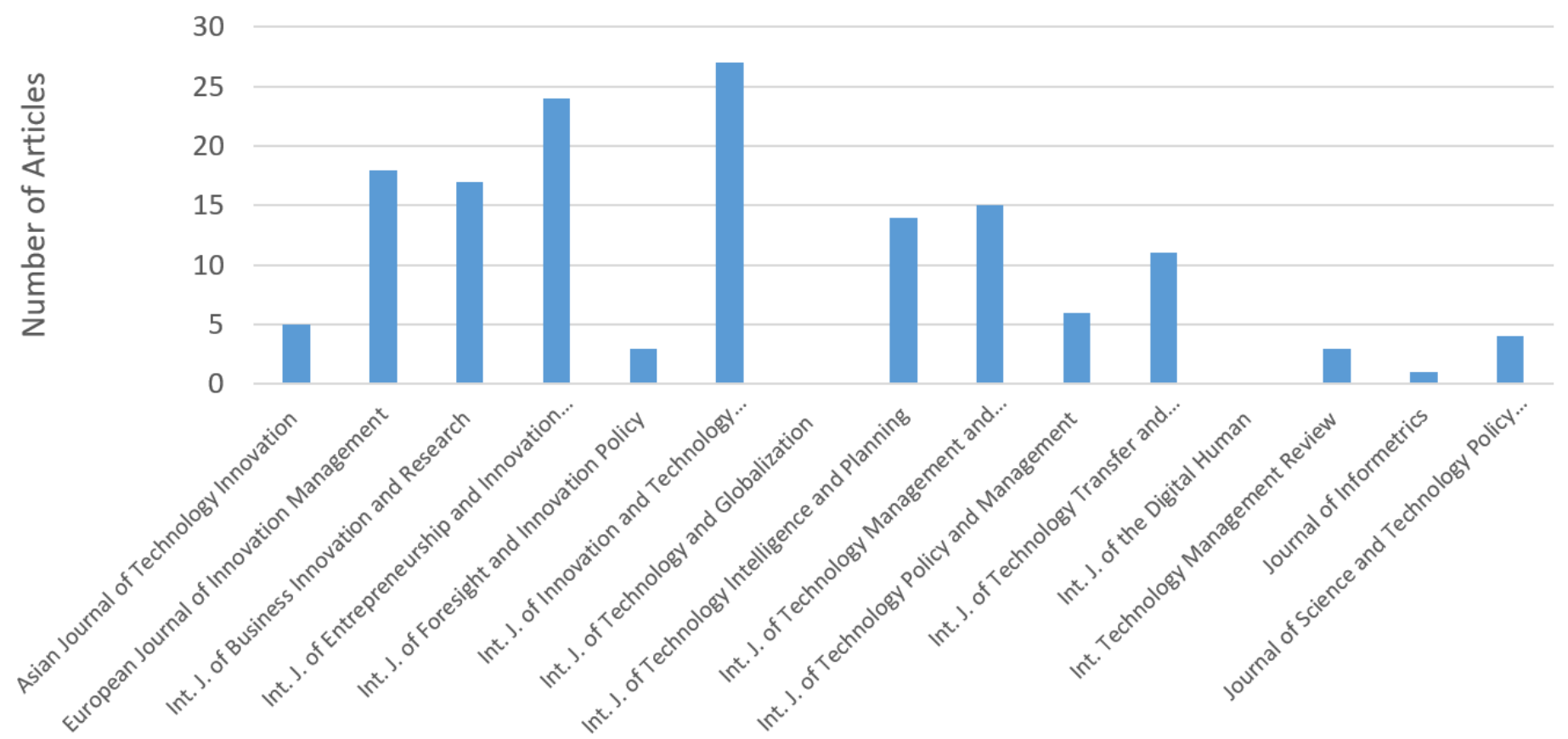

Figure 4. Number of articles mentioning action research published between 2000 and 2018 in individual innovation journals ranked 1 in the AJG 


\section{Choosing an Outlet for Action Research: Publication Patterns in Innovation Journals} Magnus Hoppe

Business Innovation and Research (17). All these four journals also publish quite a few articles (a total of 21) containing the terms "participatory/participative action research" and "participatory/participative research", indicating at least a general interest in these approaches.

\section{The TIM Review}

Since its first issue in July 2007, the Technology Innovation Management Review (TIM Review) has turned out a total of 30 articles mentioning participatory and action research. The first appear in 2012 with a surge of articles from 2016, as shown in Figure 5. Starting in 2016, it has averaged eight articles a year (out of a total output of approximately 60 articles a year). With two special issues on action research to be published in 2019, this trend is likely to hold or increase.

Looking closer at the articles published, most of them (25) are restricted to the term "action research". Three articles use "participatory research" and two "participatory action research" (none use "participative"). All of these five were published from the surge in 2016 and onwards, thus also giving some support to a growing interest in participatory/participative research.

Notably, 10 of the 25 action research articles in the TIM Review report on research conducted through living labs. The journal's first action research article (Seppä, 2012) also addressed living labs, and the TIM Review turned out eight special issues on this theme between 2012 and 2018, indirectly boosting the numbers of recent action research articles. In a recent analysis of articles about living labs published in the journal, Westerlund, Leminen, and Rajahonka (2018) conclude that living lab articles in the TIM Review have moved from descriptions of the phenomena towards the design and management of living labs. In this way, turning attention to process issues, action research has become more relevant as a topic for the articles. This is especially noticeable in an article by Logghe and Schuurman (2017) with the title "Action research as a framework to evaluate the operations of a living lab". Also, in the special issue on living labs published in December 2018, two out of five articles mention action research and participatory research. The increase of articles mentioning action research articles can at least in part be said to be dependent on the journals' publication of living lab articles. Nonetheless, articles on living labs represent the minority of TIM Review articles that include the term action research, meaning that the trend of an increasing number of action research articles in the TIM Review goes well beyond the topic of living labs.

\section{Analysis}

The findings from the studies presented here add nuance to earlier claims made in the introductory review. Judging by the figures from the bibliographic study, there is no positive support for the idea that well-established and high-ranked journals would be more hesitant to accept articles mentioning action research compared to lower-ranked journals in the field of innovation, as expressed by MacIntosh and Wilson (2003) and Mathiassen and colleagues (2012). On the contrary, higher-ranked journals, as can be expected, have a longer publication record and have also published articles mentioning action research since well back into the 20th century. The study also indicates that highranked journals no only publish action research but do so without the negative connotation noticeable in the

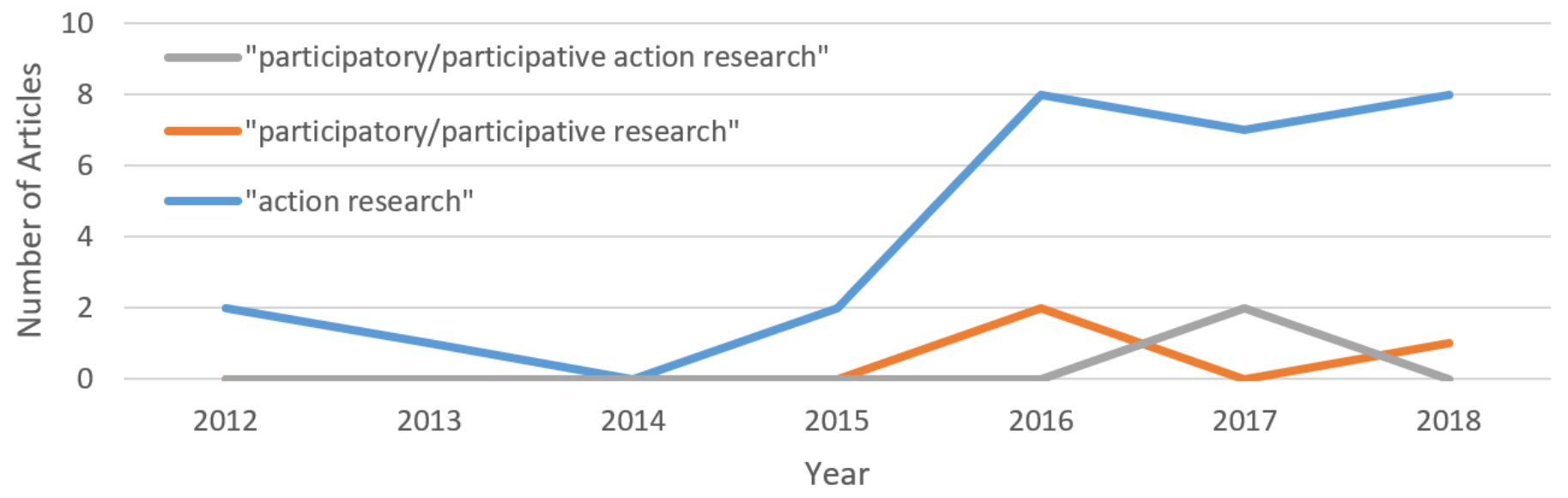

Figure 5. Number of articles mentioning participatory and action research terms in the TIM Review 


\section{Choosing an Outlet for Action Research: Publication Patterns in Innovation Journals} Magnus Hoppe

article by Ahlstrom (2015). The highest-ranked journal, Research Policy, is also the journal that has published most articles containing action research since the year 2000. Noticeably, this journal is also ranked as a journal of distinction in the 2018 AJG, where the journal's relatively frequent publications of articles mentioning action research did not hinder it from moving upwards in the ranking. Adding to this, more recently launched and lower-ranked innovation journals do not, compared to high-ranked journals, especially favour articles mentioning action research, according to the findings of this study. There is also a positive trend for more articles mentioning action research each year in the journals of the AJG, indicating weakening support for earlier claims that action research would be hard to publish in conventional journals.

If we instead go to participatory/participative research, the lower-ranked Science, Technology \& Human Values and Social Studies of Science (both ranked 2), together with the higher-ranked Technovation (ranked 3), published relatively more articles compared to other journals in the AJG. There is no clear reason for this, except that they all clearly state that they are interdisciplinary or multidisciplinary, with aims to publish research that scrutinizes innovation and current societal development and how it affects both research and human values. Engagement and border-breaking aspects should thus interest the editorial boards and possibly favour publication of participatory/participative research. On the other hand, other journals within the AJG display similar statements, weakening this possible explanation.

Turning to the complementary study, the TIM Review supplies us with an example of a relatively new open access journal with the goal of both serving and reaching out beyond the scholarly sphere. Since 2012, it has published publish action research articles, and increasingly so. Complementary information from the Editor-inChief explains this trend, in part, based on the increasing attention paid to action research at conference events put on by the International Society for Professional Innovation Management (ISPIM; ispim-innovation.com), which has frequently partnered with the journal on special issues. It is his impression that action research has become a growing topic of interest at ISPIM events, and this increased awareness has possibly increased his propensity to encourage submissions of articles based on action research. However, the increase of action research articles in the TIM Review is not something unique. Although it is not included in the $2018 \mathrm{AJG}$, it follows the overall trend for the journals ranked 4,3 , and 2 in the AJG, where the total output is close to 20 articles a year since 2016. But, at that point, the similarities end. Since then, the TIM Review has published eight action research articles a year, where the average is just about one article a year for the journals in the AJG. Interestingly, it is the most renowned conventional journal, Research Policy, that this last year, 2018, has almost come to match the TIM Review's total.

In the result section, the publication patterns of a few journals were noted to change suddenly. For example, Scientometrics displayed a surge in 2015 after a long period with no action research publications at all, whereas the TIM Review has an even more dramatic increase in articles from 2016. Possible reasons behind these changes are adjustments in practiced institutional and personal standards, as discussed by Shani and colleagues (2007), for example, through the substitution of editors. Although this is not the case for the TIM Review, we cannot rule out that this explanation holds for other journals. Another possible reason behind temporal surges is the publication of special issues. For instance, MacIntosh and Wilson (2003) mention that Human Relations (not part of this survey) had a special issue on action research in 1993 that encompassed 12 articles, thus obscuring an underlying trend. But, special issues would only boost the numbers for specific years. As all parts of the study show that more and more articles are being published each year, it indicates that institutional or personal standards are becoming more positive towards action research. It is also possible that these standards are moving with the whole innovation field and that publishing patterns just follow. If an increasing number of research projects are conducted using action research methods, it should become visible in the relative number of published articles.

As the general publishing development within the AJG is quite stable over the years, there is no real support for claiming that ideas of more open development processes should have had any significant influence on the methods used and described in innovation articles, except for a more pronounced use of participatory/participative research in the reviewed journals from the year 2000 and onwards, and in the TIM Review from 2016. There is thus some support for our hypothesis that the terms "participative" and "participatory", due to the popularization of open approaches and efforts to dismantle borders between the researchers and the researched, ought to be more commonly used as methodological descriptors in recent articles. 


\section{Choosing an Outlet for Action Research: Publication Patterns in Innovation Journals} Magnus Hoppe

Finally, there are a few journals that do not appear to have published anything at all mentioning "action research", which is worth reflection. It might be due to the search terms used and the journals' indexation in Google Scholar, for example. However, if we assume that these numbers are correct, a possible explanation might be that these journals do publish articles with a research design similar to action research, but they use another vocabulary to describe it (Reason \& Bradbury, 2008). Still, the term action research seems to be excluded from a few innovation journals.

\section{Discussion}

The results presented here imply that all journals, regardless of rank, are about as keen or hesitant to publish action research articles. Contrary to expectations, the high-ranked journals seem to be even more positive towards action research than the low-ranked ones. But this might be a generalization too far. Instead, it is the individual differences between journals that are most prominent in this study.

The journals present in the current study, and especially those highly ranked ones, have a long publishing record and are predominantly built on more conventional publishing standards within a specified field. New publishing channels do not have to obey to these kinds of limitations. Hence, it is likely that the most interesting publishing trends, especially for interdisciplinary or multidisciplinary action researchers, will appear outside the publishing of conventional and indexed journals. New journals and publishing models, including open access publishing, in this perspective, are both a complement and an alternative to conventional outlets. But, there is no clear answer to the initial question of what the best outlets are for those of us who are interested in both innovation and action research. Instead, the study invites us to reflect upon what kind of impact we want to have and then chose outlets accordingly. What the study also indicates is that there are interesting outlets beside those ranked and indexed in more conventional ways. In some respects, action researchers interested in innovation might have more publication options than those with more bounded ideas of scope and objectives, and that is solace for battered souls pressed by academic managers and demands for more citations.

The number of published action research articles has successively increased over the years, and close to 20 articles are now published yearly in innovation journals ranked 4, 3, and 2 in the AJG. In particular, we see an increased interest in participatory/participative research since the year 2000 - a trend also visible in the articles published in the TIM Review, but then for a more recent period. The study thus indicates that action research methods at least are mentioned more frequently in recent research articles on innovation. Indirectly, the results also suggest that articles striving towards adding practical relevance to research are becoming more frequent. A word of caution though: these claims are built on absolute numbers and not relative numbers. We cannot rule out that the positive trend is part of an overall increase in academic output in the indexed journals.

From the bibliographic study, we also conclude that there is no support for the notion that more renowned and highly ranked journals would be more hesitant to accept articles with action research methods. On the contrary, highly ranked journals (ranked 4 and 3 in the study) seem to be even better conventional outlets for action research compared to lower ranked journals (ranked 2 and 1). A researcher that strives for conventional impact in the innovation field should therefore not hesitate to submit to the most prestigious and highly ranked journals in the field but will do well in looking into the publishing history of each considered journal.

The most interesting publication pattern noticed through the bibliographic study might be that there is not much in the way of clear patterns at all. This is due to the fact that the total score of mentions of action research is quite limited within this finite sample. Each published article counts as much and has great effect on the total (at present, one new article increases the number of total publications by 5 percent a year for journals ranked 4,3 , and 2), meaning we should be careful not to "make a hen out of a feather", as we say in Sweden. However, the overall publishing trend is positive for action researchers in terms of the increasing total number of articles related to action research being published each year.

The case study of the TIM Review does not so much challenge the bibliographic study but complements it with an example of an established open access journal that seeks to reach readers from both academia and surrounding society. The TIM Review appears not just to follow the general trend of increasing interest in action research but exceeds it with a margin. The surge in action research publications in TIM Review since 2016 is interesting to note for researchers but also practitioners interested in innovation and action research. In total numbers, there are more recent articles addressing action research in this outlet each year than any of the 


\section{Choosing an Outlet for Action Research: Publication Patterns in Innovation Journals} Magnus Hoppe

bibliographic study's journals. Still, as the TIM Review is just an example chosen for convenience and for the interest of its readers, there might be other journals that are even more devoted to action research and participatory methods. It means that both innovation scholars and practitioners should view this journal, and possibly also any other journals with a broader target group as well as those with an open access model, which helps reach a non-academic audience. as not just a viable outlet but also as most relevant when looking for current knowledge and inspiring examples for how to approach both practical and theoretical problems addressed through action research.

\section{Conclusion}

The openness of new research processes as well as in publishing practices might successively change the way we judge, rank, and relate to journals and articles in the future. But we are not fully there, yet. The ranking of the AJG builds on conventional ways of dividing research into specific fields and give good numbers to those journals who have been able to attract attention from a specific audience over time. This has not changed. These journals still count and are important but mainly to those working within academia's traditional paradigm with respect to publications. Open access is sometimes offered by these journals, but only for those privileged with funds for this. This situation does not square well with the democratic ideals, inherited in the traditions of action research and participatory action research, and many researchers might still be standing before a difficult choice between intended academic or societal impact. Even though open access might be offered as a choice when aiming for a highranked journal, it is possibly not enough to get the desired societal impact. A good thing about being an action researcher, however, is that one makes this choice within a context where academic and societal impact are both desirable rather than strange or conflicting.

Reflecting on this choice, some recommendations can be given. On the one hand, researchers should check the fit of their article with the publication record and the publication policy of the desired outlet. A longer and richer publication record will also provide a better choice of internal references to include in an article before submission. On the other hand, if the journal's publication record in the field is minimal but there are interesting statements in the journal's publication policy, it may worth considering contacting the editor with a "sales pitch" for opening up a new stream of interesting articles to fulfill those statements. Building on the popularity of open approaches in innovation might be a complementary argumentative path to pursue.

Facilitating the choice of outlets is the trend towards openness and societal impact - these forces work against obsolete divisions in society between researchers and those researched. There is an increasing number of journals, but also articles as this study reveals, recognizing this. For all of you who feel you do not belong to the traditional "inside of academia" perspective, the study indicates that you (through a rising interest in action research) are increasingly defined as being on the inside of ongoing knowledge constructions, and you have a stake in how we best join together to achieve desired outcomes.

Finally, what we have not assessed in this study, is a more in-depth analysis of the quality, content, disposition, and scope of identified articles. There is thus a need for a complementary qualitative study that addresses other types of publication patterns in the content of the articles covered in this study.

\section{About the Author}

Magnus Hoppe is an Associate Professor at the School of Economics, Society and Engineering at Mälardalen University, Sweden. At the university, he is member of the Faculty Board, and leads processes for collaborative research in sustainable development. Magnus holds a $\mathrm{PhD}$ in Business Administration from Åbo Akademi University in Finland, where he presented his thesis on organized intelligence work in modern organizations. His current research concerns both private and public organizations and spans intelligence, entrepreneurship, and innovation. A special research interest lies in questioning dominating perspectives that bind our understanding of specific topics, and he now works to establish new ways of talking and thinking about innovation. His aim is to help organizations build new insights that will enhance their ideation processes and strategy building and, thereby, improve their innovative capabilities. 


\section{Choosing an Outlet for Action Research: Publication Patterns in Innovation Journals}

\section{Magnus Hoppe}

\section{References}

Ahlstrom, D. 2015. Successful Publishing in Academic and Scientific Journals: Framing and Organizing the Scholarly Paper. International Journal of Higher Education Management, 2(1): $106-120$.

Chesbrough, H. W. 2003. The Logic of Open Innovation: Managing Intellectual Property. California Management Review, 45(3): 33-58. https://www.jstor.org/stable/i40051903

cOAlition S. 2018. What is cOAlition S? Plan S: Making Full and Immediate Open Access a Reality. Accessed April 1, 2019: https://www.coalition-s.org/about/

Dewey, J. 1937. Education and Social Change. Bulletin of the American Association of University Professors (1915-1955), 23(6): 472-474. https://doi.org/10.2307/40219908

Flicker, S. 2014. Disseminating Action Research. In D. Coghlan \& M. Brydon-Miller (Eds.), The SAGE Encyclopedia of Action Research: 276-280. London: SAGE.

Johansson, A. W., \& Lindhult, E. 2008. Emancipation or Workability? Critical versus Pragmatic Scientific Orientation in Action Research. Action Research, 6(1): 95-115. https://doi.org/10.1177/1476750307083713

Lewin, K. 1946. Action Research and Minority Problems. Journal of Social Issues, 2(4): 34-46. https://doi.org/10.1111/j.1540-4560.1946.tb02295.x

Logghe, S., \& Schuurman, D. 2017. Action Research as a Framework to Evaluate the Operations of a Living Lab. Technology Innovation Management Review, 7(2): 35-41.

https://doi.org/10.22215/timreview/1056

MacIntosh, R., \& Wilson, F. 2003. Publishing Action Research. Paper presented at the 19th EGOS Colloquium, Copenhagen.

Mathiassen, L., Chiasson, M., \& Germonprez, M. 2012. Style Composition in Action Research Publication. MIS Quarterly, 36(2): 347-363.

Rau, H., Goggins, G., \& Fahy, F. 2018. From Invisibility to Impact: Recognising the Scientific and Societal Relevance of Interdisciplinary Sustainability Research. Research Policy, 47(1): 266-276.

https://doi.org/10.1016/j.respol.2017.11.005

Reason, P., \& Bradbury, H. 2008. Handbook of Action Research: Participative Inquiry and Practice. London: SAGE.

Schön, D. A. 1995. Knowing-in-Action: The New Scholarship Requires a New Epistemology. Change: The Magazine of Higher Learning, 27(6): $27-34$.

https://doi.org/10.1080/00091383.1995.10544673

Seppä, M. 2012. From Business Administration to Business Creation: The Case of the Kalevala Global Business Creation School. Technology Innovation Management Review, 2(6): 6-11. https://doi.org/10.22215/timreview/562

Shani, A. B., Mohrman, S. A., Pasmore, W. A., Stymne, B., \& Adler, N. 2007. Handbook of Collaborative Management Research. London: SAGE Publications.

Westerlund, M., Leminen, S., \& Rajahonka, M. 2018. A Topic Modelling Analysis of Living Labs Research. Technology Innovation Management Review, 8(7): 40-51.

https://doi.org/10.22215/timreview/1170
Citation: Hoppe, M. 2019. Choosing an Outlet for Action Research: Publication Patterns in Innovation Journals. Technology Innovation Management Review, 9(4): 66-77. http://doi.org/10.22215/timreview/1234

Keywords: action research, participatory action research, participative, innovation, journals, bibliography, case study 


\section{Author Guidelines}

These guidelines should assist in the process of translating your expertise into a focused article that adds to the knowledge resources available through the Technology Innovation Management Review. Prior to writing an article, we recommend that you contact the Editor to discuss your article topic, the author guidelines, upcoming editorial themes, and the submission process: timreview.ca/contact

\section{Topic}

Start by asking yourself:

- Does my research or experience provide any new insights or perspectives?

- Do I often find myself having to explain this topic when I meet people as they are unaware of its relevance?

- Do I believe that I could have saved myself time, money, and frustration if someone had explained to me the issues surrounding this topic?

- Am I constantly correcting misconceptions regarding this topic?

- Am I considered to be an expert in this field? For example, do I present my research or experience at conferences?

If your answer is "yes" to any of these questions, your topic is likely of interest to readers of the TIM Review.

When writing your article, keep the following points in mind:

- Emphasize the practical application of your insights or research.

- Thoroughly examine the topic; don't leave the reader wishing for more.

- Know your central theme and stick to it.

- Demonstrate your depth of understanding for the topic, and that you have considered its benefits, possible outcomes, and applicability.

- Write in a formal, analytical style. Third-person voice is recommended; first-person voice may also be acceptable depending on the perspective of your article.

\section{Format}

1. Use an article template: .doc .odt

2. Indicate if your submission has been previously published elsewhere. This is to ensure that we don't infringe upon another publisher's copyright policy.

3. Do not send articles shorter than 2000 words or longer than 5000 words.

4. Begin with a thought-provoking quotation that matches the spirit of the article. Research the source of your quotation in order to provide proper attribution.

5. Include an abstract that provides the key messages you will be presenting in the article.

6. Provide a 2-3 paragraph conclusion that summarizes the article's main points and leaves the reader with the most important messages.

7. Include a 75-150 word biography.

8. List the references at the end of the article.

9. If there are any texts that would be of particular interest to readers, include their full title and URL in a "Recommended Reading" section.

10. Include 5 keywords for the article's metadata to assist search engines in finding your article.

11. Include any figures at the appropriate locations in the article, but also send separate graphic files at maximum resolution available for each figure. 


\section{Issue Sponsor}

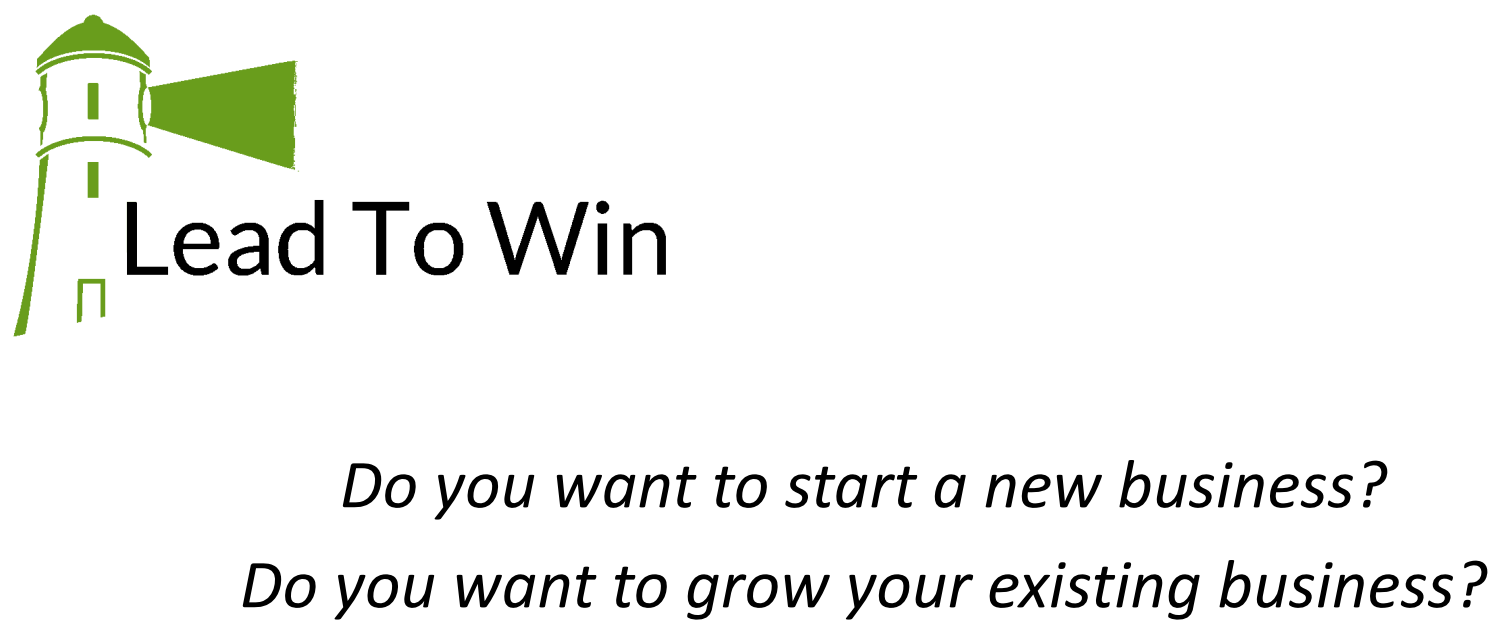

Lead To Win is a free business-development program to help establish and grow businesses in Canada's Capital Region.

Benefits to company founders:

- Knowledge to establish and grow a successful businesses

- Confidence, encouragement, and motivation to succeed

- Stronger business opportunity quickly

- Foundation to sell to first customers, raise funds, and attract talent

- Access to large and diverse business network

\section{Apply Now}

* Twitter

f Facebook

in Linkedin

E Eventbrite

9 Slideshare

- YouTube

- Flickr 


\section{TIm Technology Innovation Management Review}

\section{Academic Affiliations and Funding Acknowledgements}
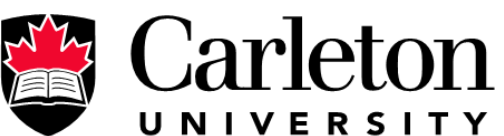

U N I V E R S I T Y

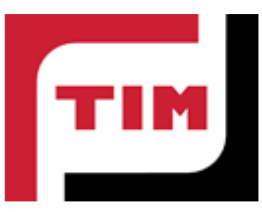

Technology Innovation Management (TIM; timprogram.ca) is an international master's level program at Carleton University in Ottawa, Canada. It leads to a Master of Applied Science (M.A.Sc.) degree, a Master of Engineering (M.Eng.) degree, or a Master of Entrepreneurship (M.Ent.) degree. The objective of this program is to train aspiring entrepreneurs on creating wealth at the early stages of company or opportunity lifecycles.

- The TIM Review is published in association with and receives partial funding from the TIM program. 